\title{
DESEMPENHO DO TENSIÔMETRO COM MANÔMETRO DE MERCÚRIO, REFLECTÔMETRO NO DOMÍNIO DO TEMPO E SONDA DE NÊUTRONS NO MONITORAMENTO DO TEOR DE ÁGUA NO SOLO
}

CLAUDIA FERNANDA ALMEIDA TEIXEIRA

Engenheiro Agrícola

Orientador: Prof. Dr. SERGIO OLIVEIRA MORAES

Tese apresentada à Escola Superior de Agricultura "Luiz de Queiroz", Universidade de São Paulo, para obtenção do título de Doutor em Agronomia, Área de Concentração: Solos e Nutrição de Plantas.

PIRACICAB A

Estado de São Paulo - Brasil

Agosto - 2001 


\section{Errata}

CLAUDIA FERNANDA ALMEIDA TEIXEIRA. Desempenho de tensiômetros com manômetro de mercúrio, reflectômetro no domínio do tempo e sonda de nêutrons no monitoramento de água no solo.
p. item linha
onde se lê
leia-se
$47 \quad 3.4 .2 \quad$ terceira
$\mathrm{V}_{\mathrm{A}}=\operatorname{vazão}\left[\mathrm{L}^{3} \mathrm{~T}^{-1}\right]$
$\mathrm{V}_{\mathrm{A}}=$ volume $\left[\mathrm{L}^{3}\right]$

$65 \quad 4.3 .1$ tabela 7

$$
\begin{aligned}
& \text { Método Indireto } \\
& \theta=6,5343 C R-1,3129 \\
& \theta=14,1252 C R-5,0709 \\
& \theta=14,3652 C R-5,2919 \\
& \theta=4,5914 C R-0,3498 \\
& \theta=13,4039 C R-4,6885 \\
& \theta=3,4667 C R+0,1323 \\
& \theta=3,4234 C R+0,2378 \\
& \theta=3,6102 C R+0,0939 \\
& \theta=5,4601 C R-0,8189
\end{aligned}
$$

\begin{tabular}{cc}
\hline \multicolumn{1}{c}{ Método Indireto } \\
\hline$\theta=0,1530 \mathrm{CR}+0,2009$ \\
$\theta=0,0708 \mathrm{CR}+0,3590$ \\
$\theta=0,0696 \mathrm{CR}+0,3684$ \\
$\theta=0,2178 \mathrm{CR}+0,0762$ \\
$\theta=0,0746 \mathrm{CR}+0,3498$ \\
$\theta=0,2885 \mathrm{CR}-0,0382$ \\
$\theta=0,2921 \mathrm{CR}-0,0695$ \\
$\theta=0,2770 \mathrm{CR}-0,0260$ \\
$\theta=0,1831 \mathrm{CR}+0,1500$ \\
\hline
\end{tabular}




\title{
Dados Internacionais de Catalogação na Publicação (CIP) DIVISĀo dE BIBLIOTECA E DOCUMENTAÇÃO - Campus "Luiz de Queiroz"/USP
}

\author{
Teixeira, Claudia Fernanda Almeida \\ Desempenho do tensiômetro com manômetro de mercúrio, reflectômetro no domínio \\ do tempo e sonda de nêutrons no monitoramento do teor de água no solo / Claudia \\ Fernanda Almeida Teixeira. - - Piracicaba, 2001. \\ 115 p. : il. \\ Tese (doutorado) - Escola Superior de Agricultura Luiz de Queiroz, 2001. \\ Bibliografia. \\ 1. Reflectometria de domínio temporal 2. Sonda de nêutron 3. Tensiômetro 4. \\ Umidade do solo I. Título
}

CDD 631.432

"Permitida a cópia total ou parcial deste documento, desde que citad a a fonte - $O$ autor"

Tata de depóslto junto à CPG/ESALQ

231.081201 


\begin{abstract}
A Alaides e Clair Teixeira,
as palavras nunca serão suficientes para expressar

a gratidão e o respeito que tenho por vocês,

que não só me deram a vida,

como também orientaram meus passos.

Foi por vocês que cheguei até aqui

e é por vocês que seguirei em frente
\end{abstract}

\title{
DEDICO
}

Ao meu irmão Elton, meus sobrinhos Luan e Suzana

e a minha cunhada Débora 


\section{AGRADECIMENTOS}

À Coordenação do Programa de Pós-Graduação em Solos e Nutrição de Plantas da ESALQ/USP pela oportunidade concedida.

À Comissão de Aperfeiçoamento do Pessoal de Ensino Superior-CAPES, pela concessão da bolsa de estudo.

Ao Professor Dr. Sergio Oliveira Moraes pela orientação sempre constante, pela amizade e sobretudo, pelo estímulo durante os momentos de desânimo.

Aos Professores Dr. Quirijn de Jong van Lier e Dr. Paulo Leonel Libardi pelos ensinamentos, amizade e apoio.

A RAMAL Instalações Elétricas, na pessoa do Sr. Amaury de Sordi Abdala pelo importante auxílio na medição do sistema de aterramento.

Aos Engenheiros Eletricistas Juarez Renó do Amaral e Luiz Masahiro Kawaguche e ao Técnico em Eletrônica e Analista de Sistemas Adilson Rodrigues, pelas importantes contribuições técnicas durante a realização do trabalho.

Aos funcionários Francisco Bernardo Dias, Luiz Fernando Novello e Manoel Israel ("Seu Mané") do Departamento de Ciências Exatas, pelo apoio em todas as etapas deste trabalho.

Aos estagiários Tulio Cícero Teodoro da Silva e Newton de Almeida Prado Jr. pelo auxílio durante a instalação do experimento em campo. 
Aos professores e funcionários da UFPel, em especial aos amigos Prof. Dr. Eloy Antonio Pauletto e Rosani Guidotti, pelas constantes palavras de incentivo à realização deste Curso.

$\grave{A}$ amiga de todas as horas, Marcia Aparecida Simonete, pelas palavras de incentivo e ajuda sempre presentes durante a realização do Programa.

À amiga Glaucia Regina Anti pela presença sempre constante e pelos ótimos momentos vividos em Piracicaba.

À amiga Janaina Braga do Carmo pela ótima convivência e pelos momentos alegres vividos durante o final do Curso.

Aos amigos Aderbal Rocha, Silvino Guimarães, Luciana Gomes Castro, Maria da Glória Bastos Freitas de Mesquita, Jeane Portela, Jean Marques, José Fernandes Filho, Luis Carlos Timm, Walcylene Pereira, Ana Lúcia Hurtado, Antonio Carlos Cruz, Genelício Rocha, Rogério Cichota, Gilberto Joaquim Jr., Laércio de Carvalho pela amizade e convivio durante a realização do trabalho.

A todos os colegas dos Programas de Pós-Graduação da ESALQ/USP, pela convivência agradável.

Finalmente a todos aqueles que direta ou indiretamente colaboraram para a realização deste trabalho, o meu sincero agradecimento.

À Deus que, no surgimento de problemas aparentemente sem solução, deume a força necessária para solucioná-los. 


\section{SUMÁRIO}

Página

LISTA DE FIGURAS ..................................................................... viii

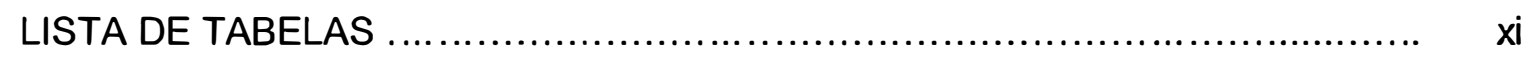

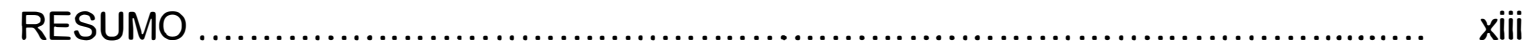

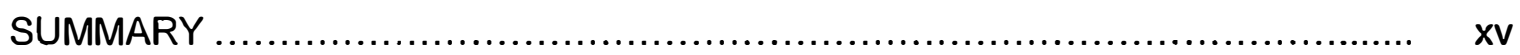

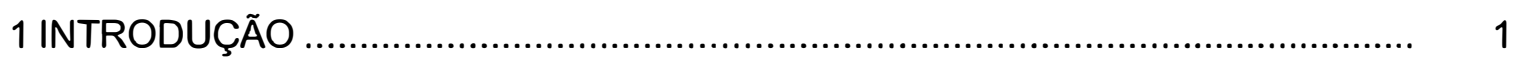

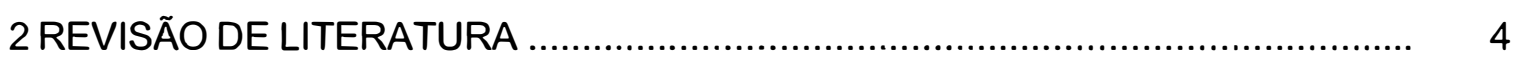

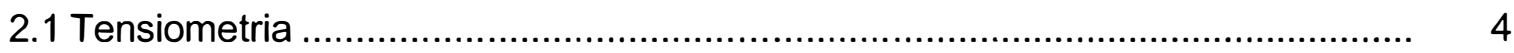

2.2 Técnica da Moderação de Nêutrons .................................................................... 6

2.3 Técnica da Reflectometria no Domínio do Tempo ............................................ 9

2.4 Condutividade Hidráulica do Solo ................................................................... 17

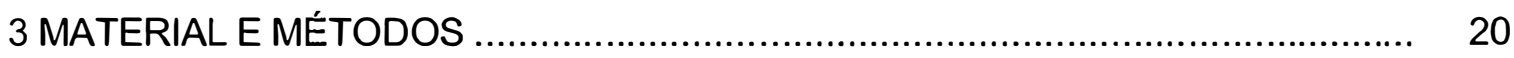

3.1 Descrição geral da área ...................................................................... 20

3.1.1 Localização ..................................................................................... 20

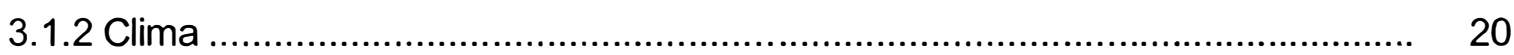

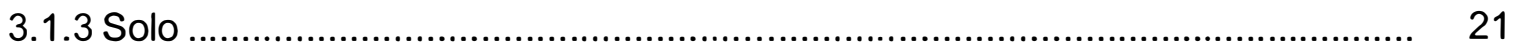

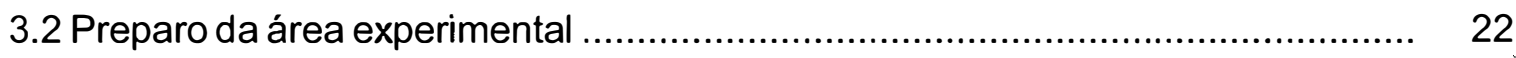

3.3 Equipamentos utilizados ......................................................................... 24

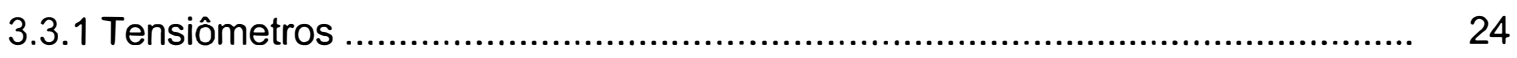

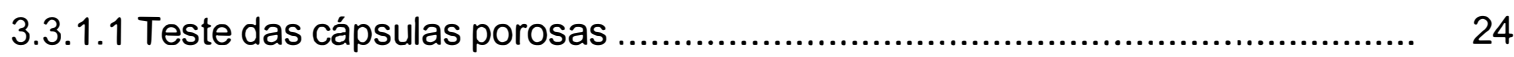

3.3.1.2 Construção dos tensiômetros ............................................................ 26

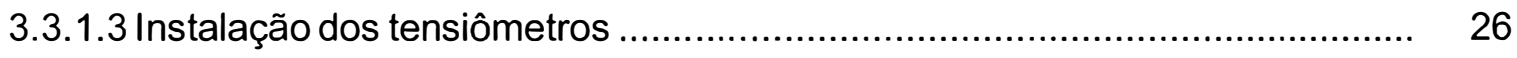

3.3.2 Sonda de nêutrons ........................................................................ 28 
3.3.3 Reflectômetro no domínio do tempo ("Time-Domain Reflectometry", TDR) e sistema automático de aquisição de dados ("Datalogger", DL) ......... 31

3.3.3.1 Componentes do sistema (TDR e periféricos) ................................... 32

3.3.3.2 Designação de endereçamentos ......................................................... 34

3.3.3.3 Instalação do sistema ................................................................. 37

3.3.3.4 Coleta e recuperação dos dados de TDR ............................................. 40

3.3.3.5 Proteção eletromagnética, aterramento e proteção contra surtos de tensão nos equipamentos utilizados ............................................... 42

3.4 Determinações de laboratório ................................................................. 42

3.4.1 Curvas de retenção de água no solo .................................................... 42

3.4.2 Condutividade hidráulica do solo saturado e densidade do solo ................... 45

3.5 Método do perfil instantâneo ................................................................ 47

4 RESULTADOS E DISCUSSÃO .......................................................... 51

4.1 Blindagem eletromagnética, aterramento e proteção contra surtos de 51 tensão

4.2 Características físicas do solo .......................................................... 56

4.2.1 Densidade do solo e condutividade hidráulica do solo saturado ................... 56

4.2.2 Curva de retenção de água no solo ...................................................... 59

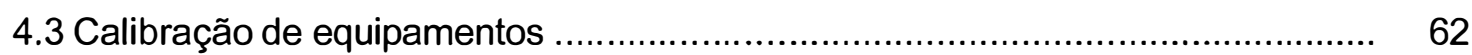

4.3.1 Calibração da sonda de nêutrons ............................................................. 62

4.3.2 Calibração do testador de cabos .......................................................... 68

4.4 Condutividade hidráulica do solo não saturado .......................................... 74

4.4.1 Saturação da parcela experimental ...................................................... 74

4.4.2 Sensibilidade dos equipamentos tensiômetro, testador de cabos e sonda de nêutrons na deteç̧ão da umidade do solo ....................................... 79

5. CONCLUSÕES ......................................................................... 92

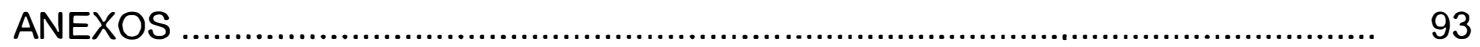

REFERÊNCIAS BIBLIOGRÁFICAS ....................................................... 106 


\section{LISTA DE FIGURAS}

Página

1 Diagrama de blocos do arranjo eletrônico de uma sonda de nêutrons..................

2 Diagrama de blocos do arranjo eletrônico de um TDR. ..................................... 12

3 Exemplo da reflexão de um traço obtido de uma linha de transmissão de três hastes não balanceada............................................................................. 14

4 Localização da área experimental e dos equipamentos ....................................21

5 Chapa galvanizada utilizada e abertura do solo para a sua introdução ...............23

6 Representação da montagem para determinação da condutância hidráulica de cápsulas porosas utilizadas na confecção dos tensiômetros. .........................26

7 Distribuição dos tensiômetros e respectivas profundidades de instalação, tubos de acesso para sonda de nêutrons e manômetros de mercúrio.................29

8 Esquema utilizado na calibração direta da sonda de nêutrons, posição do tubo de acesso e das amostragens. .................................................................. 30

9 Representação do abrigo ambientalmente selado contendo o testador de cabos, "datalogger", supressor de transientes e os cabos associados. .............. 31

10 Diagrama de blocos do sistema de alimentação.................................................33

11 Esquema de conexões da interface SDM1502 para o "datalogger" e multiplexadores

12 Sensor de umidade de três hastes, modelo CS605, compatível com o cabo coaxial RG58.

13 Sistema de chaveamento para o endereçamento do SDM1502. 
14 Exemplo da localização dos "jumpers" de endereçamento nas placas dos circuitos do primeiro nível de multiplexação (SDMX50) ......................................36

15 TDR e "datalogger" instalados na caixa de alvenaria localizada próxima ao Posto Agrometeorológico do DCE/ESALQ/USP............................................... 38

16 Localização dos multiplexadores na caixa de cimento amianto ..........................39

17 Sensores do TDR instalados horizontalmente à parcela experimental nas

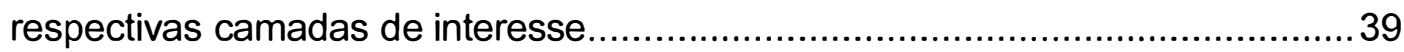

18 Detalhe da proteção dos cabos dos sensores de umidade por meio de tubulações plásticas flexíveis

19 Esquema da localização dos quinze sensores do TDR nas profundidades de interesse.

20 Diagrama esquemático da conexão do módulo de armazenamento à porta "COM" de um computador utilizando a interface SC532.

21 Amostrador do tipo Uhland utilizado para a coleta das amostras indeformadas.

22 Mesas de tensão utilizadas para a obtenção dos pontos de baixa tensão das curvas de retenção.

23 Câmaras de pressão de Richards utilizadas para a obtenção dos pontos de alta tensão das curvas de retenção.

24 Saturação das amostras indeformadas utilizando sistema de gotejamento por meio do Frasco de Mariotte.

25 Diagrama esquemático do sistema utilizado na determinação da condutividade hidráulica saturada em amostras com estrutura indeformada .......47

26 Parcela experimental coberta após a inundação, com plástico de polietileno preto e estrutura de chapas galvanizadas 49

27 Diagrama esquemático representando os equipamentos instalados no campo para monitoramento automático do teor de água no solo e respectiva proteção eletromagnética. 
28 Diagrama esquemático da instalação do supressor de transientes ("Clamper"). 55

29 Curvas de retenção de água no solo para as diferentes camadas do perfil........61

30 Curvas de calibração para sonda de nêutrons obtidas pelos métodos direto e indireto, para as diferentes profundidades do solo.

31 Curvas de calibração para o TDR, obtidas para as diferentes profundidades do solo.

32 Variação dos potenciais mátrico e de pressão em função do tempo, obtida por tensiometria antes do fechamento da parcela, para a profundidade de $0,70 \mathrm{~m}$ (terceira bateria de tensiômetros)

33 Variação do potencial de pressão em função do tempo, obtida pelo TDR antes do fechamento da parcela, para a camada de $0,70 \mathrm{~m}$ (repetição 1).

34 Variação da umidade volumétrica com o tempo para as três baterias de tensiômetros, profundidade de $0,70 \mathrm{~m}$.

35 Variação da umidade volumétrica com o tempo para as três baterias de tensiômetros, profundidade de $1,00 \mathrm{~m}$.

36 Variação da umidade volumétrica com o tempo para os três tubos de acesso da sonda de nêutrons, profundidade de $0,70 \mathrm{~m}$

37 Variação da umidade volumétrica com o tempo para os três tubos de acesso da sonda de nêutrons, profundidade de 1,00 m

38 Variação da umidade volumétrica com o tempo para os dois sensores de TDR, profundidade de $0,70 \mathrm{~m}$.

39 Variação da umidade volumétrica com o tempo para os dois sensores de TDR, profundidade de $1,00 \mathrm{~m}$. 


\section{LISTA DE TABELAS}

Página

1 Dados de granulometria (areia, silte e argila), classe textural, matéria orgânica (M.O.) e densidade dos sólidos $\left(\rho_{\mathrm{s}}\right)$ do solo nas camadas de interesse.

2 Teores (\%) dos óxidos de Silício, Alumínio, Ferro, Titânio e Manganês para as camadas de interesse

3 Características hidráulicas das cápsulas porosas selecionadas para confeç̧ão dos tensiômetros e respectivas profundidades de instalação.

4 Valores médios e coeficientes de variação da densidade do solo nas diferentes camadas de interesse

5 Valores médios e coeficientes de variação da condutividade hidráulica saturada $\left(K_{\text {sat }}\right)$, obtida com permeâmetro de carga constante, para as diferentes camadas de interesse

6 Parâmetros de ajuste da equação de van Genuchten(1980) correspondentes às diferentes profundidades de interesse

7 Equações de calibração da sonda de nêutrons para os métodos direto e indireto, obtidas para as diferentes camadas.

8 Índices para verificação da concordância entre as curvas de calibração obtidas pelos métodos direto e indireto para cada profundidade do solo em estudo

9 Valores de altura de coluna de mercúrio $\left(\mathrm{cm} \mathrm{H}_{\mathrm{g}}\right)$ correspondentes ao potencial mátrico nulo 
10 Valores médios e coeficientes de variação da porosidade total calculada, para as diferentes camadas do perfil em estudo

11 Valores médios de umidade volumétrica máximos $\left(\theta_{\text {máx }}\right)$ e mínimos $\left(\theta_{\min }\right)$

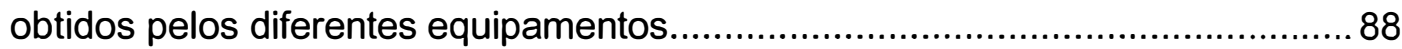

12 Condutividade hidráulica do solo não saturado $(K(\theta))$ obtida para os três equipamentos, correspondente a profundidade de $0,70 \mathrm{~m}$

13 Condutividade hidráulica do solo não saturado $(K(\theta))$ obtida para os três equipamentos, correspondente a profundidade de $1,00 \mathrm{~m}$

14 Índices para verificação da concordância entre as condutividades hidráulicas obtidas para a profundidades de $0,70 \mathrm{~m}$ e 1,00 m considerando as interações entre os equipamentos. 


\title{
DESEMPENHO DO TENSIÔMETRO COM MANÔMETRO DE MERCÚRIO, REFLECTÔMETRO NO DOMÍNIO DO TEMPO E SONDA DE NÊUTRONS NO MONITORAMENTO DO TEOR DE ÁGUA NO SOLO
}

\author{
Autora: CLAUDIA FERNANDA ALMEIDA TEIXEIRA \\ Orientador: Prof. Dr. SERGIO OLIVEIRA MORAES
}

\section{RESUMO}

O objetivo do trabalho foi comparar o desempenho da sonda de nêutrons e do reflectômetro no domínio do tempo (TDR) com o tensiômetro com manômetro de mercúrio (considerado como instrumento padrão), dando-se ênfase na sensibilidade de deteç̧ão de variações na umidade do solo sob condições de molhamento e secagem (Método do Perfil Instantâneo para determinação da condutividade hidráulica do solo); nas vantagens da automação de equipamentos nessas determinações e no desenvolvimento de um sistema de proteção eletromagnética para esse conjunto automatizado. Um experimento foi instalado em um solo classificado como Nitossolo Vermelho distrófico latossólico de textura muito argilosa, localizado próximo ao Posto Meteorológico do Departamento de Ciências Exatas, ESALQ/USP, Piracicaba (SP), Brasil, $22^{\circ} 42^{\prime} 30^{\prime \prime}$ de latitude sul e $47^{\circ} 38^{\prime} 00^{\prime \prime}$ de longitude oeste. A utilização de vários sistemas combinados de proteção eletromagnética, envolvendo proteções na rede elétrica, Gaiola de Faraday e hastes de aterramento permitiu lograr um aterramento do sistema dentro dos padrões internacionais de segurança $\left(R_{\text {terra }} \leq 5 \Omega\right)$, evitando queima de componentes e interferências nos sinais do TDR. O testador de cabos do tipo TDR não apresentou a mesma sensibilidade dos tensiômetros na detecção de oscilações entre potencial de pressão e mátrico da água no solo durante 
a aplicação do método do perfil instantâneo. Embora o TDR apresente como grande vantagem a possibilidade de automatização das medições, o experimento não permitiu concluir pela sua superioridade na medição da umidade para monitoramento da condutividade hidráulica do solo não saturado ao longo do tempo. A sonda de nêutrons não permitiu o acompanhamento da redistribuição da água no solo em curto espaço de tempo, confirmando sua inadequação em experimentos dessa natureza. 


\title{
PERFORMANCE OF A MERCURY TENSIOMETER, A TDR AND A NEUTRON PROBE FOR MONITORING SOIL WATER CONTENT
}

\author{
Author: CLAUDIA FERNANDA ALMEIDA TEIXEIRA \\ Adviser: Prof. Dr. SERGIO OLIVEIRA MORAES
}

\section{SUMMARY}

The performance of a neutron probe and a time domain-reflectometer (TDR) was compared with a mercury tensiometer (considered to be the norm), enphasizing the detection of variations in soil water content under wetthing and drying conditions (instantaneous profile method to determine soil hydraulic conductivity); the advantages of automation of equipment under these conditions and the development of electromagnetic protection for the automized equipment. An experiment was performed in a Nitossolo Vermelho distrófico latossólico argiloso (Brazilian classification system), close to the meteorological observatory of the ESALQ/USP, Piracicaba (SP), Brazil, latitude $22^{\circ} 42^{\prime} 30^{\prime \prime} \mathrm{S}$, longitude $47^{\circ} 38^{\prime} 00^{\prime \prime} \mathrm{W}$. The use of a combined set of electromagnetic protection, including electric net protection, a Faraday-cage and earth-pins permitted an earthing within international security norms ( $R_{\text {earth }} \leq 5 \Omega$ ), avaiding shorts of components and signal interference in TDR. The TDR cable tester did not show the same sensibility as the tensiometers for detecting oscillations between pressure and matric soil water potential during the instantaneous profile experiment. Although the TDR has, as a major advantage, its automation possibilities, the experiment did not permit to conclude for its superiority in measuring soil water content for monitoring unsaturated soil hydraulic conductivity through time. The neutron probe 
did not permit the monitoring of water redistribution in short time intervals, confirming its inadequacy for this kind of experiment. 


\section{INTRODUÇÃO}

O conteúdo de água no solo é uma variável utilizada em estudos que envolvem agricultura, hidrologia e meteorologia, entre outros. $\mathrm{Na}$ agricultura essa informação é necessária para muitas aplicações, que incluem aumento da produção agrícola e planejamento da irrigação. Dentro deste contexto, o monitoramento do conteúdo de água torna-se importante para a obtenção, por exemplo da função condutividade hidráulica do solo não saturado $(K(\theta))$, sendo necessária a utilização de um instrumento/equipamento de rápida resposta e de preferência que possa ser mantido no local, coletando informações continuamente ao longo do tempo. O método padrão de medida do conteúdo volumétrico de água de uma amostra de solo é o método gravimétrico, sendo demorado, destrutivo e não permite a repetição da amostragem no mesmo local. Soma-se a esse fato a aproximação dos momentos mais críticos de tomada de decisão, ou seja, a medida que o solo torna-se mais seco é necessária uma frequência maior nas amostragens, tornando-se mais difícil devido a baixa umidade. O método da moderação de nêutrons é um método indireto, que utiliza a relação entre a contagem relativa e a umidade volumétrica, e que, além de necessitar de curvas de calibração, apresenta o inconveniente de utilizar uma fonte radioativa e portanto, não permite o monitoramento contínuo no solo, ou seja, permanecer instalado no local. Para resolver esse inconveniente seria necessário desenvolver um sistema automatizado de elevação e abaixamento da sonda no tubo e, dessa forma, não haveria condições viáveis para a repetição no espaço, apenas no tempo.

A reflectometria no domínio do tempo constitui uma técnica promissora que busca solucionar os problemas citados acima. Dentre as vantagens da técnica destacam-se: característica não destrutiva, rapidez na obtenção dos resultados, segurança do operador, permite a multiplexação e dessa forma o monitoramento contínuo da água no solo, tanto no espaço quanto no tempo. 
Apesar das várias vantagens da técnica de TDR sobre os outros equipamentos de medida do conteúdo de água no solo, ainda existem desvantagens que merecem destaque. Dentre elas podemos citar: elevado custo do equipamento e condições adequadas para sua instalação no campo.

Portanto a criação de novos métodos e equipamentos que possibilitem a análise das propriedades físicas do solo, com maior precisão, rapidez e confiabilidade, é sempre um desafio da pesquisa científica. Neste aspecto técnicas que envolvam a utilização da instrumentação agronômica com vistas à determinação do conteúdo de água no solo são de grande importância para a pesquisa científica. A atualidade do tema pode ser sentida em recente publicação da Agência Internacional de Energia Atômica (IAEA, 2000) e também na realização do I Workshop sobre Aplicações da Técnica de TDR na Agricultura ocorrido em julho de 2001.

Face ao exposto, o objetivo geral do trabalho é comparar o desempenho da sonda de nêutrons e do TDR, com o tensiômetro (equipamento considerado padrão), buscando verificar se o complexo sistema de automação/proteção eletromagnética, compensa de alguma maneira a utilização do TDR. Para tanto este objetivo foi subdividido em cinco etapas:

1) Implementar um sistema de blindagem eletromagnética, aterramento e proteção contra surtos de tensão para a instalação do TDR a campo;

2) comparar curvas de calibração para a sonda de nêutrons, obtidas diretamente pela relação entre contagem relativa e umidade volumétrica de amostra coletada e indiretamente pela contagem relativa e potencial mátrico, obtidas por tensiometria e sua posterior relação com a umidade volumétrica através da curva de retenção de água no solo;

3) avaliar a sensibilidade dos equipamentos durante os processos de saturação e redistribuição em estudos de drenagem interna visando suas utilizações no método do perfil instantâneo para determinação da condutividade hidráulica do solo;

4) analisar as faixas de umidade volumétrica para cada equipamento utilizado durante esses processos (item 3); 
5) determinar a função condutividade hidráulica $K(\theta)$ a partir dos dados da curva de retenção de água no solo e, utilizando valores de umidade volumétrica conforme cada instrumento, comparar as respectivas condutividades. 


\section{REVISÃO DE LITERATURA}

Neste capítulo serão apresentados inicialmente, aspectos gerais relacionados aos instrumentos utilizados para a obtenção da umidade volumétrica do solo, com vistas, por exemplo, a determinação da condutividade hidráulica do solo não saturado. Procurar-se-á enfatizar o princípio envolvido, vantagens e desvantagens, uso, instalação, calibração e sensibilidade de cada instrumento. Na segunda parte serão apresentados aspectos relevantes relacionados à condutividade hidráulica do solo não saturado, dando-se ênfase aos fatores que influenciam a sua determinação.

\subsection{Tensiometria}

Apesar do conteúdo de água do solo ser necessário em investigações de Física do Solo, o mesmo não é suficiente para indicar o respectivo estado de energia. Esse estado está relacionado às interações entre a matriz e a solução do solo, que resultam das forças de adsorção e capilaridade, responsáveis pelo fenômeno da retenção da solução do solo. O potencial gravitacional associado ao potencial mátrico possibilita a obtenção do potencial total, utilizado em estudos de movimento de água no solo. O tensiômetro é um instrumento de campo bastante utilizado para a obtenção do potencial mátrico e consiste de uma cápsula porosa de cerâmica, conectada a um manômetro através de um tubo preenchido com água (Libardi, 2000). Maiores informações sobre as características e construção desse equipamento podem ser obtidas em Olitta (1976) e Assis Júnior (1995).

O princípio de funcionamento do tensiômetro está relacionado ao estabelecimento do contato hidráulico entre a água em seu interior e a água do solo através da cápsula porosa, possibilitando o equilíbrio após um determinado tempo. Quando houver alguma mudança no conteúdo de água do solo e, consequentemente em seu estado de energia, essa alteração será transmitida à água no interior do 
tensiômetro, sendo indicada rapidamente pelo manômetro, que pode ser de coluna de mercúrio, analógico ou digital.

A facilidade de instalação, a possibilidade de fornecimento de uma medida direta do estado de energia com que a água se encontra no solo e o baixo custo, quando comparado a outros equipamentos, tornam o tensiômetro com manômetro de mercúrio muito útil em estudos de manejo de irrigação e de movimento de água em solos não saturados. Apesar da grande utilidade desse equipamento no cenário agrícola, algumas desvantagens do tensiômetro são o tempo de resposta e a faixa de potencial mátrico da água no solo na qual se pode utilizá-lo.

O tempo de resposta está relacionado ao tempo necessário para que ocorra novamente o equilíbrio de energia da água no tensiômetro com a água no solo, após qualquer alteração na mesma. Klute \& Gardner (1962) consideram que três fatores influem no tempo de resposta: sensibilidade do tensiômetro, condutância hidráulica da cápsula porosa e condutividade hidráulica do solo. Em trabalho de Villagra et al. (1988) os autores enfocam a problemática do uso de tensiômetros para fins práticos de manejo de água e uma das conclusões do trabalho está relacionada a variabilidade espacial do solo, que contribui para a variância total do potencial mátrico com um coeficiente de variação de mais de $40 \%$, sendo a variância instrumental desprezível. Outro aspecto estudado foi o tempo de resposta, sendo tanto maior quanto mais negativo o potencial mátrico do solo, não ultrapassando oito horas para potenciais em torno de $-50 \mathrm{KPa}$. Como elevados potenciais negativos significam baixo teor de água e portanto menor condutividade do solo, tem-se a corroboração do proposto por Klute \& Gardner (1962).

A faixa de potencial mátrico da água no solo na qual se pode utilizar esse equipamento constitui uma possivel desvantagem. Apesar de relativamente estreita (zero até aproximadamente 0,8 da pressão atmosférica local), Reichardt (1990) considera que mesmo com essa limitação, o tensiômetro é um ótimo instrumento de campo para indicar o começo da irrigação. Como normalmente é assumido um valor de potencial mátrico que corresponderia a umidade à capacidade de campo e, este valor está dentro da faixa de operação do tensiômetro, o mesmo acaba sendo útil mesmo limitado, conforme Reichardt (1990). 
Muito pouco tem se estudado sobre o "design" do tensiômetro nos últimos tempos. Pesquisas têm sido realizadas para melhor adaptar o uso do mesmo em conjunto com outros equipamentos, como, por exemplo, com o TDR (item 2.3), permitindo a obtenção simultânea da umidade volumétrica e do potencial mátrico. Or \& Wraith (1999) desenvolveram um sensor baseado na técnica de TDR para medir o potencial mátrico, construído a partir de discos porosos com diferentes distribuições de tamanhos de poros, contidos em uma célula coaxial. A umidade volumétrica foi obtida após o equilíbrio hidráulico com o solo ao redor e, em seguida, a determinação do potencial mátrico. Os resultados experimentais mostraram relações consistentes entre o conteúdo de água e o potencial mátrico obtidos pelo sensor, com respostas similares àquelas obtidas com as sondas convencionais de três hastes. Nesta mesma linha, Noborio et al. (1999) também desenvolveram uma sonda de TDR para medidas simultâneas de potencial mátrico e conteúdo de água do solo em laboratório. Os autores utilizaram o gesso como meio poroso para a obtenção do potencial mátrico e encontraram que o tempo de resposta foi similar a outros equipamentos que utilizam o mesmo material. Entretanto, comentam a necessidade de mais pesquisas para definir materiais porosos com uma faixa maior de retenção de água e resposta mais rápida a mudanças no estado de energia da água no solo.

\subsection{Técnica da Moderação de Nêutrons}

A técnica da moderação de nêutrons pode ser utilizada para determinar o conteúdo de água a uma dada profundidade no solo, a quantidade total de água no perfil e também para monitorar as mudanças de umidade ao longo do tempo. Convém ressaltar, como a grande vantagem na utilização da sonda de nêutrons, a sua natureza não destrutiva, o que a torna de grande importância nas determinações do conteúdo de água citadas anteriormente.

A sonda de nêutrons consiste basicamente de uma fonte radioativa que emite nêutrons rápidos, um detector de nêutrons lentos e um pré-amplificador (CPN, 1980), cujo sinal é conduzido ao sistema eletrônico de contagem (Figura 1). As características da sonda como geometria, tipo e atividade da fonte de nêutrons, tipos de detectores e pré-amplificadores variam consideravelmente, segundo o fabricante. Seu princípio de funcionamento é discutido com maiores detalhes em Gardner \& 
Kirkham (1952), mas de uma maneira simplificada, nêutrons rápidos são emitidos por uma fonte emissora de nêutrons e interagem com a matéria ao redor da sonda. Um dos processos que pode ocorrer é a dispersão dos nêutrons por colisões elásticas ou inelásticas. Através das colisões, os nêutrons rápidos de alta energia (cerca de $2 \mathrm{MeV}$ ), perdem energia (moderação) e se tornam lentos ou térmicos, de baixa energia (cerca de $0,025 \mathrm{eV}$ ). O hidrogênio é considerado o elemento químico mais eficiente na redução de energia de um nêutron rápido, tornando-se, então um bom moderador de nêutrons. Como o hidrogênio é o principal constituinte da água, em um solo com elevada umidade, maior será a quantidade de nêutrons lentos presentes ao redor do detector e maior será a taxa de contagem por unidade de tempo (contagem por segundo, cps ou contagem por minuto, cpm), fornecida pelo sistema eletrônico de contagem.

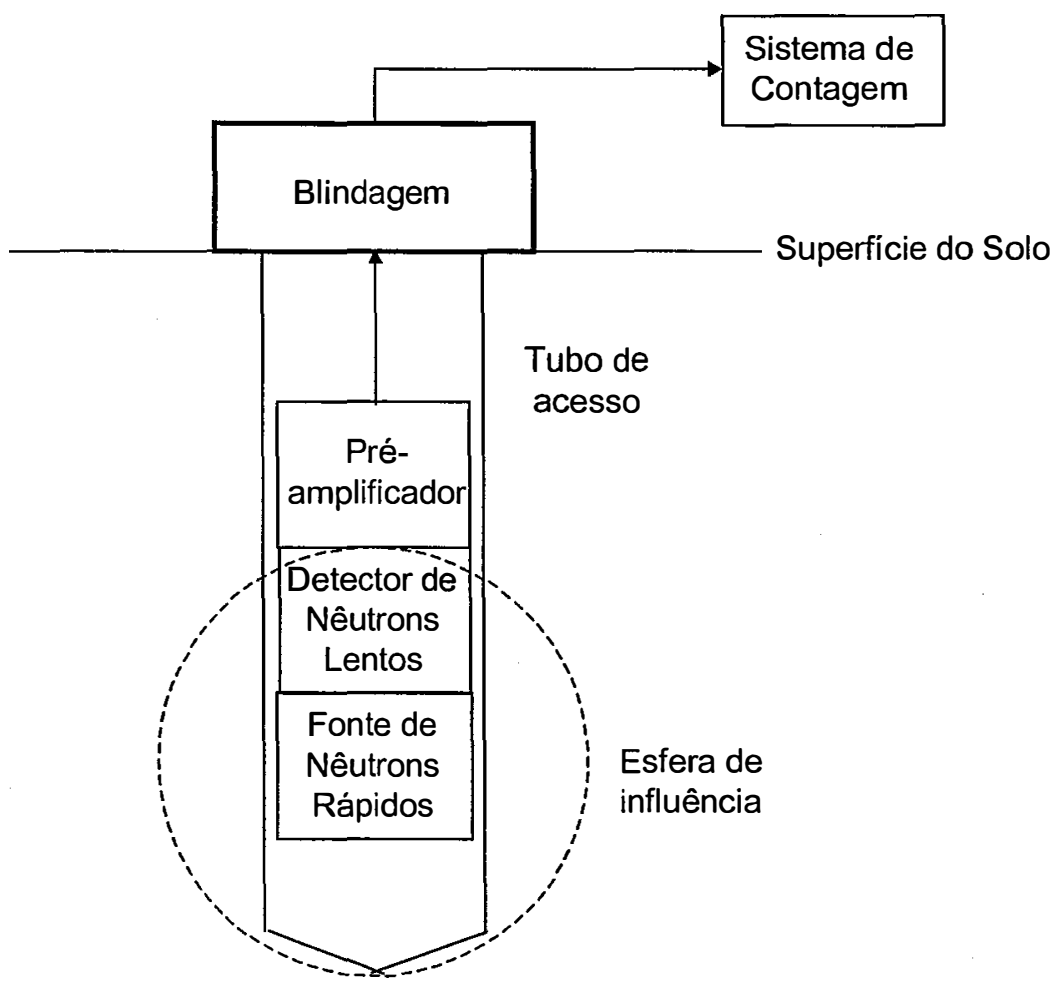

Figura 1 - Diagrama de blocos do arranjo eletrônico de uma sonda de nêutrons

Como a sonda fornece valores de contagem por unidade de tempo, há a necessidade da construção de curvas de calibração para a obtenção da umidade do solo, relacionando a contagem relativa (contagem solo/contagem no padrão) com o 
conteúdo volumétrico de água no solo. Na literatura são encontrados basicamente três métodos para a calibração da sonda de nêutrons: calibração teórica, em tanques e em campo (Gardner et al., 1991), sendo o mais comum o método de campo. Esse método apresenta alguns inconvenientes, como por exemplo a necessidade da retirada de várias amostras de solo para a determinação da umidade gravimétrica e o volume amostrado pela sonda não constitui o mesmo da amostra coletada (Bacchi et al., 1998). Aliado a isso existe ainda a influência da variabilidade espacial (Turatti et al., 1990), representada pela umidade gravimétrica e a densidade do solo. Em função disso, estudos têm surgido com o intuito de facilitar a calibração da sonda de nêutrons, pois na maioria dos casos as relações entre as contagens no solo e a umidade volumétrica, não apresentam coeficientes de correlação considerados adequados (Turatti et al.,1990).

Santos et al. (1999) utilizaram uma metodologia simplificada, que trata somente de pontos extremos do conteúdo de água do solo (úmido e seco) e encontraram que a calibração simplificada da sonda de nêutrons apresentou melhor estimativa do conteúdo de água no solo com maior rapidez e simplicidade.

Outro aspecto importante a ser considerado na utilização da sonda de nêutrons é a sua esfera de influência, que varia em função do conteúdo de água. Para cada umidade, a sonda amostra diferentes volumes de solo e como o número de nêutrons lentos detectados pelo sistema de contagem varia em função do conteúdo de água, a esfera de influência será maior em solos secos do que em solos mais úmidos. Esse fato poderá acentuar os problemas causados pela utilização da sonda de nêutrons em camadas superficiais do solo, ocorrendo a fuga de nêutrons para a atmosfera.

A utilização da sonda de nêutrons para o monitoramento continuo da água no solo tem sido restrita, apesar da relativa facilidade do equipamento ser acoplado a um sistema automático de aquisição de dados. O principal inconveniente reside na presença de uma fonte radioativa e, portanto há a necessidade da observância e conhecimento de leis e normas que regulamentam e fiscalizam o uso desses materiais, constituindo uma grande desvantagem da sonda de nêutrons quando comparada, por exemplo, ao TDR. A possibilidade de roubo e/ou vandalismo é uma questão que impossibilita sua utilização para monitoramento contínuo. 


\subsection{Técnica da Reflectometria no Domínio do Tempo (TDR)}

A reflectometria no domínio do tempo (TDR) é uma técnica relativamente recente e foi originalmente criada para diagnosticar descontinuidades em sistemas eletrônicos de comunicação, como por exemplo, cabos e linhas de transmissão subterrânea. No final da década de 60, Fellner-Feldegg (1969), introduziu a técnica para medir a permitividade dielétrica complexa de líquidos. Através da medida da velocidade de propagação de um pulso de voltagem, encontrou a relação de dependência da frequência em função da constante dielétrica, do tempo de relaxação molecular e da condutividade elétrica de líquidos. A partir de então, a aplicação da técnica de TDR para medida do conteúdo de água no solo tem sido bastante utilizada para estudos de campo e laboratório. O princípio do método está relacionado ao envio de um pulso eletromagnético de alta frequência a hastes metálicas enterradas no solo (sondas). Parte do pulso é refletido ao chegar ao fim das hastes e o intervalo de tempo entre os pulsos incidentes e refletidos é medido.

Para o entendimento da técnica da reflectometria no domínio do tempo algumas considerações teóricas são necessárias.

As propriedades moleculares da água são a base de recentes desenvolvimentos em medidas eletromagnéticas no solo a altas frequências (faixas de ondas de rádio e microondas). Feng et al. (1999) consideram que as propriedades eletromagnéticas de um material são caracterizadas por três parâmetros: 1) permitividade dielétrica, $\varepsilon$; 2) condutividade elétrica, $\sigma, e$; 3 ) permeabilidade magnética, $\mu$. Em geral estes parâmetros são dependentes da frequência. A diferença entre a permeabilidade magnética e a permeabilidade magnética do vácuo, $\mu_{0}$, e a dependência da condutividade da frequência são desprezíveis para materiais como solo. Devido ao mecanismo de polarização dipolar da água, o solo úmido é um material dielétrico que tem uma permitividade relativa complexa dependente da frequência, que de uma maneira simplificada pode-se representar por:

$$
\varepsilon(f)=\varepsilon^{\prime}(f)-\varepsilon^{\prime \prime}(f)
$$


onde f é a frequência e $\varepsilon^{\prime}$ e $\varepsilon^{\prime \prime}$, são a parte real e a imaginária da permitividade $\varepsilon$, respectivamente. A parte real da permitividade é frequentemente chamada de constante dielétrica (Ka) e é uma medida do quanto de energia de um campo elétrico externo é armazenada no interior de um material contido no respectivo campo (Anexo A). A parte imaginária da permitividade representa as perdas elétricas, tornando-se significante somente a frequências acima de $10 \mathrm{GHz}$.

A técnica de TDR utiliza a constante dielétrica da água para estimar o conteúdo de água do solo. Na faixa de frequência das ondas de rádio $(\cong 50 \mathrm{MHz})$, a constante dielétrica da água é cerca de 80 , do ar é 1 e dos outros componentes varia de 2 a 7 . Assim, uma medida da constante dielétrica do solo nesta faixa de frequência é uma boa medida do seu conteúdo de água. Um dos trabalhos precursores nessa linha foi o de Topp et al. (1980), que mostraram a aplicação da técnica para medir o conteúdo volumétrico de água em cinco solos e concluíram que o parâmetro que mais contribuiu nas variações da constante dielétrica foi o conteúdo de água do solo. Gardner et al. (1991) fazem uma definição prática da constante dielétrica de um material, como o quociente entre a capacitância de um capacitor com o respectivo material entre as placas, comparado ao valor obtido considerando o ar entre as armaduras. Sob a influência de um campo elétrico em um material dielétrico, as cargas positivas e negativas são deslocadas e pequenos dipolos são produzidos. Alguns materiais, como a água, também possuem dipolos permanentes. Os dipolos elétricos são alinhados pelo campo elétrico, tornando o meio dielétrico como um todo polarizado. A constante dielétrica como definida acima é uma medida da polarização e como consequência, um material cujas moléculas têm um momento dipolar permanente e são livres para se alinhar com o campo elétrico, têm uma constante dielétrica muito grande. Maiores detalhes sobre o entendimento da constante dielétrica de um material qualquer podem ser vistos no Anexo $A$.

A técnica da reflectometria no domínio do tempo consiste da medida do tempo de trajeto de pulsos eletromagnéticos ao longo de uma linha de transmissão de duas, três ou mais hastes com comprimento conhecido. Este tempo que leva para a onda eletromagnética ir e voltar na linha de transmissão é relacionado à constante dielétrica do meio no qual a linha está inserida: 


$$
v=\frac{c}{\sqrt{K a}}
$$

onde $v$ é a velocidade de propagação, $c$ a velocidade da luz no vácuo $\left(3 \times 10^{8} \mathrm{~m} \mathrm{~s}^{-1}\right)$ e $\mathrm{Ka}$ a constante dielétrica do meio. Como a velocidade de propagação num movimento retilíneo uniforme também pode ser escrita como $v=2 \mathrm{~L} / \mathrm{t}$, tem-se:

$$
K a=\left(\frac{c}{2 L} \cdot t\right)^{2}
$$

onde $L(m)$ é o comprimento da linha de transmissão e $t$ (s) o tempo que a onda leva para percorrê-la.

Para os instrumentos de TDR existentes comercialmente, o termo ct/2 é reduzido a um comprimento aparente (La) e Ka é obtida através da seguinte relação (Nadler et al., 1991; Yu et al., 1997; Campbell, 1999).

$$
K a=\left[\frac{L_{v i s o r}}{L_{\text {sonda }} V_{p}}\right]^{2}
$$

onde $L_{\text {visor }}(m)$ é a distância inicial e final da reflexão no visor do TDR, $L_{\text {sonda }}(m)$ é o comprimento da sonda de TDR e $V_{p}$ é a velocidade do sinal no cabo expressa como uma fração da velocidade do sinal no vácuo, podendo ser escolhida e controlada por ajustes na frente do painel do testador de cabos.

De forma resumida pode-se afirmar como Feng et al. (1999), que consideram que a técnica de TDR consiste de duas partes: 1) o sistema físico de medida que inclui os equipamentos: TDR, sonda e outros equipamentos que fazem a geração de uma forma de onda consistente e; 2) a interpretação da forma de onda do TDR, incluindo a sua relação com a propriedade do material desejado. O sucesso na interpretação é o ponto principal para aplicação desta tecnologia.

Para Kutílek \& Nielsen (1994) os principais componentes que fazem parte de um TDR são: um gerador de sinais que produz o pulso de voltagem, um receptor que 
mede a voltagem na linha de transmissão a intervalos de tempo selecionados e um contador que controla a ação dos dois componentes. Um microprocessador interno produz e analisa as medidas de voltagem como uma relação voltagem versus tempo, mostrando no visor a forma de onda produzida. Cabos coaxiais fazem a conexão do TDR com as linhas de transmissão (sondas) que são inseridas no solo (Figura 2). 0 gerador de pulsos envia um pulso eletromagnético para a sonda de TDR ou guias de onda enterradas no solo. Mudanças no conteúdo de água do meio entre as hastes ou na configuração das guias de onda causam uma mudança na impedância da sondà. Em qualquer ponto ao longo da sonda em que o pulso encontrar uma mudança na impedância, uma porção da energia do pulso é refletida e volta ao longo da guia de onda retornando para o amostrador. Esta energia é mostrada como uma função do tempo numa forma de onda no visor do TDR (analogamente ao que ocorre num osciloscópio). O tempo transcorrido entre a reflexão parcial do pulso quando entra no solo e a reflexão final quando atinge o fim das hastes pode ser obtido na forma de onda mostrada no visor.

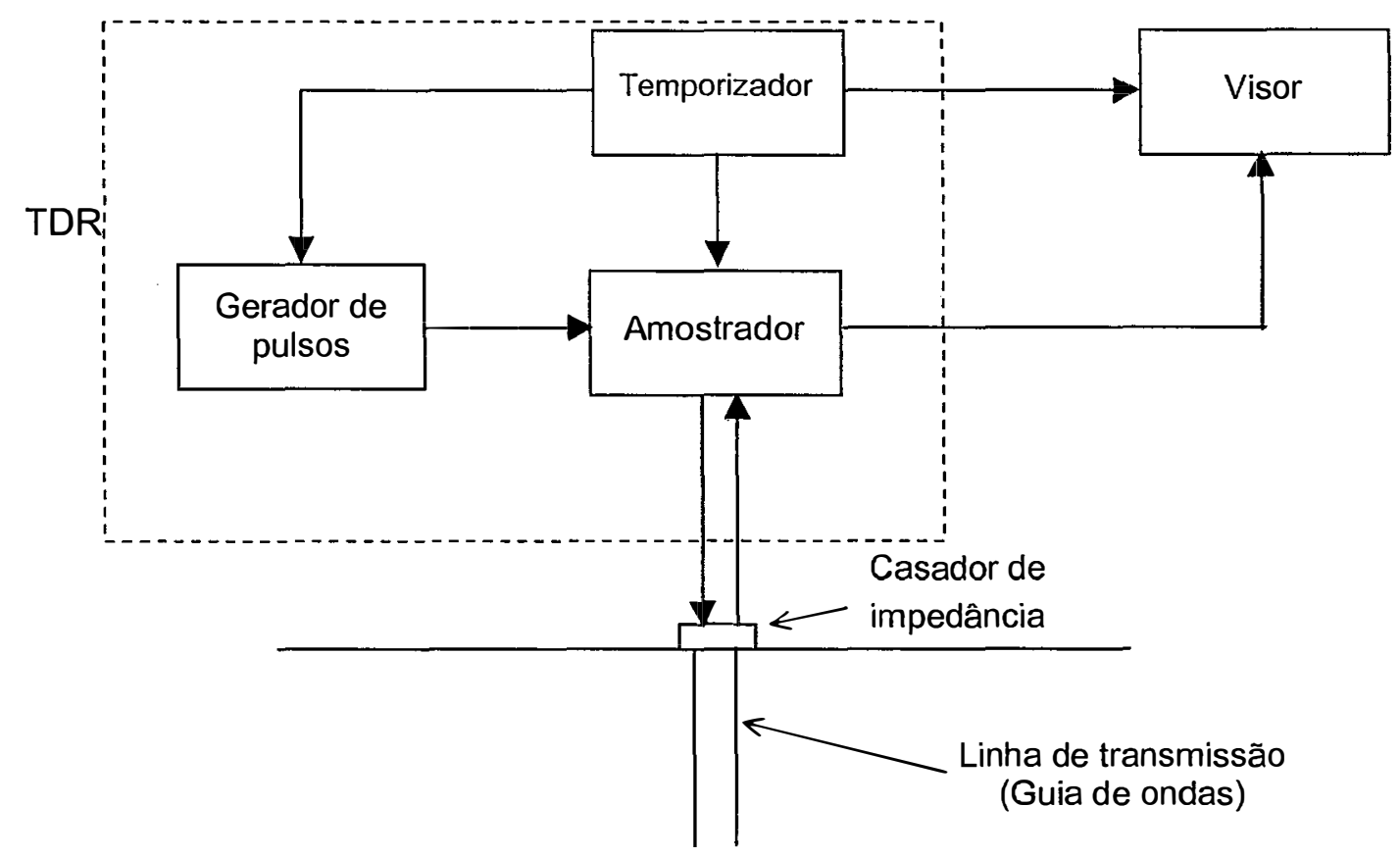

Figura 2 - Diagrama de blocos do arranjo eletrônico de um TDR (Gardner et al., 1991) 
Apesar da evolução da técnica de TDR nos últimos anos, muitas questões ainda permanecem em aberto. Dentre elas pode-se destacar: o efeito do comprimento do cabo na precisão da medida, tipos de sonda, calibração do equipamento e também a interpretação das formas de onda produzidas, quando não se dispõe de um sistema de aquisição de dados automatizado.

Com relação ao efeito do comprimento do cabo de TDR na reflexão do sinal, Herkelrath et al. (1991) encontraram, em estudos realizados em laboratório, que os cabos longos tendem a atenuar o sinal, tornando a medida impraticável. Os autores concluíram que cabos que apresentam um comprimento de até $27 \mathrm{~m}$ não causam problemas na reflexão do sinal. Hook \& Livingston (1995) verificaram que os cabos coaxiais de $75 \Omega$ apresentam "menor tempo de resposta" (rise time), menor diâmetro e mais baixo custo quando comparado ao cabo RG58 de $50 \Omega$.

A grande versatilidade de formas e tamanhos de sondas de TDR, torna a sua escolha uma tarefa às vezes difícil, devendo levar em consideração aspectos relacionados ao tipo de solo, as características da própria sonda e também o estado de umidade do solo no ato da instalação.

Neste sentido Rothe et al. (1997) estudando mudanças causadas na estrutura do solo pela instalação de sondas de TDR e também sua influência nas medidas de umidade, encontraram mudanças significativas na sua estrutura e compressão. $\mathrm{O}$ efeito mais pronunciado ocorreu na umidade próxima à saturação $\mathrm{e}$ menos na umidade abaixo da capacidade de campo.

Alguns aspectos relacionados ao "design" das sondas de TDR para medida de água no solo devem ser considerados. Seguindo esta linha Whalley (1993) destaca as vantagens e desvantagens das linhas de transmissão de duas e três hastes. $O$ autor destaca como vantagem do sensor de duas hastes maior volume de amostragem, enquanto que o de três hastes (linha de transmissão de sinal não balanceada) produz uma reflexão do sinal com maior clareza, maior facilidade de introduzir em solos úmidos e apresentam melhor desempenho. Isto está relacionado principalmente ao sistema de não balanceamento existente nestes sensores, pois pela Figura 3 observase que as hastes constituem um prolongamento do cabo coaxial, dispensando, dessa forma o uso de casadores de impedância, comuns nos sensores de duas hastes. 
Salienta ainda que se deve dar preferência a hastes com menor diâmetro e menor espaçamento entre as mesmas, para minimizar os erros provenientes da compactação causados durante a introdução do sensor no solo. Zegelin et al. (1989) realizaram estudos para comparar a influência do "design" de sonda de três e quatro hastes na reflexão do sinal (ruídos e perdas de informação) e encontraram que as mesmas são muito similares na determinação da constante dielétrica, mas em função do distúrbio causado na introdução da sonda de quatro hastes, são menos atrativas para aplicações no campo.

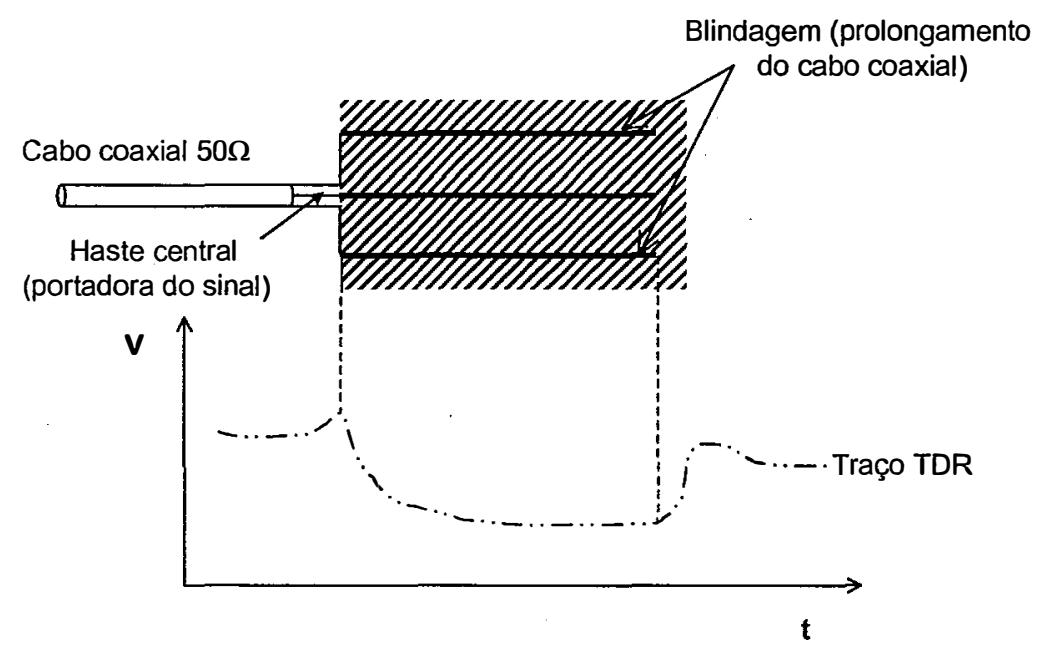

Figura 3 - Exemplo da reflexão de um traço obtido de uma linha de transmissão de três hastes não balanceada

A maioria dos trabalhos que envolvem a técnica de TDR estão relacionados a calibração do equipamento (Roth et al., 1990; Dasberg \& Hopmans, 1992; Dirksen \& Dasberg, 1993; Serrarens et al., 2000), demonstrando que muitos estudos ainda devem ser conduzidos nesta linha. Topp et al. (1980) com o objetivo de estabelecer em laboratório a dependência da constante dielétrica e umidade volumétrica para cinco solos e vários materiais, encontraram uma relação empírica que poderia ser usada como uma curva de calibração universal, eliminando a necessidade de curvas de calibração especificas para cada solo. Os autores concluiram que a constante dielétrica foi praticamente independente da densidade do solo, textura e conteúdo de sais. Atualmente a equação universal proposta por Topp et al. (1980) tem sido bastante citada em trabalhos de calibração de TDR. Entretanto, Tommaselli (1997) discute a 
validade desta equação e afirma que a vantagem do modelo é a não exigência da determinação de parâmetros adicionais do solo. $O$ autor considera que a aplicação da equação tem apresentado bons resultados, com exceção de solos heterogêneos, com altos teores de matéria orgânica e sais.

Em trabalho mais recente Chudinova \& Ponizovskii (1998) avaliaram 4 solos e duas misturas de solos contendo diferentes granulometrias, com o objetivo de analisar o comportamento da constante dielétrica. Em uma das conclusões do trabalho os autores salientam que a relação entre a constante dielétrica e o conteúdo de água apresenta, para solos de textura mais fina, uma mudança abrupta na declividade da curva, quando comparada a solos com textura mais grosseira. Os valores de constantes dielétricas para os solos de textura mais fina foram mais baixos devido a mudanças em suas densidades com o aumento do conteúdo de água. Concluíram ainda que a equação polinomial de terceira ordem de Topp et al. (1980) foi satisfatória somente para as amostras arenosas e insatisfatórias para as amostras com texturas mais finas.

A possibilidade da combinação de um sistema de aquisição automático de dados acoplado ao TDR tem diminuído o tempo de obtenção das formas de onda e também os erros associados ao exame manual dos traços produzidos. No trabalho de Timlin \& Pachepsky (1996) os autores discutem três procedimentos para obter Ka dos traços de TDR na calibração do equipamento: método manual (Topp et al., 1982), método da diferenciação numérica (Baker \& Allmaras, 1990) e o método baseado na técnica da reflexão múltipla proposto por Yanuka et al. (1988). Os autores encontraram vantagens e desvantagens nos métodos utilizados, mas concluem o trabalho confirmando a necessidade da utilização de métodos automatizados de determinação de Ka, resultando em menores erros quando comparados a métodos manuais.

Algumas das vantagens da técnica de reflectometria no domínio do tempo são: a possibilidade da automatização (Baker \& Allmaras, 1990; Herkelrath et al., 1991), permitindo o monitoramento da umidade do solo com alta resolução, em escala temporal e espacial; a utilização para medidas simultâneas de conteúdo de água e condutividade elétrica no mesmo volume de amostra, tanto para medidas no campo (Dasberg \& Dalton, 1985; Dalton \& van Genuchten, 1986), como em colunas no 
laboratório (Nadler et al., 1991), principalmente onde os métodos de moderação de nêutrons e radiação gama se tornam inadequados.

Existem outras aplicações da técnica de TDR que tornam o estudo atrativo para os cientistas interessados em explorar/ampliar as potencialidades de utilização da referida técnica. Em estudos realizados em laboratório, utilizando rochas instrumentadas com uma série de sondas de TDR, Hokett et al. (1992), mostraram que a técnica pode ser usada com uma precisão comparável a obtida em solos. Os autores apresentam quatro vantagens da técnica: a) resposta imediata a mudanças de conteúdo de água; b) sensibilidade de medidas obtidas na área imediatamente ao redor e entre as hastes; c) possibilidade de automatização e d) permite a utilização em amostras de pequeno tamanho no laboratório. Topp \& Davis (1981) aplicaram a técnica com o objetivo de avaliar o conteúdo de água em solos com rachaduras, e encontraram que a técnica apresenta vantagens nesse tipo de estudo que são: volume da amostra, natureza não destrutiva e a simplicidade nas medidas com o TDR.

Existem poucos trabalhos que comparam metodologias para a determinação da umidade do solo. Um deles é o trabalho de Dong Wang et al. (1998), que conduziram o experimento com o objetivo de determinar medidas simultâneas de taxa de infiltração, conteúdo de água no solo e potencial mátrico, utilizando infiltrômetros de tensão, TDR e tensiômetros, e concluíram que o uso de pequenas sondas e tensiômetros durante o experimento, possibilitou as medidas simultâneas desejadas. Apesar de escassos trabalhos existentes na área, a International Atomic Energy Agency (IAEA, 2000) salienta que novos caminhos são necessários para comparar as tecnologias e formular recomendações, estabelecendo linhas de pesquisas futuras.

Apesar dos avanços tecnológicos aplicados à técnica de TDR, os estudos disponiveis no Brasil ainda são poucos, principalmente os relacionados à calibração, à sensibilidade da medida e à comparação com outros equipamentos para medida do conteúdo de água. Parte dos estudos devem estar voltados às diferentes caracteristicas de nossos solos que podem interferir nas medidas, como textura, matéria orgânica, teor de óxidos, etc. 


\subsection{Condutividade Hidráulica do Solo}

O movimento da água no perfil do solo é de fundamental importância para a resolução de problemas que envolvem irrigação, drenagem, armazenamento e transporte de água e de nutrientes, controle da infiltração e escoamento superficial. Para o entendimento e descrição desses e outros processos, as propriedades hidráulicas que governam o movimento da água no solo devem ser bem quantificadas e dentre essas, a condutividade constitui uma das mais importantes para o estudo do fluxo de água em solo não saturado.

A primeira equação que possibilitou a quantificação do movimento da água em meios porosos foi apresentada por Darcy (1856). Em meios porosos nãosaturados, a primeira modificação da equação de Darcy foi feita por Buckingham (1907), envolvendo o conhecimento de que a condutividade hidráulica é função da área do espaço poroso do solo não ocupado pelo ar, tornando-se dependente, portanto, do conteúdo de água ou do potencial mátrico do meio. A equação diferencial geral que descreve o movimento da água em meios porosos foi apresentada por Richards (1931), obtida pela substituição da equação de Darcy na equação da continuidade, ou seja:

$$
\frac{\partial \theta}{\partial t}=\frac{\partial}{\partial z}\left(K(\theta) \frac{\partial \psi_{t}}{\partial z}\right)
$$

em que $\theta\left(\mathrm{m}^{3} \mathrm{~m}^{-3}\right)$ é a umidade volumétrica, $\mathrm{t}(\mathrm{h})$ é o tempo, $\mathrm{K}\left(\mathrm{m}^{2} \mathrm{~h}^{-1} \mathrm{kPa} \mathrm{a}^{-1}\right)$ é a condutividade hidráulica, $\psi_{\mathrm{t}}(\mathrm{kPa})$ é o potencial total da água e $\mathrm{z}(\mathrm{m})$ é a coordenada vertical de posição.

A partir da equação de Richards, vários pesquisadores têm desenvolvido métodos de campo e de laboratório para a determinação da condutividade hidráulica do solo não saturado. Dirksen (1991) apresenta e discute vários critérios utilizados para a seleção dos métodos existentes. Mas qualquer que seja o método selecionado, há a necessidade da obtenção das propriedades hidráulicas do solo, como potencial mátrico $\left(\psi_{\mathrm{m}}\right)$ em função da umidade $(\theta)$ e da condutividade hidráulica $(K)$ em função da umidacte $(K(\theta))$ ou do potencial mátrico $\left(K\left(\psi_{m}\right)\right)$. Saunders et al. (1978) consideram que 
a determinação da condutividade hidráulica em condições de campo apresenta uma maior aproximação das condições reais, ao contrário do laboratório, que utiliza simples amostras de solo, podendo conduzir a erros ocasionados pela alteração das condições naturais do solo.

Para determinar a função $K(\theta)$, cobrindo uma faixa maior de umidade, é comum a utilização do método do perfil instantâneo. O método foi inicialmente desenvolvido por Watson (1966), aperfeiçoado por Hillel et al. (1972) e simplificado por Libardi et al. (1980). Uma de suas vantagens consiste na obtenção de medidas diretas no campo e, portanto medidas com maior confiabilidade quando comparadas com as obtidas em laboratório. Dentre as desvantagens pode-se destacar o consumo elevado de tempo e mão-de-obra, tornando-se um dos grandes problemas para solos que apresentam camadas adensadas ou compactadas, onde o processo de drenagem é muito lento (Jong van Lier \& Libardi, 1999).

Com o intuito de tornar o método de Hillel et al. (1972) ainda mais simples para a determinação de $\mathrm{K}(\theta)$, vários pesquisadores consideraram o gradiente de potencial hidráulico como sendo unitário, ou seja, partiram da pressuposição de que a água drena quase que na mesma razão em todas as profundidades. Nessa linha podese destacar o trabalho de Libardi et al. (1980) que, com apenas medidas de umidade do solo ao longo do perfil em função do tempo de redistribuição, permite estimar a condutividade hidráulica em função da umidade do solo.

Devido às desvantagens apresentadas pelo método do perfil instantâneo, avanços no estudo de métodos para a determinação da função $K(\theta)$ baseada em outras características físicas têm surgido, principalmente aqueles com base nos dados obtidos da curva de retenção de água no solo, dentre eles o de Pauletto et al. (1988), Tomasella \& Hodnett (1997) e Arya et al. (1999).

Normalmente adota-se que a relação entre os valores de $K(\theta)$ e a umidade é uma relação exponencial do tipo:

$$
K(\theta)=K_{0} e^{\gamma\left(\theta-\theta_{0}\right)}
$$


em que $\mathrm{K}_{0}\left(\mathrm{~m}^{2} \mathrm{~h}^{-1} \mathrm{kPa} \mathrm{a}^{-1}\right)$ e $\theta_{0}\left(\mathrm{~m}^{3} \mathrm{~m}^{-3}\right)$ são valores de $\mathrm{K}$ e $\theta$ no tempo zero da redistribuição e y uma constante adimensional (Libardi, 2000).

Verifica-se que como a relação acima é exponencial, qualquer pequena variação no valor da umidade volumétrica do solo $(\theta)$, causará uma mudança significativa nos valores finais de condutividade hidráulica $(K)$.

Isto também contribui para que a condutividade hidráulica, dentre as características físicas do solo, seja uma das que apresenta a mais alta variabilidade. Warrick \& Nielsen (1980) apresentam dados de condutividade hidráulica do solo saturado com coeficiente de variação de cerca de $100 \%$ e $400 \%$ para a condutividade hidráulica do solo não saturado.

Portanto, metodologias e instrumentos capazes de obter a umidade volumétrica do solo com confiabilidade, rapidez e segurança serão, com certeza, de grande aceitação por parte dos pesquisadores em Física do Solo. 


\section{MATERIAL E MÉTODOS}

A escolha do local baseou-se no nivel de dificuldade que o mesmo oferece, tanto do ponto de vista físico-hídrico do solo com a presença de estratificação, no caso com "B-textural" (Saunders et al., 1978; Prevedello et al., 1981; Pauletto et al., 1988; Jong van Lier \& Libardi, 1999) como sob o ponto de vista de localização geográfica, tais como a altitude do local, presença de contatores que acionam moto-bombas, cerca elétrica, rede de alta tensão, etc. Portanto o item Material e Métodos abordará a metodologia empregada no estudo e a descrição dos componentes do sistema utilizado, no intuito de inferir sobre a melhor forma de obter-se resultados confiáveis, para cada estudo em particular, considerando-se os equipamentos e solo adotados.

\subsection{Descrição geral da área}

\subsubsection{Localização}

O experimento foi instalado próximo ao Posto Meteorológico do Departamento de Ciências Exatas da Escola Superior de Agricultura Luiz de Queiroz, Universidade de São Paulo, Piracicaba, cujas coordenadas geográficas são: $22^{\circ} 42^{\prime} 30^{\prime \prime}$ de latitude sul, $47^{\circ} 38^{\prime} 00^{\prime \prime}$ de longitude oeste, a $546 \mathrm{~m}$ de altitude (Figura 4).

\subsubsection{Clima}

No municipio de Piracicaba o clima é do tipo Cwa, segundo a classificação de Köppen, denominado "tropical de altitude". É um clima mesotérmico de inverno seco, em que a temperatura média do mês mais frio é inferior a $17,1^{\circ} \mathrm{C}$ e a do mês mais quente $24,8^{\circ} \mathrm{C}$. As médias anuais de temperatura, precipitação e umidade relativa são de $21,4^{\circ} \mathrm{C}, 1.278 \mathrm{~mm}$ e $74 \%$, respectivamente. A estação seca ocorre entre os meses de abril e setembro, sendo julho o mês mais seco. O mês mais chuvoso oscila entre janeiro e fevereiro e o total das chuvas do mês mais seco não ultrapassa $30 \mathrm{~mm}$ (Sentelhas et al., 1998). 


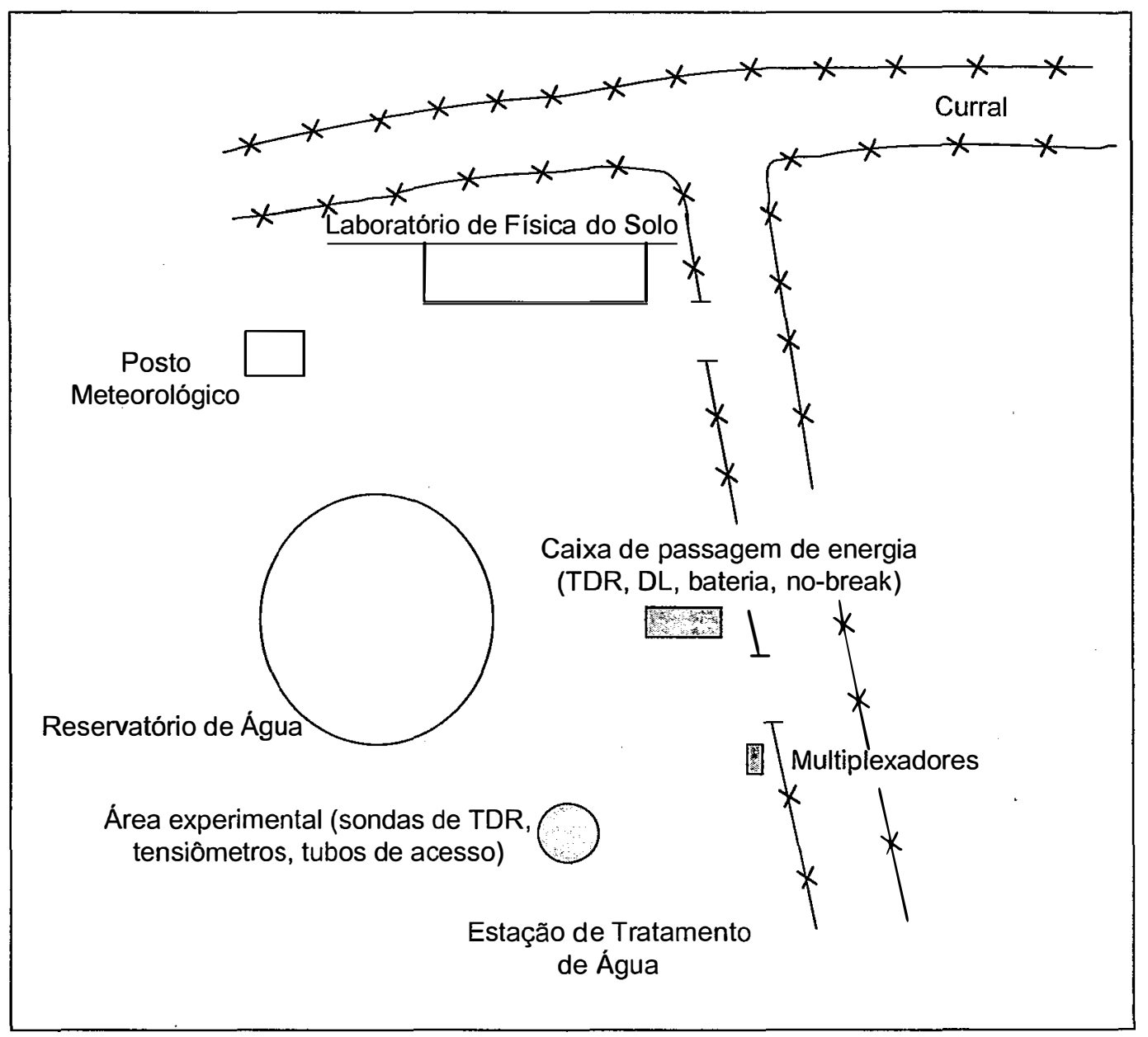

Figura 4 - Localização da área experimental e dos equipamentos (sem escala)

\subsubsection{Solo}

Conforme Embrapa (1999) o solo é classificado como Nitossolo Vermelho distrófico latossólico (NVdf). A caracterização morfológica foi realizada em trincheira aberta na área, anteriormente a instalação do experimento e encontra-se detalhada no Anexo B.

Foram realizadas as seguintes determinações: análise granulométrica, densidade de partículas, matéria orgânica e a determinação de óxidos por ataque sulfúrico, segundo a metodologia utilizada no laboratório do Departamento de Solos e Nutrição de Plantas da ESALQ/USP. Para todas as determinações foi considerada apenas uma repetição para cada camada, em função do custo das análises. Os 
percentuais de areia, silte e argila, classe textural, matéria orgânica e densidade de sólidos, para as profundidades de interesse, são apresentados na Tabela 1.

$\mathrm{Na}$ Tabela 2 encontram-se os teores de óxidos de Silício, Alumínio, Ferro, Titânio e Manganês considerando as camadas do solo em estudo.

Tabela 1. Dados de granulometria (areia, silte e argila), classe textural, matéria orgânica (M.O.) e densidade dos sólidos $\left(\rho_{s}\right)$ do solo nas camadas de interesse

\begin{tabular}{ccccccc}
\hline $\begin{array}{c}\text { Prof. } \\
(\mathrm{m})\end{array}$ & $\begin{array}{c}\text { Areia } \\
\left(\mathrm{g} \mathrm{kg}^{-1}\right)\end{array}$ & $\begin{array}{c}\text { Silte } \\
\left(\mathrm{g} \mathrm{kg}^{-1}\right)\end{array}$ & $\begin{array}{c}\text { Argila } \\
\left(\mathrm{g} \mathrm{kg}^{-1}\right)\end{array}$ & Classe Textural & $\begin{array}{c}\text { M.O. } \\
\left(\mathrm{g} \mathrm{kg}^{-1}\right)\end{array}$ & $\begin{array}{c}\overline{\rho_{\mathrm{s}}} \\
\left(\mathrm{Kg} \mathrm{m}^{-3}\right)\end{array}$ \\
\cline { 2 - 7 } $0-\overline{0,40}$ & 260 & 160 & 580 & Argilosa & 18 & 2500 \\
$0,40-0,50$ & 180 & 140 & 680 & Muito argilosa & 8 & 2670 \\
$0,50-0,60$ & 180 & 140 & 680 & Muito argilosa & 8 & 2590 \\
$0,60-0,70$ & 210 & 140 & 650 & Muito argilosa & 5 & 2560 \\
$0,70-0,80$ & 150 & 140 & 710 & Muito argilosa & 3 & 2530 \\
$0,80-0,90$ & 230 & 140 & 630 & Muito argilosa & 5 & 2530 \\
$0,90-1,00$ & 170 & 180 & 650 & Muito argilosa & 5 & 2380 \\
$1,00-1,10$ & 210 & 140 & 650 & Muito argilosa & 5 & 2560 \\
$1,10-1,20$ & 190 & 160 & 650 & Muito argilosa & 5 & 2600 \\
$1,20-1,30$ & 190 & 160 & 650 & Muito argilosa & 8 & 2600 \\
\hline
\end{tabular}

\subsection{Preparo da área experimental}

A área experimental constituiu-se em um volume de solo com $7,07 \mathrm{~m}^{2}$ de área e 1,30 $\mathrm{m}$ de profundidade, delimitada por uma chapa galvanizada de 1,00 $\mathrm{m}$ de altura e $1,5 \mathrm{~m}$ de raio, introduzida no solo até $0,80 \mathrm{~m}$ de profundidade (Figura 5 ), contendo em seu interior 3 tubos de acesso para sonda de nêutrons, 30 tensiômetros e 30 sondas de TDR. O objetivo da utilização da chapa galvanizada foi "quebrar" o B textural e dessa forma auxiliar a infiltração da água no solo, evitando-se o fluxo lateral. 
Tabela 2. Teores (\%) dos óxidos de Silício, Alumínio, Ferro, Titânio e Manganês para as camadas de interesse

\begin{tabular}{cccccc} 
Prof. & $\mathrm{SiO}_{2}$ & $\mathrm{Al}_{2} \mathrm{O}_{3}$ & $\mathrm{Fe}_{2} \mathrm{O}_{3}$ & $\mathrm{TiO}_{2}$ & $\mathrm{MnO}$ \\
\cline { 2 - 4 }$(\mathrm{m})$ & & & $(\%)$ & & \\
$0-0,40$ & 12,80 & 14,88 & 16,70 & 2,95 & 0,15 \\
$0,40-0,50$ & 17,00 & 18,36 & 16,48 & 2,93 & 0,11 \\
$0,50-0,60$ & 17,30 & 18,86 & 16,94 & 2,85 & 0,10 \\
$0,60-0,70$ & 17,20 & 18,97 & 17,21 & 2,66 & 0,10 \\
$0,70-0,80$ & 16,80 & 18,56 & 16,33 & 2,76 & 0,10 \\
$0,80-0,90$ & 16,20 & 19,07 & 16,26 & 2,81 & 0,10 \\
$0,90-1,00$ & 13,00 & 18,46 & 16,10 & 2,99 & 0,10 \\
$1,00-1,10$ & 16,00 & 18,05 & 15,62 & 2,94 & 0,10 \\
$1,10-1,20$ & 17,90 & 17,85 & 15,22 & 2,80 & 0,10 \\
$1,20-1,30$ & 17,00 & 17,75 & 15,65 & 2,91 & 0,13 \\
\hline
\end{tabular}

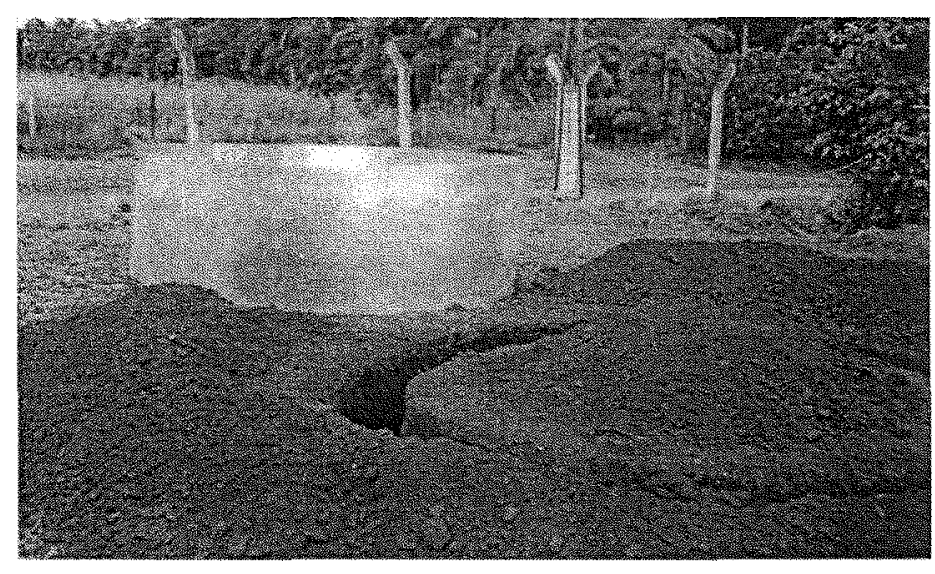

Figura 5 - Chapa galvanizada utilizada e abertura do solo para a sua introdução

Anteriormente à instalação dos equipamentos a área destinada ao experimento foi devidamente preparada de forma a ficar relativamente plana e livre de vegetação.

As profundidades de instalação dos equipamentos foram definidas como sendo de 0,10 em $0,10 \mathrm{~m}$, sendo a primeira profundidade a $0,40 \mathrm{~m}$ da superfície, com 
o objetivo de evitar, além do efeito da temperatura (Libardi, 2000), qualquer possível interferência de camadas superficiais compactadas pelo pisoteio. Outro aspecto considerado foi com relação a esfera de influência da sonda, a qual aumenta ou diminui em função do teor de água do solo (Bacchi et al., 1998). Dessa forma procurouse evitar a utilização da sonda de nêutrons nas camadas superficiais, principalmente quando o solo está seco, onde a esfera de influência da sonda é maior, podendo ocasionar problemas nas medidas, bem como a perda de nêutrons para a atmosfera.

\subsection{Equipamentos utilizados}

\subsubsection{Tensiômetros}

Os tensiômetros foram construídos artesanalmente, dando-se preferência ao modelo com manômentro de mercúrio, pela sua sensibilidade. No presente experimento é considerado como padrão por ser mais simples que os demais, com maior tempo de utilização nas pesquisas e pela facilidade de aquisição/construção, não exigindo pessoal especializado. As cápsulas porosas utilizadas para a realização dos testes e posterior construção dos tensiômetros são de procedência Soil Moisture Inc.

\subsubsection{Teste das cápsulas porosas}

De posse de um número relativamente grande de cápsulas porosas (52), procedeu-se a seleção das mesmas, a fim de que os tensiômetros de uma mesma profundidade (três repetições) possuíssem cápsulas o mais homogêneas possível. A seleção das 30 cápsulas a serem utilizadas levou em consideração características de pressão de borbulhamento e condutância hidráulica. O primeiro teste objetivou eliminar cápsulas danificadas, ou seja, ocorrência de borbulhamento de ar a pressões inferiores a $100 \mathrm{kPa}$, que corresponde a aproximadamente o valor máximo de pressão de funcionamento do instrumento. $O$ objetivo do segundo teste foi a uniformização das mesmas, a fim de que o tempo de resposta dos tensiômetros, para uma mesma camada, fosse o mais semelhante possivel.

Para os testes realizados, utilizou-se um compressor de ar existente no Laboratório de Física do Solo do Departamento de Ciências Exatas. As cápsulas foram previamente saturadas, por um período total de 48 horas. Para tal foram colocadas na 
posição vertical com o gargalo para cima em um balde, onde o nível da lâmina de água foi elevado até a borda superior da cápsula, adicionando-se água por gotejamento, por meio de um Frasco de Mariotte, durante um período mínimo de 24 horas. O restante do período de 48 horas foi utilizado de forma a facilitar a saída e dissolução de bolhas de ar contidas nas cápsulas. No teste de pressão de borbulhamento as cápsulas porosas foram imersas em uma canaleta com água destilada e aplicada a pressão de $100 \mathrm{kPa}$. As cápsulas consideradas em bom estado foram aquelas em que não havia passagem de ar pelos seus poros, quando submetidas a pressão de $100 \mathrm{kPa}$.

Para a determinação da condutância hidráulica foi utilizado o método da carga decrescente (Youngs, 1991), que consiste na determinação do tempo necessário para que uma coluna de água, que atua sobre a cápsula porosa, decresça a partir de alturas previamente determinadas (Figura 6). No dispositivo utilizado é possivel observar o processo por intermédio de um tubo transparente. A condutância hidráulica é obtida pela seguinte expressão:

$$
C=\frac{a \cdot \ln \left(H_{1} / H_{2}\right)}{t_{2}-t_{1}}
$$

sendo:

$$
\begin{aligned}
& C=\text { condutância hidráulica }\left(\mathrm{cm}^{2} \mathrm{~s}^{-1}\right) \\
& a=\text { área da seção transversal do tubo de acrílico transparente }\left(\mathrm{cm}^{2}\right) \\
& H_{1} \text { e } H_{2}=\begin{array}{c}
\text { carga hidráulica ( }\left(\mathrm{cm} \text { de água) na cápsula, nos tempos } t_{1} \text { e } t_{2},\right. \\
\text { respectivamente }
\end{array} \\
& t_{2}-t_{1}=\text { intervalo de tempo (s) para que o nível de água no tubo decresça de } H_{1} \\
& \text { para } H_{2} .
\end{aligned}
$$

A Tabela 3 mostra os valores de condutância hidráulica e pressão de borbulhamento das cápsulas submetidas ao ensaio, bem como as profundidades em que foram instaladas no campo. Os tensiômetros, após a construção, foram submetidos novamente a pressão de $100 \mathrm{kPa}$ para verificar a possível existência de vazamentos nas cápsulas e conexões. 


\subsubsection{Construção dos tensiômetros}

Após todas as cápsulas porosas terem sido devidamente testadas procedeuse a construção dos tensiômetros com manômetros de mercúrio. Os instrumentos foram construídos com tubo de PVC, com comprimento que variou de acordo com a profundidade de instalação; uma cápsula porosa em uma das extremidades do tubo e uma tampa rosqueável na outra; tubos de "nylon" de comprimento variável ("espagueti"), conectados numa das extremidades ao tubo de PVC e a outra imersa em uma cubeta com mercúrio. Maiores detalhes da confecção desses instrumentos podem ser obtidos em Prevedello (1987) e Assis Júnior (1995).

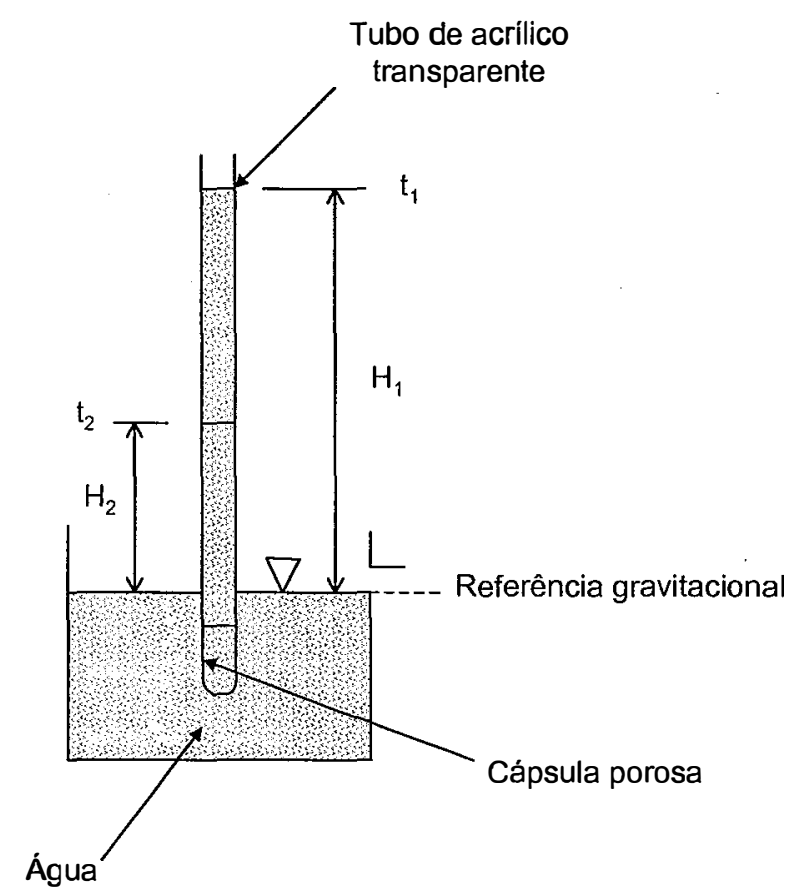

Figura 6 - Representação da montagem para determinação da condutância hidráulica de cápsulas porosas utilizadas na confecção dos tensiômetros

\subsubsection{Instalação dos tensiômetros}

No centro da área experimental foram instaladas três baterias de tensiômetros, compostas por 10 tensiômetros cada, distanciados lateralmente entre si de 0,20 m (Figura 7). Procurou-se dispor os tensiômetros na parcela de forma que os mais profundos ficassem no centro e os mais superficiais lateralmente. 
Tabela 3. Características hidráulicas das cápsulas porosas selecionadas para confecção dos tensiômetros e respectivas profundidades de instalação

\begin{tabular}{|c|c|c|c|}
\hline $\begin{array}{l}\text { Prof. } \\
(\mathrm{cm})\end{array}$ & $\begin{array}{c}\text { № da } \\
\text { Cápsula }\end{array}$ & $\begin{array}{l}\text { Condutância hidráulica } \\
\qquad\left(\mathrm{cm}^{2} \mathrm{~s}^{-1}\right)\end{array}$ & $\begin{array}{l}\text { Pressão de borbulhamento } \\
\qquad(\mathrm{kPa})\end{array}$ \\
\hline & 34 & $1,14 \times 10^{-4}$ & $>100$ \\
\hline \multirow[t]{3}{*}{40} & 48 & $1,12 \times 10^{-4}$ & $>100$ \\
\hline & 14 & $1,03 \times 10^{-4}$ & $>100$ \\
\hline & 32 & $1,33 \times 10^{-4}$ & $>100$ \\
\hline \multirow[t]{3}{*}{50} & 38 & $1,15 \times 10^{-4}$ & $>100$ \\
\hline & 27 & $1,21 \times 10^{-4}$ & $>100$ \\
\hline & 18 & $2,29 \times 10^{-5}$ & $>100$ \\
\hline \multirow[t]{3}{*}{60} & 43 & $2,09 \times 10^{-5}$ & $>100$ \\
\hline & 1 & $2,10 \times 10^{-5}$ & $>100$ \\
\hline & 20 & $2,93 \times 10^{-5}$ & $>100$ \\
\hline \multirow[t]{3}{*}{70} & 52 & $2,65 \times 10^{-5}$ & $>100$ \\
\hline & 3 & $2,68 \times 10^{-5}$ & $>100$ \\
\hline & 5 & $3,68 \times 10^{-5}$ & $>100$ \\
\hline \multirow[t]{3}{*}{80} & 28 & $3,07 \times 10^{-5}$ & $>100$ \\
\hline & 4 & $3,57 \times 10^{-5}$ & $>100$ \\
\hline & 17 & $3,97 \times 10^{-5}$ & $>100$ \\
\hline \multirow[t]{3}{*}{90} & 23 & $3,80 \times 10^{-5}$ & $>100$ \\
\hline & 12 & $3,80 \times 10^{-5}$ & $>100$ \\
\hline & 16 & $4,04 \times 10^{-5}$ & $>100$ \\
\hline \multirow[t]{3}{*}{100} & 51 & $4,01 \times 10^{-5}$ & $>100$ \\
\hline & 15 & $4,08 \times 10^{-5}$ & $>100$ \\
\hline & 37 & $4,16 \times 10^{-5}$ & $>100$ \\
\hline \multirow[t]{3}{*}{110} & 45 & $4,22 \times 10^{-5}$ & $>100$ \\
\hline & 2 & $4,22 \times 10^{-5}$ & $>100$ \\
\hline & 8 & $4,36 \times 10^{-5}$ & $>100$ \\
\hline \multirow[t]{3}{*}{120} & 44 & $4,64 \times 10^{-5}$ & $>100$ \\
\hline & 9 & $4,38 \times 10^{-5}$ & $>100$ \\
\hline & 10 & $5,24 \times 10^{-5}$ & $>100$ \\
\hline \multirow[t]{2}{*}{130} & 39 & $4,70 \times 10^{-5}$ & $>100$ \\
\hline & 29 & $4,74 \times 10^{-5}$ & $>100$ \\
\hline
\end{tabular}


Os tensiômetros foram instalados por meio da abertura de orifícios no solo com ajuda de um trado helicoidal, de diâmetro relativamente menor ao da cápsula porosa. Antes da introdução dos tensiômetros, o orifício foi alargado utilizando-se uma ferramenta cilíndrica cuja extremidade inferior possui o formato e o tamanho da cápsula porosa. A ferramenta foi utilizada com a intenção de alargar o orifício até a profundidade anterior ao início da cápsula, de forma a facilitar a entrada do tubo de PVC e garantir que a cápsula seja introduzida no solo o mais justo possível, possibilitando um melhor contato com o solo.

Três manômetros de mercúrio foram instalados externamente a aproximadamente $0,50 \mathrm{~m}$ da parcela experimental em uma posição em que houvesse a menor interferência possível de aquecimento pelo sol, principalmente durante os horários de leitura.

\subsubsection{Sonda de nêutrons}

A sonda de nêutrons utilizada foi uma 503 Hydroprobe da CPN Corporation, munida de uma fonte de ${ }^{241} \mathrm{Am} / \mathrm{Be}$ de intensidade radioativa de 1,85 GBq e tempo de contagem de $30 \mathrm{~s}$.

Próximo a cada bateria de tensiômetros foi instalado um tubo de alumínio para o acesso da sonda, distanciados cerca de 0,40 m do tensiômetro mais externo da repetição (tensiômetro a $0,40 \mathrm{~m}$ ). O tubo é selado na extremidade inferior com uma rolha de borracha, possui cerca de $0,045 \mathrm{~m}$ de diâmetro e $2 \mathrm{~m}$ de comprimento, e introduzido no solo até $1,70 \mathrm{~m}$ de profundidade. Para a instalação foi utilizado um trado do tipo holandês de diâmetro externo semelhante ao do tubo.

Para a confecção das curvas de calibração da sonda de nêutrons utilizou-se duas metodologias: a primeira obtida diretamente pela relação entre a contagem relativa e a umidade volumétrica da amostra coletada por ocasião da contagem, e a segunda indiretamente pela contagem relativa e potencial mátrico obtido por tensiometria e sua posterior relação com a umidade volumétrica através da curva de retenção de água no solo.

Para o método direto, a calibração foi realizada em um tubo de alumínio localizado a aproximadamente $2 \mathrm{~m}$ da área experimental (Figura 8). Imediatamente 
antes das leituras nos tubos de acesso (com a sonda dentro da blindagem, mas com a carcaça já encaixada no tubo) eram realizadas 5 leituras, com tempo de contagem de $30 \mathrm{~s}$, consideradas padrão. Esse procedimento era repetido também ao término de cada jornada de leitura, totalizando 10 leituras (início e fim), a fim de compor a taxa média de contagem no padrão.

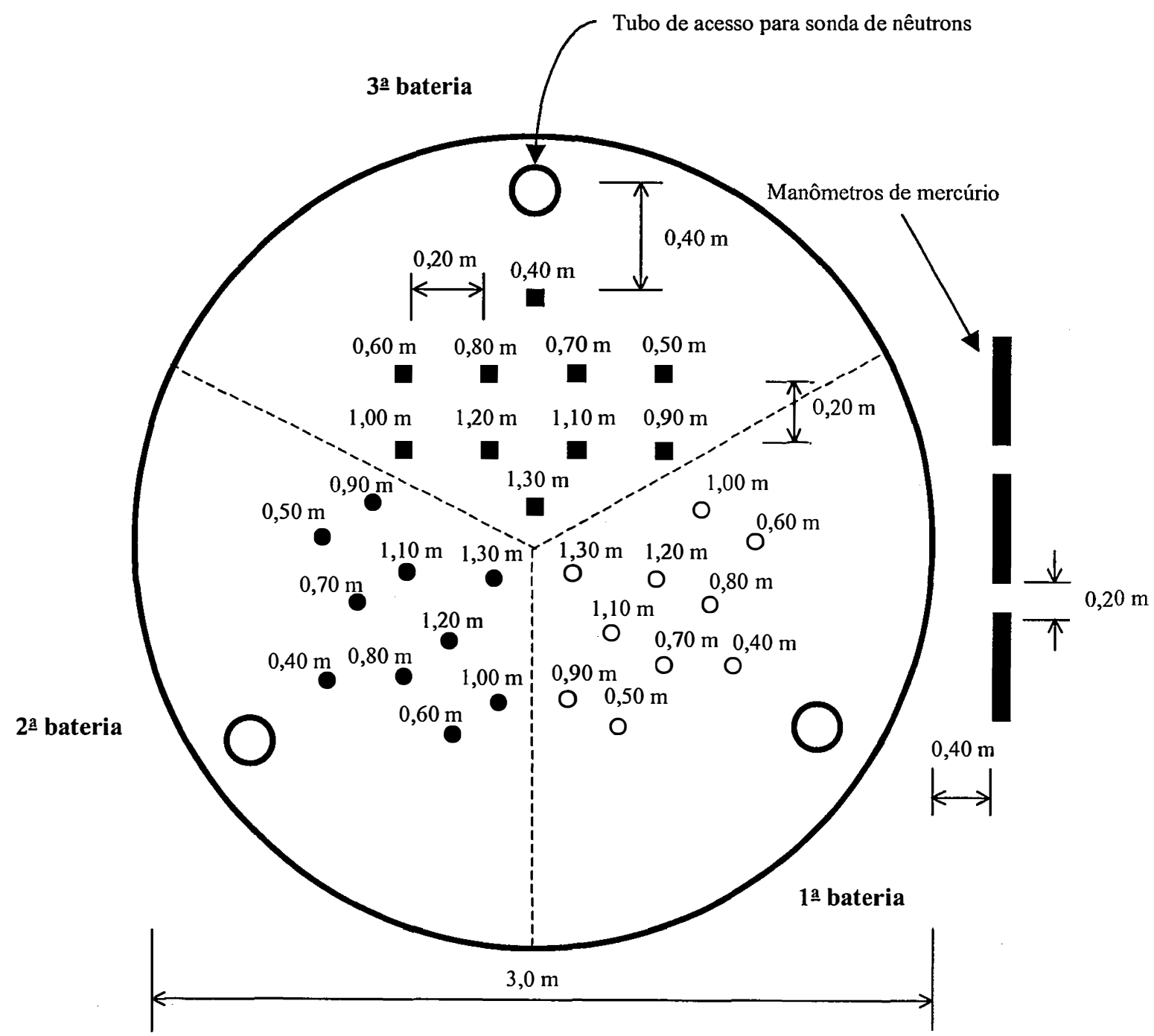

Figura 7 - Distribuição dos tensiômetros e respectivas profundidades de instalação, tubos de acesso para sonda de nêutrons e manômetros de mercúrio (sem escala) 
A calibração pelo método indireto foi realizada quando havia a concordância entre os horários de leituras da contagem relativa obtida pela sonda de nêutrons e do potencial mátrico obtido pelos tensiômetros, totalizando 18 pares de pontos.

As leituras com a sonda imersa no tubo de acesso foram realizadas com três repetições em cada camada de solo. Paralelamente, foram retiradas amostras por tradagens em um mesmo orifício e nas mesmas profundidades das leituras realizadas com a sonda, a uma distância de $0,40 \mathrm{~m}$ do tubo. As amostragens seguintes, para compor a curva de calibração, foram realizadas em sentido circular, de forma a manter sempre a mesma distância em relação ao tubo (Figura 8). As amostras foram levadas ao laboratório para a determinação da umidade gravimétrica e em seguida a conversão da contagem relativa da seguinte maneira:

$$
C R=\frac{C_{S}}{C_{P}}
$$

sendo:

$$
\begin{aligned}
& C R=\text { Contagem relativa; } \\
& C_{S}=\text { Taxa de contagem no solo (cps); } \\
& C_{P}=\text { Taxa média de contagem no padrão (cps). }
\end{aligned}
$$
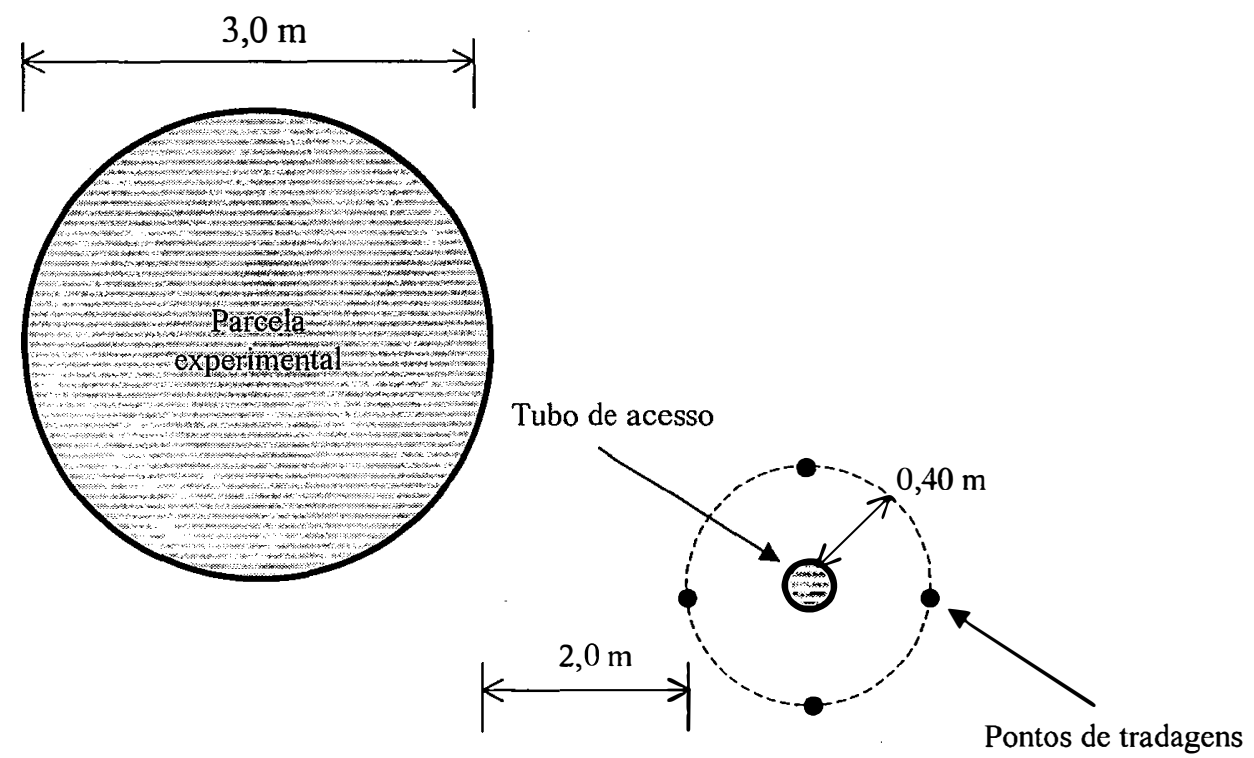

Figura 8 - Esquema utilizado na calibração direta da sonda de nêutrons, posição do tubo de acesso e das amostragens (sem escala) 


\subsubsection{Reflectômetro no domínio do tempo ("Time-Domain Reflectometry", TDR) e} sistema automático de aquisição de dados ("Datalogger”, DL)

O equipamento utilizado, baseado na técnica da reflectometria no domínio do tempo (TDR), foi um testador de cabos da marca Tektronix, modelo 1502B. Conectado ao TDR foi instalado um "datalogger" (DL), que controla e analisa as formas de onda produzidas pelo testador de cabos e possibilita o acesso aos sensores do TDR através do sistema de multiplexação (Figura 9).

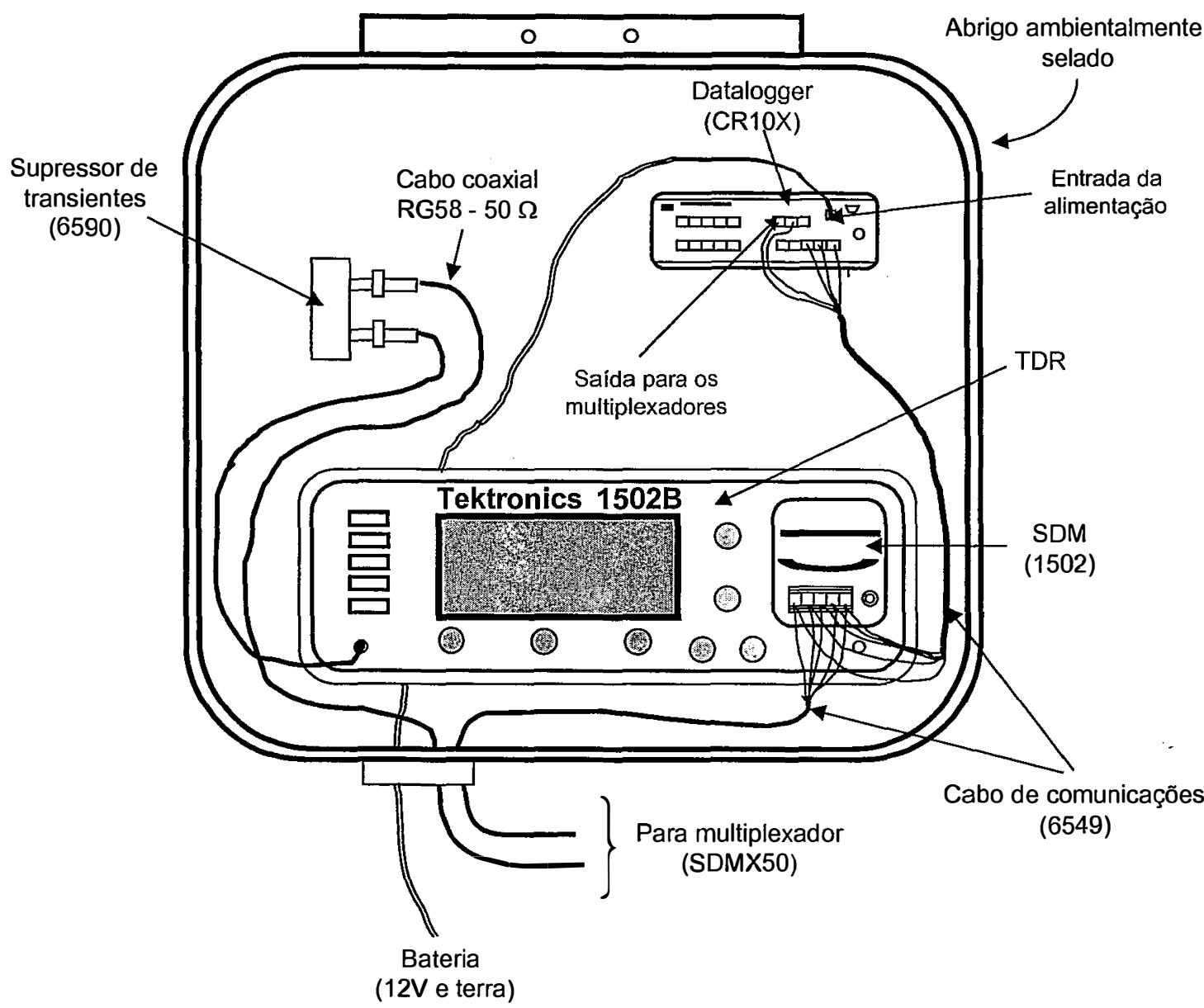

Figura 9 - Representação do abrigo ambientalmente selado contendo o testador de cabos, "datalogger", supressor de transientes e os cabos associados (sem escala) 


\subsubsection{Componentes do sistema (TDR e periféricos)}

\section{a) TDR 1502B}

O testador de cabos da marca Tektronics, modelo 1502B foi o equipamento utilizado para a medida do teor de água no solo. O 1502B consiste de uma fonte de pulso de período muito curto que é aplicado ao sensor, cujo sinal refletido é coletado e mostrado na tela do aparelho. Um "no-break" instalado no mesmo local forneceu 127 VCA para a alimentação do 1502B (Figura 10).

\section{b) “Datalogger"}

Para a aquisição automática dos dados foi utilizado um "datalogger" marca Campbell Scientific, Inc. (CS), modelo CR10X, que controla, via programação, a sequência de abertura e fechamentos de relés dos multiplexadores, monitora a tensão na bateria de 12 VCC, realiza as medidas, aplica algoritmos para o cálculo da constante dielétrica, armazena o resultado e, através da comunicação com periféricos transfere os dados armazenados.

A alimentação do "datalogger" foi feita por meio de uma bateria de 12 VCC (fios $12 \mathrm{~V}$ e terra), e esta por sua vez conectada a um "no-break" (Figura 10).

\section{c) "Synchronous device for measurement" (SDM1502)}

As funções de comunicação para a transferência das instruções e dados entre o TDR e o "datalogger", foram realizadas pela interface SDM1502, fabricada pela CS. A interface foi conectada ao painel frontal do TDR (Figura 9) e a comunicação realizada por intermédio de cinco fios dedicados ao controle, alimentação e transferência de dados. Dois desses fios levam energia (12 VCC e terra) do "datalogger" para o SDM1502 e os outros três são responsáveis pela comunicação via portas de controle, denominadas C1, C2 e C3. Na Figura 11 é possivel visualizar a conexão dos cinco fios responsáveis pela interligação do SDM1502 aos multiplexadores. 


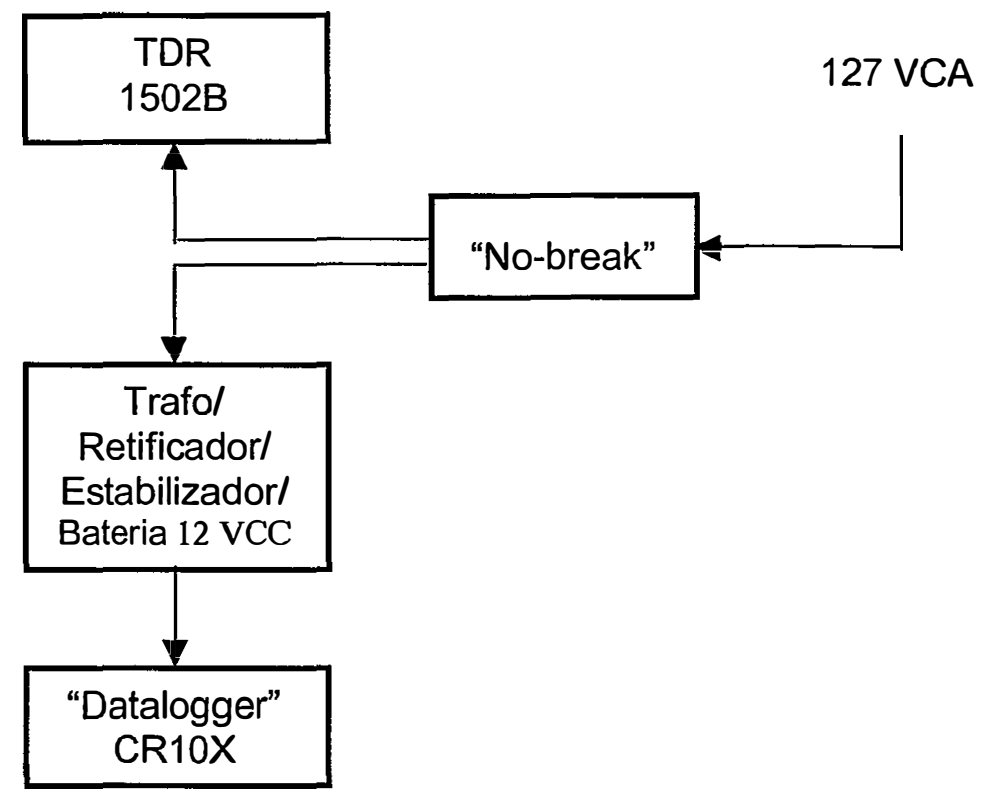

Figura 10 - Diagrama de blocos do sistema de alimentação

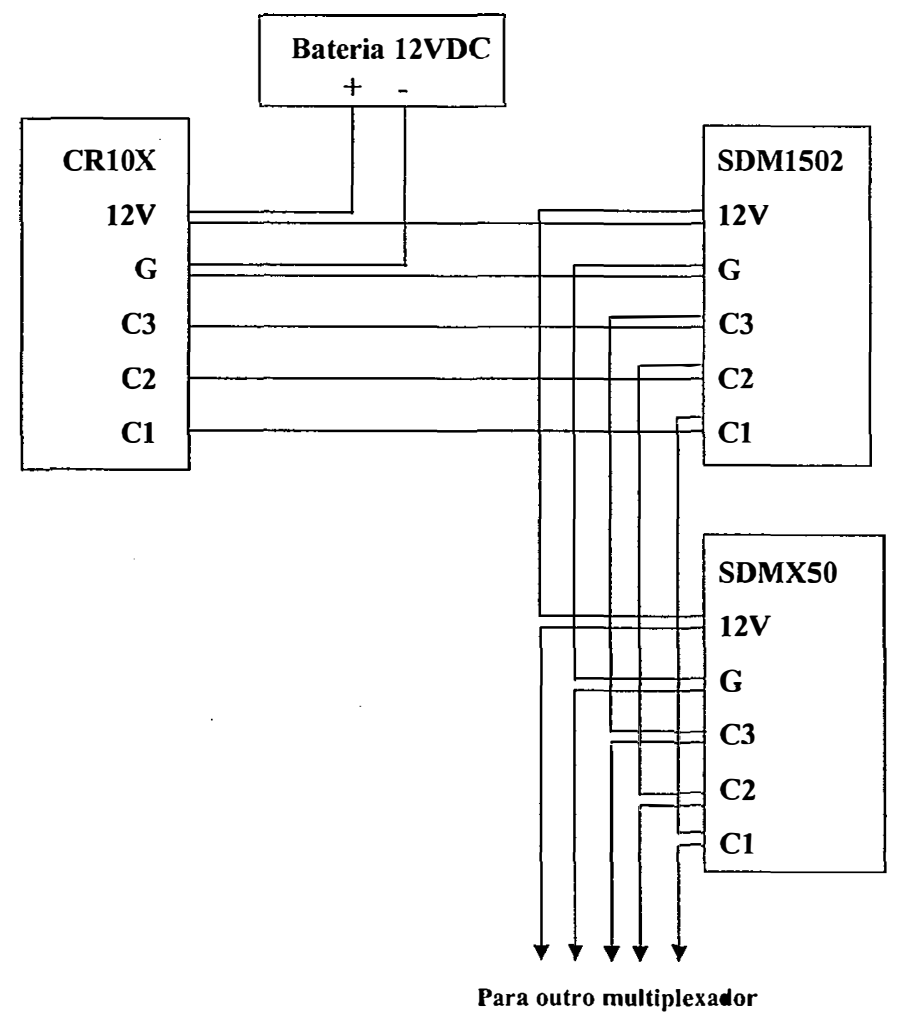

Figura 11 - Esquema de conexões da interface SDM1502 para o "datalogger" e multiplexadores 


\section{d) Multiplexadores SDMX50}

Os dois multiplexadores utilizados foram do tipo coaxiais $8: 1$, modelo SDMX50, com impedância de 50 ohms, compatível, portanto, com o cabo RG58, fabricados pela CS. No primeiro multiplexador foram conectados 7 sensores de umidade e no segundo 8 sensores.

\section{e) Supressor de transientes 6590}

O supressor de transientes 6590, fabricado pela CS, faz parte do sistema de proteção. A função do supressor é reduzir as variações de tensão a um nivel que não cause danos aos equipamentos a ele conectados (Figura 9).

\section{f) Sensores de umidade CS605}

Os sensores de umidade utilizados foram de três hastes, modelo CS605, marca CS, os quais transportam um sinal não-balanceado (Figura 12). Foram utilizados 15 sensores distribuídos nas camadas do perfil do solo, conectados aos multiplexadores por meio de conectores do tipo BNC.

\subsubsection{Designação de endereçamentos}

Como o SDM1502 e o SDMX50 necessitam de uma comunicação síncrona, foram feitos os devidos ajustes nos sistemas de chaveamento. $O$ primeiro passo foi verificar o chaveamento do SDM1502, obtido pela inspeção de um conjunto de 4 chaves, com duas posições cada, localizadas em um orifício na parte superior do SDM1502 (Figura 13). Após a verificação da posição das chaves, cujo valor encontrado foi 1010, e de posse do Quadro 1, obteve-se o valor do endereço do SDM1502: 11 e as respectivas configurações dos "jumpers" que devem constar nos multiplexadores: $1^{\circ}$ multiplexador $(M S D=1$ e $L S D=2)$ e $2^{\circ}$ multiplexador $(M S D=1$ e LSD =3). Um exemplo do esquema da localização dos "jumpers" nas placas dos circuitos do primeiro nivel de multiplexação, cujo endereço é 12 , pode ser visto na Figura 14. 


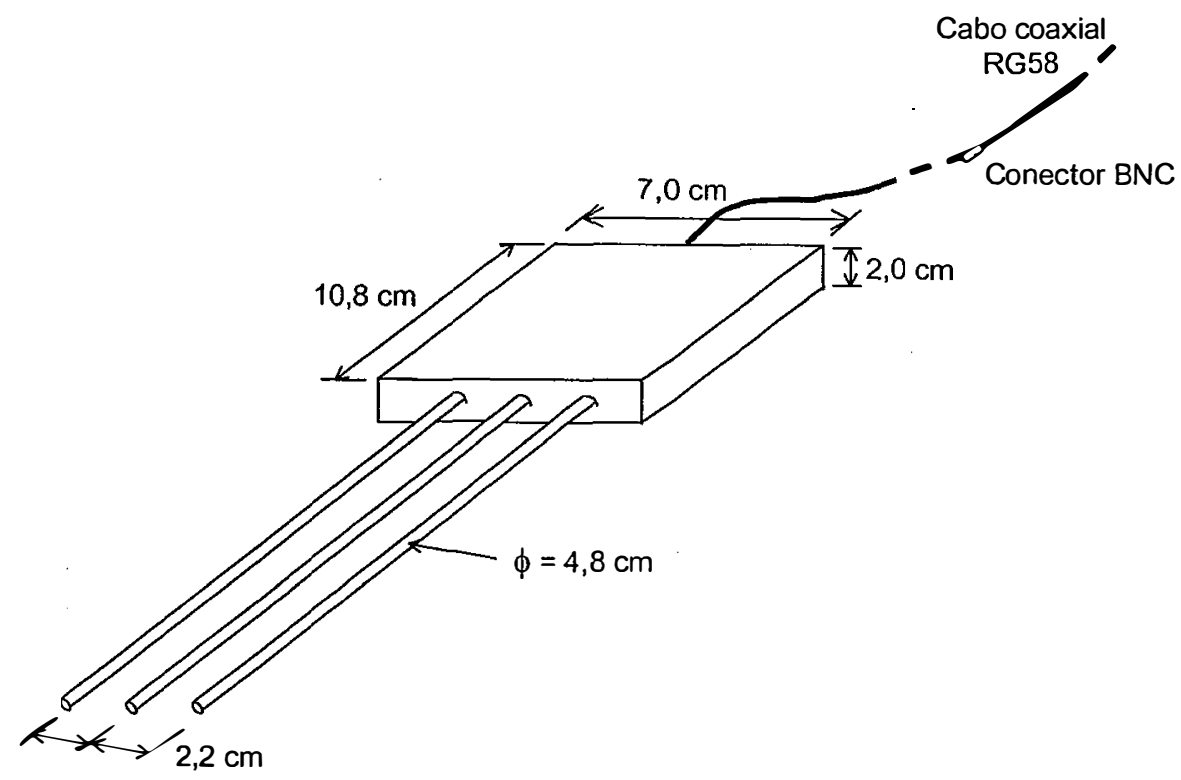

Figura 12 - Sensor de umidade de três hastes, modelo CS605, compatível com o cabo coaxial RG58
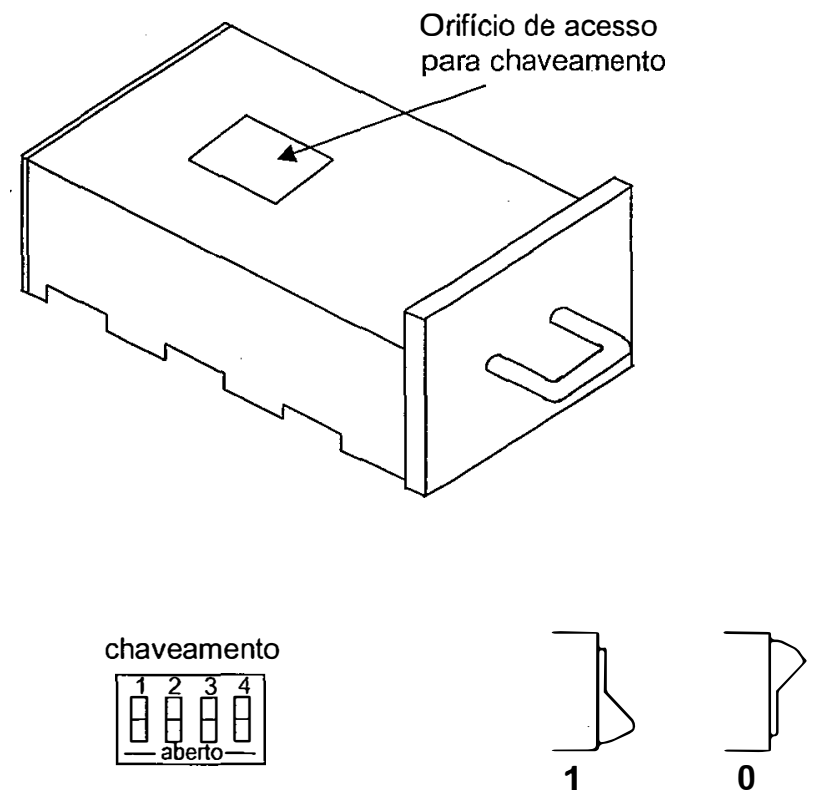

Figura 13 - Sistema de chaveamento para o endereçamento do SDM1502 


\begin{tabular}{|c|c|c|c|}
\hline SDM1502 & Endereço & \multicolumn{2}{|c|}{ SDMX50 } \\
\hline Chaves & Base 4 & $\begin{array}{c}\text { Configurações dos } \\
\text { "Jumpers" }\end{array}$ \\
\hline 1234 & Valores & MSD & LSD \\
\hline 0000 & 00 & 0 & 0 \\
1000 & 01 & 0 & 1 \\
0100 & 02 & 0 & 2 \\
1100 & 03 & 0 & 3 \\
0010 & 10 & 1 & 0 \\
1010 & 11 & 1 & 1 \\
0110 & 12 & 1 & 2 \\
1110 & 13 & 1 & 3 \\
0001 & 20 & 2 & 0 \\
1001 & 21 & 2 & 1 \\
0101 & 22 & 2 & 2 \\
1101 & 23 & 2 & 3 \\
0011 & 30 & 3 & 0 \\
1011 & 31 & 3 & 1 \\
0111 & 32 & 3 & 2 \\
1111 & 33 & 3 & 3 \\
\hline
\end{tabular}

Fonte: Campbell Scientific (1999)

Quadro 1 - Conjunto de possíveis endereços para o SDM1502 e SDMX50.

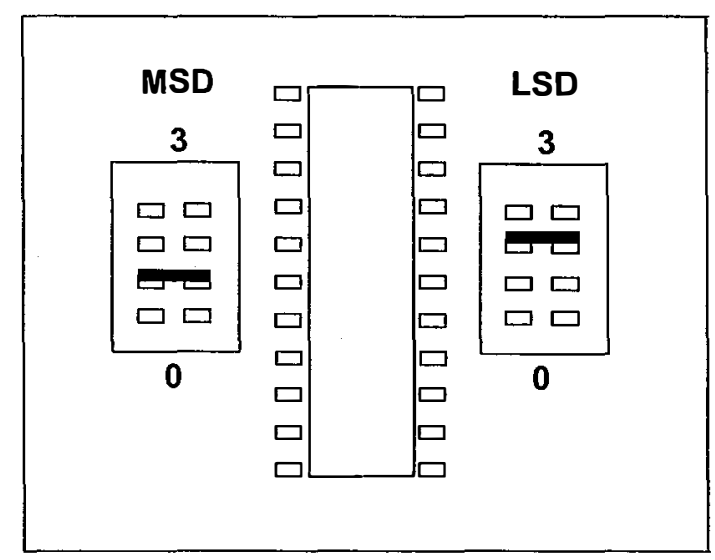

Figura 14 - Exemplo da localização dos "jumpers" de endereçamento nas placas dos circuitos do primeiro nível de multiplexação (SDMX50) 


\subsubsection{Instalação do sistema}

O sistema foi montado previamente em laboratório com o objetivo de testar o funcionamento dos equipamentos e obter, consequentemente, uma maior confiabilidade nas leituras. O teste constou do ajuste de endereçamentos do TDR e multiplexadores, funcionamento da bateria e também do programa (Anexo C). No campo, os equipamentos TDR e CR10X foram instalados em um mesmo abrigo ambientalmente selado fornecido pela CS, contendo as seguintes divisões: suporte para fixação do testador, instalação do "datalogger" e do sistema de alimentação, supressor de transientes e engates para posicionamento dos cabos associados (Figura 9). O conjunto foi montado verticalmente em uma caixa de passagem de energia construida em alvenaria, localizada próxima ao Posto Meteorológico do Departamento de Ciências Exatas/ESALQ/USP (Figura 15). Na mesma caixa de passagem há vários contatores, que fazem o acionamento de moto-bombas hidráulicas localizadas ao redor. O objetivo da utilização da referida caixa foi proporcionar, além de uma proteção física para o conjunto, uma situação extrema, ou seja, o mais longe possivel da área experimental e testar a proteção eletromagnética do equipamento quanto a possiveis interferências em função do acionamento automático de uma motobomba hidráulica. A caixa de passagem possui as dimensões internas de 1,60 x 1,70 $x$ $0,55 \mathrm{~m}$, e as portas metálicas foram pintadas externamente de branco, e recobertas internamente com folhas de isopor com $2 \mathrm{~cm}$ de espessura, a fim de isolar o ambiente interno do efeito da temperatura. A mesma proteção foi colocada internamente e externamente ao teto da caixa de passagem. Como os equipamentos utilizados são bastante sensiveis ao efeito da temperatura (faixa máxima de funcionamento de $40^{\circ} \mathrm{C}$ ) foi colocado um termômetro de máxima junto aos mesmos para monitoramento, obtendo-se leituras diárias. No interior da caixa de passagem de energia foram acondicionados: uma bateria de $12 \mathrm{~V}$ que alimenta o CR10X e um "no-break" marca APC Smart-UPS, $1 \mathrm{KVA}$, que faz a ligação da bateria e do TDR à energia (Figura 10). Os dois multiplexadores foram instalados a cerca de $30 \mathrm{~m}$ do TDR e a $15 \mathrm{~m}$ da área experimental em uma caixa de cimento amianto, adaptada para funcionar como abrigo (Figura 16).

Os sensores do TDR foram introduzidos na área experimental de forma contínua e regularmente distanciados, após a abertura do solo para a introdução da 
chapa galvanizada (item 3.2), nas mesmas camadas de interesse, aproveitando-se uma das paredes laterais, como mostra a (Figura 17). Foram coletadas, concomitantemente, amostras deformadas e indeformadas para a determinação de propriedades físicas do solo. Todos os cabos coaxiais que ligam os sensores do TDR aos multiplexadores foram protegidos individualmente em tubulações plásticas flexíveis do tipo utilizado para passar fiação elétrica em residências e indústrias (Figura 18).

Convém esclarecer que inicialmente o intuito era utilizar-se dois testadores de cabos iguais, um acoplado a um "datalogger" a fim de obter o monitoramento contínuo da água no solo e o outro utilizado de forma manual, conectado diariamente a um sistema de chaveamento composto por 15 sensores, totalizando, então os 30 sensores instalados no campo. Em função da utilização de um "no-break" de forma inadequada, funcionando em condições não recomendadas pelo fabricante, houve a queima do testador a ser utilizado manualmente. Dessa forma a sequência de distribuição dos sensores diferiu do mostrado na Figura 17 e a nova ordem utilizada encontra-se na Figura 19.

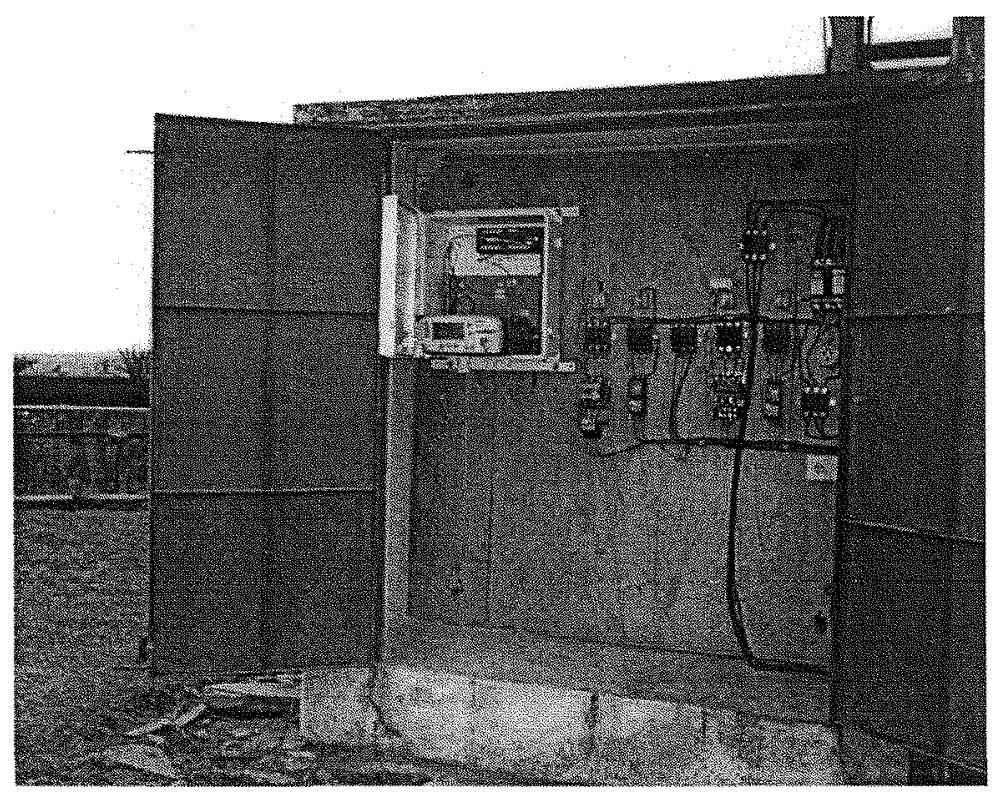

Figura 15 - TDR e "datalogger" instalados na caixa de alvenaria localizada próxima ao Posto Agrometeorológico do DCE/ESALQ/USP 


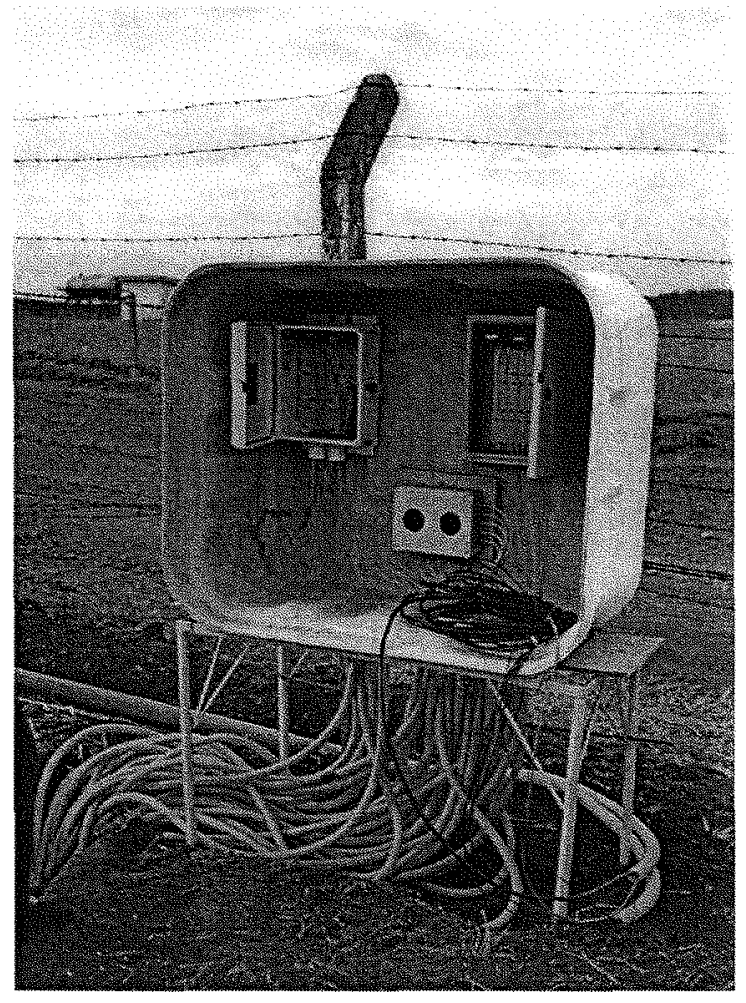

Figura 16 - Localização dos multiplexadores na caixa de cimento amianto

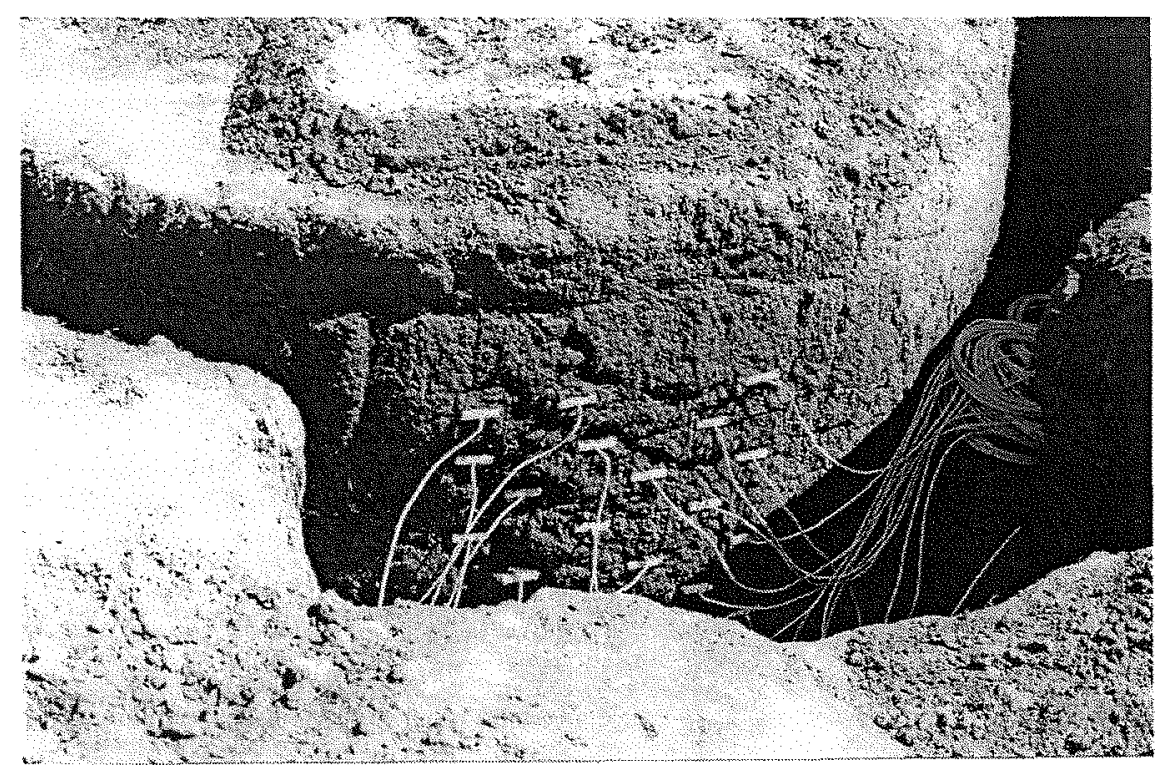

Figura 17 - Sensores do TDR instalados horizontalmente à parcela experimental nas respectivas camadas de interesse 


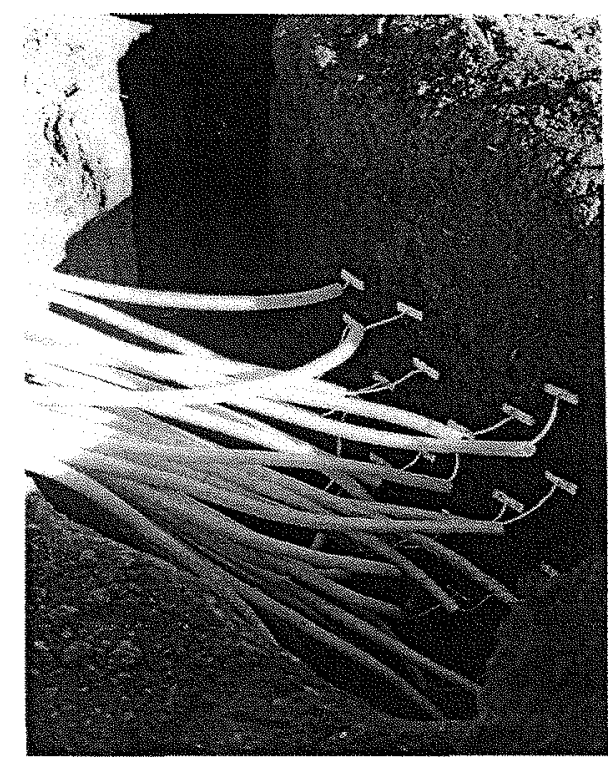

Figura 18 - Detalhe da proteção dos cabos dos sensores de umidade por meio de tubulações plásticas flexíveis

\subsubsection{Coleta e recuperação dos dados de TDR}

Para a coleta dos dados experimentais do CR10X, utilizou-se um módulo de armazenamento, modelo SM192, que conectado ao "Keyboard display", modelo CR10KD e com o protocolo adequado (Anexo D), possibilitou o armazenamento dos dados para posterior recuperação, via computador. Os equipamentos acima citados foram fornecidos pela CS.

A partir do módulo de armazenamento utilizou-se o esquema mostrado na Figura 20 para o descarregamento dos dados para o computador. Para tanto, utilizouse o "software" PC208W (Campbell Scientific, Inc.), em ambiente Windows, que possibilita a coleta e armazenamento dos dados e também a transferência de programas para o "datalogger". Para o descarregamento foi necessária a utilização de uma interface SC532 e seus cabos associados, para a conexão do módulo de armazenamento à porta COM de um computador (Figura 20). 
Superfície do Solo

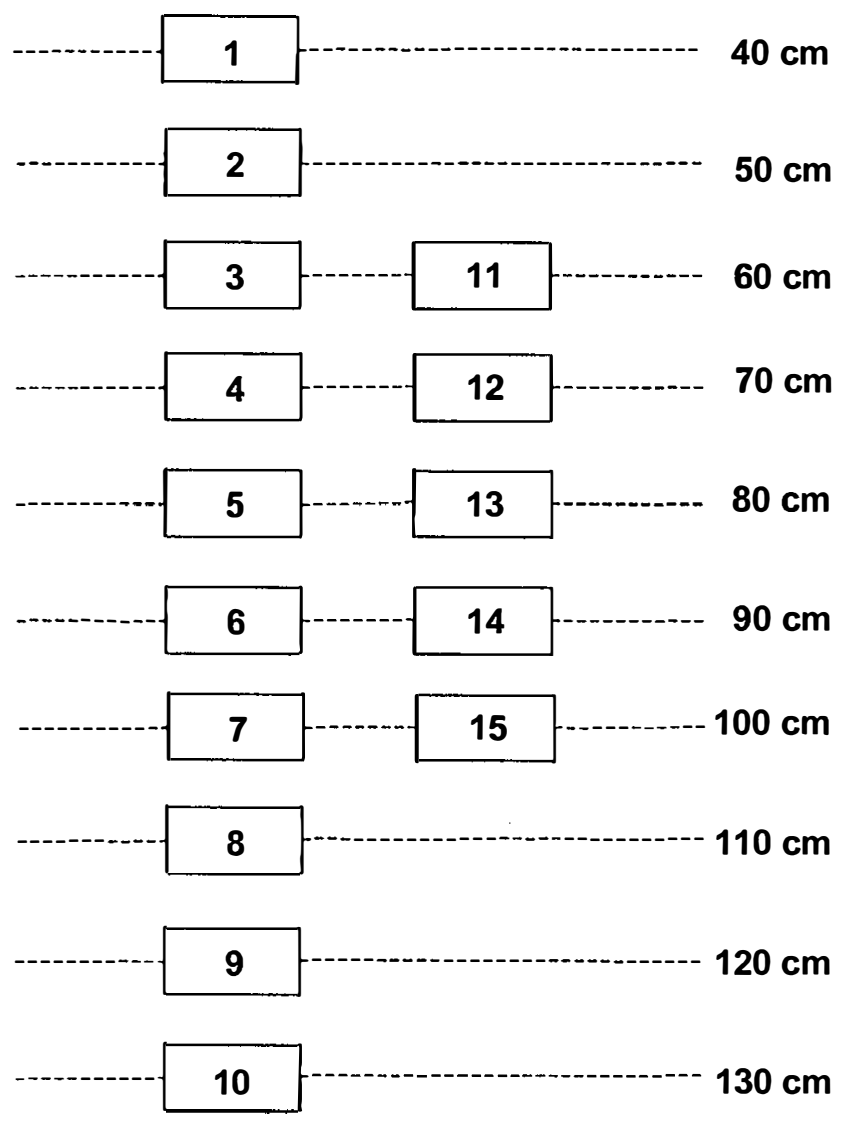

Figura 19 - Esquema da localização dos quinze sensores do TDR nas profundidades de interesse

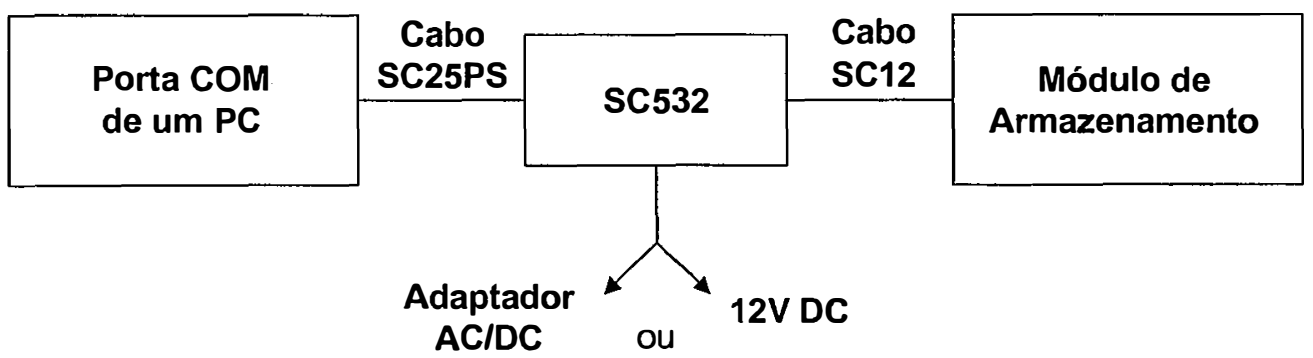

Figura 20 - Diagrama esquemático da conexão do módulo de armazenamento à porta "COM" de um computador pessoal (PC) utilizando a interface SC532 


\subsubsection{Proteção eletromagnética, aterramento e proteção contra surtos de tensão nos equipamentos utilizados}

Para o sistema de proteção foram utilizadas hastes "cooperweld", conectores de cobre e bimetálicos, cordoalha de cobre, tubos galvanizados de irrigação (fora do padrão atual) com engate rápido e canos de ferro (do tipo utilizado antigamente em instalações hidráulicas). Para as caixas de inspeção das conexões cordoalha-haste de "cooperweld" foram utilizados canos de PVC e "caps".

A proteção eletro-eletrônica constou de um disjuntor de $15 \mathrm{~A}$ para a separação do circuito de alimentação, protetor de surtos "Clamper" (pára-raio eletrônico), modelo VCL $175 \mathrm{~V}, 40 \mathrm{KA} / \mathrm{SR} / 127 \mathrm{~V}$, "no-break" marca SMS, modelo Manager II, $\mu$ SM 600 S, 600 VA de saida, posteriormente um outro "no-break" marca APC, modelo Smart-UPS 1000 e medidor de resistência de terra (Digital Earth Tester) marca Kyoritsu, modelo 410S.

\subsection{Determinações de laboratório}

\subsubsection{Curvas de retenção de água no solo}

Foram coletadas 3 amostras indeformadas de $0,073 \mathrm{~m}$ de diâmetro e $0,072 \mathrm{~m}$ de altura por profundidade, em uma trincheira aberta próxima à área experimental, com a utilização de um amostrador do tipo Uhland, conforme Moraes (1991) (Figura 21). Cada amostra consistiu de três subamostras de aproximadamente $0,024 \mathrm{~m}$ de altura cada, totalizando 9 amostras por profundidade, coletadas de forma que o ponto médio da mesma coincidisse com o centro da camada.

Durante a coleta as amostras foram devidamente numeradas e embaladas em papel alumínio, para evitar perdas de água, e em seguida levadas ao laboratório.

No laboratório as amostras foram preparadas retirando-se o excesso de solo de ambos os lados e posteriormente a separação das subamostras. As amostras do centro foram destinadas aos pontos de baixa tensão, onde a estrutura do solo exerce papel fundamental. As amostras de ambas as extremidades foram destinadas aos pontos de alta tensão, já que as mesmas são mais susceptíveis aos efeitos de perturbações na coleta e no preparo (Ghiberto, 1999). 


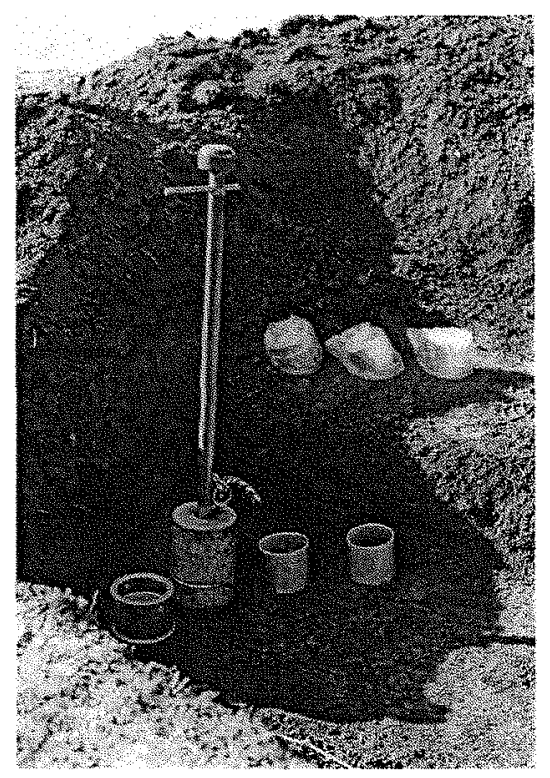

Figura 21 - Amostrador do tipo Uhland utilizado para a coleta das amostras indeformadas

Após a definição de quais amostras seriam destinadas aos pontos de alta e baixa tensão, foram coladas na parte inferior de cada amostra, um papel de filtro "speed fast", número 41 da marca Whatman, diâmetro de $125 \mathrm{~mm}$, com Araldite (24 horas). As amostras foram deixadas por um período de 24 horas para a secagem da cola e posteriormente postas para saturar. A saturação foi feita com ajuda de um Frasco de Mariotte utilizando-se água destilada e deareada conforme Moraes (1991). As amostras receberam água por gotejamento até o nivel atingir o topo da amostra e foram deixadas saturando por um período de 24 horas. Em função das amostras não terem atingido a saturação, observada visualmente pela não ocorrência de ascensão de água nas mesmas, todas as amostras foram colocadas em estufa a $60{ }^{\circ} \mathrm{C}$ por um período de 24 horas. Após foram retiradas, deixadas esfriar em dessecador e em seguida postas para saturar repetindo-se a metodologia descrita acima.

Para a obtenção dos pontos de baixa tensão foram utilizadas caixas de areia confeccionadas no próprio laboratório, que serviram como mesas de tensão, nas tensões de 0,5, 1, 2, 3, 4, 5, 6, 7, 8, 9 e 10 kPa e Câmaras de Pressão de Richards nas tensões de 20, 33 e $50 \mathrm{kPa}$, para os pontos de alta tensão (Figuras 22 e 23). Após 
atingido o equilibrio, que variava em função da amostra e da tensão aplicada, a umidade era obtida gravimetricamente (Moraes, 1991).

Os dados obtidos foram ajustados à eq. (9) (van Genuchten, 1980) utilizando o software SWRC (Dourado Neto et al., 1990). Os parâmetros $\theta_{\text {sat }}$ e $\theta_{r}$ foram obtidos por extrapolação a partir dos dados observados. $O$ ajuste foi feito a partir da restrição de dependência entre $m$ e $n: m=1-1 / n$ (Mualem, 1976).

$$
\Theta=\left[\frac{1}{1+(\alpha \psi)^{n}}\right]^{m}
$$

onde $\Theta=\left(\theta-\theta_{r}\right) /\left(\theta_{\text {sat }}-\theta_{r}\right)$ representa a saturação efetiva, sendo $\theta_{r}$ a umidade residual e $\theta_{\text {sat }}$ a umidade de saturação, $\alpha, n$ e $m$ são parâmetros característicos de cada tipo de solo obtidos pelo ajuste de dados e $\psi$ o potencial mátrico. Utilizou-se um programa de ajuste de curvas que emprega o método iterativo de Newton-Raphson, que minimiza a soma dos quadrados dos desvios em relação à umidade. Maiores detalhes sobre o ajuste de dados experimentais, proposto por van Genuchten, podem ser obtidos em Kutílek \& Nielsen (1994).

Com a simplificação de $m=1-1 / n$ (Mualem, 1976), van Genuchten (1980) obteve a seguinte equação para o cálculo da condutividade hidráulica relativa $\left(K_{r}=K(\theta) / K_{\text {sat }}\right)$ :

$$
K_{r}=\Theta^{\ell}\left[1-\left(1-\Theta^{1 / m}\right)^{n}\right]^{2}
$$

onde $\ell$ é um parâmetro empírico que assume o valor 0,5 para a maioria dos solos. 


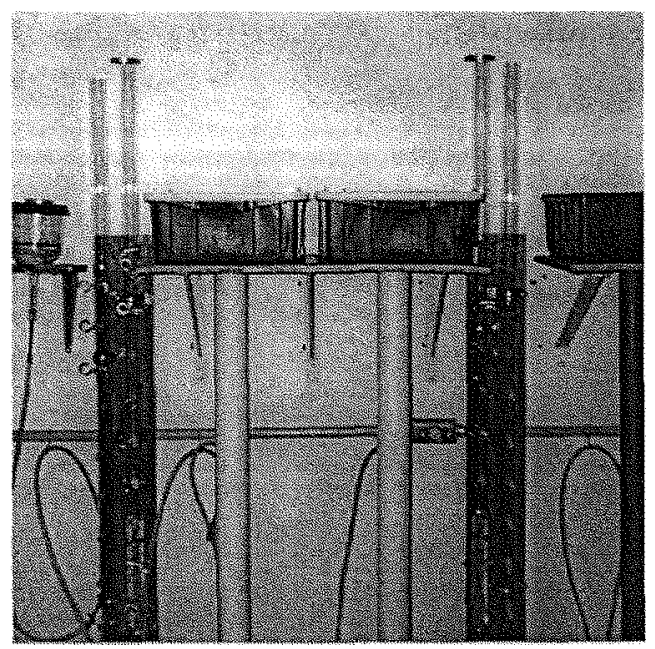

Figura 22 - Mesas de tensão utilizadas para a obtenção dos pontos de baixa tensão das curvas de retenção

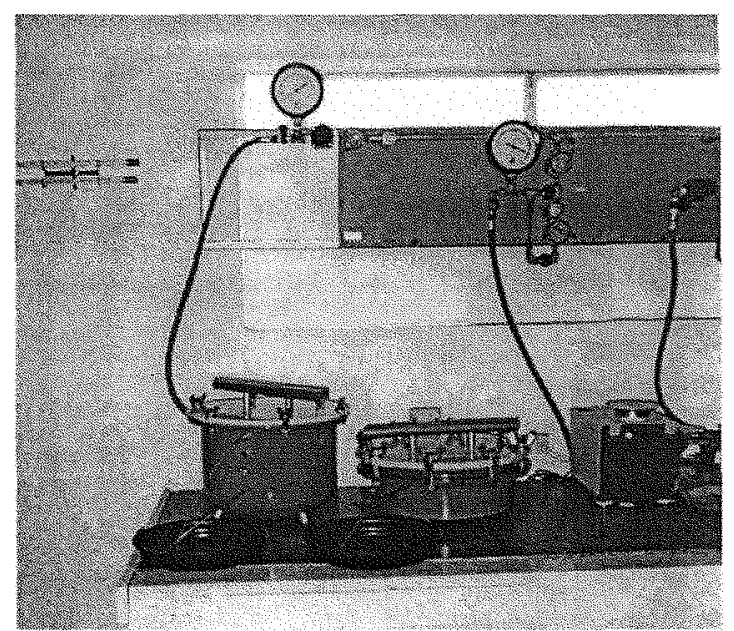

Figura 23 - Câmaras de pressão de Richards utilizadas para a obtenção dos pontos de alta tensão das curvas de retenção

\subsubsection{Condutividade hidráulica do solo saturado e densidade do solo}

Para a determinação da condutividade hidráulica do solo saturado e da densidade do solo foram coletadas três amostras de 0,073 m de diâmetro e 0,072 m de altura por profundidade, seguindo o mesmo procedimento descrito no item anterior. $O$ 
preparo das amostras, bem como a saturação em laboratório, foram idênticos ao utilizado para as curvas de retenção de água no solo (Figura 24).

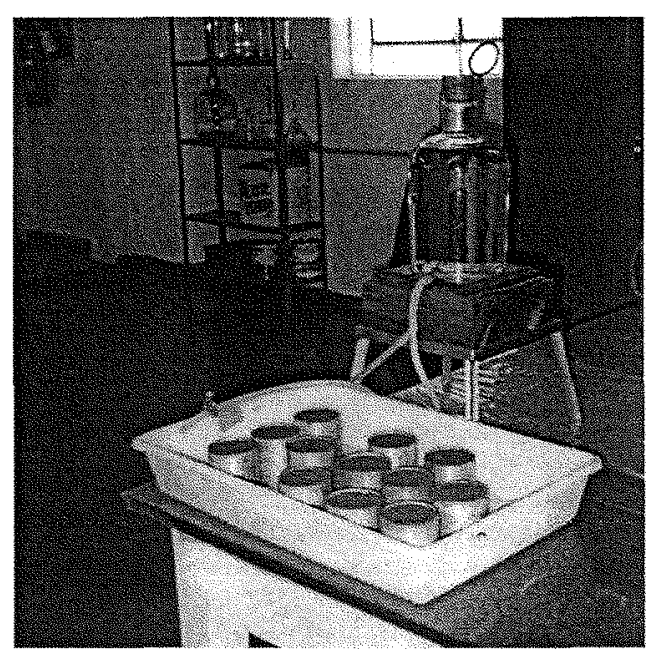

Figura 24 - Saturação das amostras indeformadas utilizando sistema de gotejamento por meio do Frasco de Mariotte

O método utilizado para a determinação da condutividade hidráulica foi o permeâmetro de carga constante segundo Youngs (1991) e para a densidade do solo o método de Blake \& Hartge (1986).

Após a saturação as amostras foram levadas a um sistema para a determinação da condutividade hidráulica do solo saturado (Figura 25). O método consiste basicamente em manter uma carga hidráulica constante, utilizando-se Frascos de Mariotte, medindo o volume drenado em função do tempo. A massa de água que passava em um tempo pré-determinado era determinada em uma balança digital, considerando-se o equilíbrio após três medidas próximas consecutivas apresentarem valores próximos.

A condutividade hidráulica do solo saturado foi calculada pela seguinte expressão:

$$
K_{s a t}=\frac{V_{A} \cdot L}{A \cdot t(h+L)}
$$


sendo:

$\mathrm{K}_{\text {sat }}=$ condutividade hidráulica saturada $\left[\mathrm{L} \mathrm{T}^{-1}\right]$

$\mathrm{V}_{\mathrm{A}}=\operatorname{vazão}\left[\mathrm{L}^{3} \mathrm{~T}^{-1}\right]$

$\mathrm{L}=$ altura da amostra [L]

$A=$ área da seção transversal da amostra $\left[L^{2}\right]$

$\mathrm{t}=$ tempo $[\mathrm{T}]$

$\mathrm{h}$ = carga hidráulica aplicada [L]

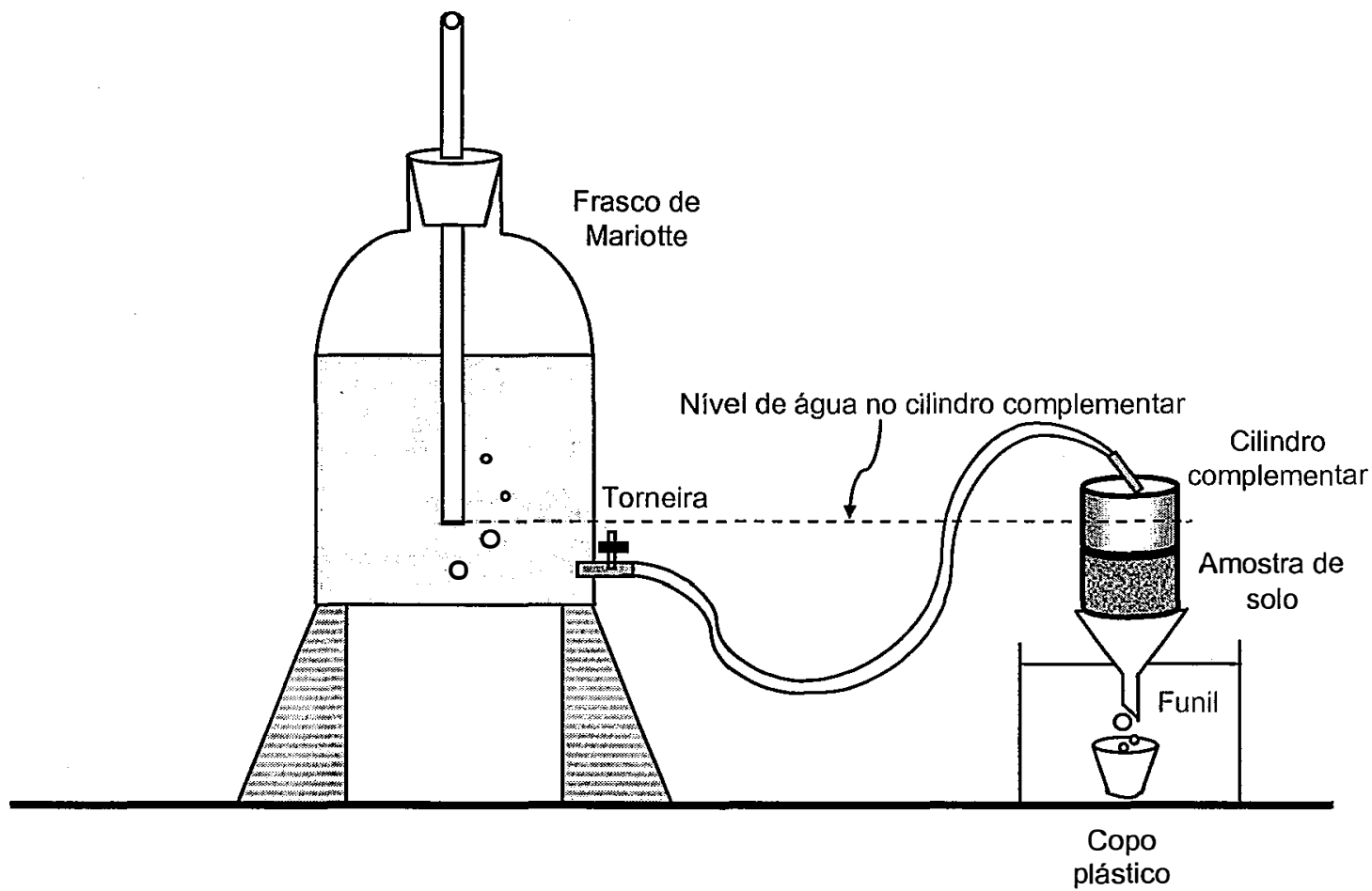

Figura 25 - Diagrama esquemático do sistema utilizado na determinação da condutividade hidráulica saturada em amostras com estrutura indeformada

\subsection{Método do perfil instantâneo}

Decorridos cinco meses após a instalação dos tensiômetros, dos tubos de acesso para a sonda de nêutrons e dos sensores de umidade, tempo necessário para uma acomodação dos equipamentos no solo, foi possível o início do processo de 
embebição da parcela experimental. Com o objetivo de conseguir uma melhor embebição foi adotado um procedimento de inundação intermitente, ou seja, foram feitas inundações periódicas em que o volume de água foi adicionado gradativamente. Esse processo foi repetido duas vezes ao dia durante 10 dias, totalizando um volume mínimo estimado de $24 \mathrm{~m}^{3}$. Os tensiômetros, fluxados previamente, eram lidos antes e após cada inundação. $O$ processo descrito acima objetivou uma melhoria na saturação dos poros do solo e, consequentemente, um favorecimento no processo de redistribuição. Dessa forma tentou-se minimizar os efeitos do potencial de pressão, que confina o ar no solo e não o deixa sair. Frequentemente este fato não é levado em consideração, principalmente em processos de saturação rápida (um dia de inundação), podendo ocasionar uma indicação errada do "tempo zero para fechamento da parcela" (Guiberto, 1999).

Após a realização da saturação intermitente foi feita a cobertura da parcela experimental com plástico de polietileno preto a fim de evitar os processos de evaporação e também entrada de água proveniente de chuvas (Figura 26). O plástico foi perfurado para dar passagem aos tensiômetros e aos tubos de acesso para a sonda de nêutrons e após devidamente amarrados, em todo o seu perímetro, com arame galvanizado. Também foi realizada a cobertura em todo o perímetro da lona excedente com terra para um perfeito cobrimento. Para proteção adicional contra eventual entrada de água e também reduzir o super aquecimento da parcela experimental, a mesma ainda foi coberta com uma estrutura formada por telhas de chapa galvanizada. A estrutura possibilitou o livre acesso para a fluxagem dos tensiômetros e leitura da sonda de nêutrons nos respectivos tubos de acesso.

A drenagem interna foi observada por meio das leituras das baterias de tensiômetros, cujos valores em alturas de coluna de mercúrio foram transformados em potencial mátrico $\left(\Psi_{m}\right)$ segundo a eq. (12):

$$
\psi_{m}=-12,6 H+h_{c}+z
$$

sendo $H$ o valor da leitura, $h_{c}$ a altura da cuba de mercúrio e $z$ a profundidade de instalação do tensiômetro. Como os manômetros foram instalados com diferentes 
alturas, os valores de hc para cada bateria de tensiômetros foram variáveis, o que foi devidamente considerado nos cálculos.

O tempo inicial $(t=0)$ foi considerado aquele no qual as leituras dos manômetros corresponderam a um suposto potencial mátrico zero, calculado anteriormente. Após o estabelecimento do tempo inicial, as leituras foram realizadas inicialmente a intervalos de 20, 40 e 60 minutos e a seguir foram estendidas a intervalos maiores como 1, 2, 3, 5 e 7 dias. A duração do experimento a campo foi de 53 dias quando houve a suspensão das leituras em função das variações das mesmas serem extremamente pequenas. As leituras foram realizadas aproximadamente nos mesmos horários, durante as manhãs, de forma a evitar-se a influência da temperatura nos manômetros de mercúrio e também na cobertura plástica.

Os valores de umidade do solo foram obtidos por meio de sonda de nêutrons, praticamente nos mesmos horários de leituras dos tensiômetros. Como o intervalo inicial de coleta de dados foi de cerca de 20 minutos, não foi possível a realização das leituras com a sonda de nêutrons, no início do processo de redistribuição, já que para uma etapa completa de leituras (três tubos de acesso), consumia-se um tempo médio de 30 minutos.

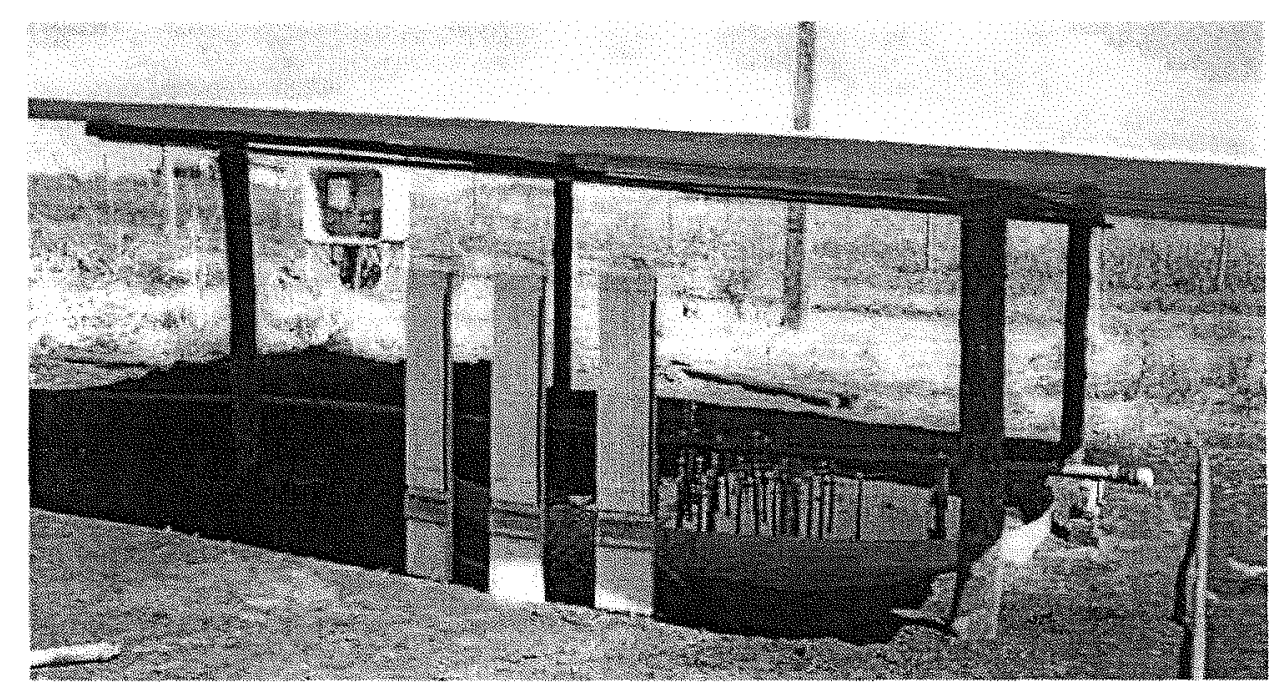

Figura 26 - Parcela experimental coberta após a inundação, com plástico de polietileno preto e estrutura de chapas galvanizadas 
Para a obtenção da constante dielétrica e, por consequência da umidade volumétrica do solo, as leituras dos sensores de TDR foram programadas, via "datalogger", para serem obtidas a intervalos de 30 minutos. O método utilizado para a calibração do TDR foi semelhante ao da sonda de nêutrons, onde foram consideradas as leituras da constante dielétrica e do potencial mátrico, obtido via tensiometria e após convertido em umidade volumétrica, a partir da curva de retenção, nos períodos de coincidência dos horários de leituras do TDR e tensiômetros.

A partir dos dados obtidos em cada camada, com os equipamentos citados, foi possível a realização dos cálculos correspondentes. 


\section{RESULTADOS E DISCUSSÃO}

Para uma melhor compreensão do trabalho o item Resultados e Discussão será dividido em três partes: a primeira discutirá aspectos da proteção adotada para a instalação dos equipamentos para o monitoramento contínuo de água no solo; a segunda tratará das características físicas do solo e das curvas de calibração dos equipamentos e na terceira procurar-se-á quantificar os erros envolvidos na determinação de $K(\theta)$, a partir de valores de $\theta$ obtidos pelos diferentes equipamentos.

\subsection{Blindagem eletromagnética, aterramento e proteção contra surtos de tensão}

O monitoramento contínuo e simultâneo da água no solo tem se tornado bastante atrativo em estudos de Física do Solo, mas apesar da tecnologia empregada, ainda não são considerados aspectos relacionados a instalação e segurança dos equipamentos e a qualidade dos sinais. Pode-se destacar aspectos que vão desde o processo de aquisição, passando pela transmissão e armazenagem, tais como: seleção do local adequado para instalação do TDR e "datalogger", condições de proteção eletromagnética e aterramento, etc, e tal segurança normalmente não é computada no custo total dos mesmos. Dessa forma qualquer problema poderá tornarse um grande prejuizo, pois a queima ou dano constitui um custo considerável, tanto do conserto, quando do tempo necessário para realizá-lo, caso não haja a possibilidade de reparo no Brasil. Aspectos dessa natureza devem, portanto, ser considerados quando da aquisição de equipamentos para monitoramento contínuo no campo, pois constitui-se um "preço a pagar" pelo benefício, comparativamente a sonda de nêutrons e tensiômetros.

Um diagrama esquemático mostrando o sistema de blindagem eletromagnética, aterramento e proteção contra surtos de tensão, bem como os 
equipamentos utilizados para monitoramento contínuo de água no solo e distâncias entre eles em campo aberto, são mostrados na Figura 27.

A configuração utilizada procurou atender o que Freeland \& Henry (1991), Moreno \& Costa (s.d.) e Capelli (2000) sugerem no sentido de que a proteção de equipamentos e seus periféricos, sejam eles os cabos de comunicação/alimentação, os multiplexadores e os sensores a eles acoplados, devem apresentar os seguintes itens: a) Proteção primária: envolve a alimentação do equipamento/periférico pela rede de energia elétrica; b) Proteção secundária: refina a proteção primária na etapa de alimentação; c) Proteção contra descargas atmosféricas: protege principalmente o operador; d) Proteção contra campos eletromagnéticos gerados por descargas nuvemnuvem, nuvem-terra e redes de alta tensão.

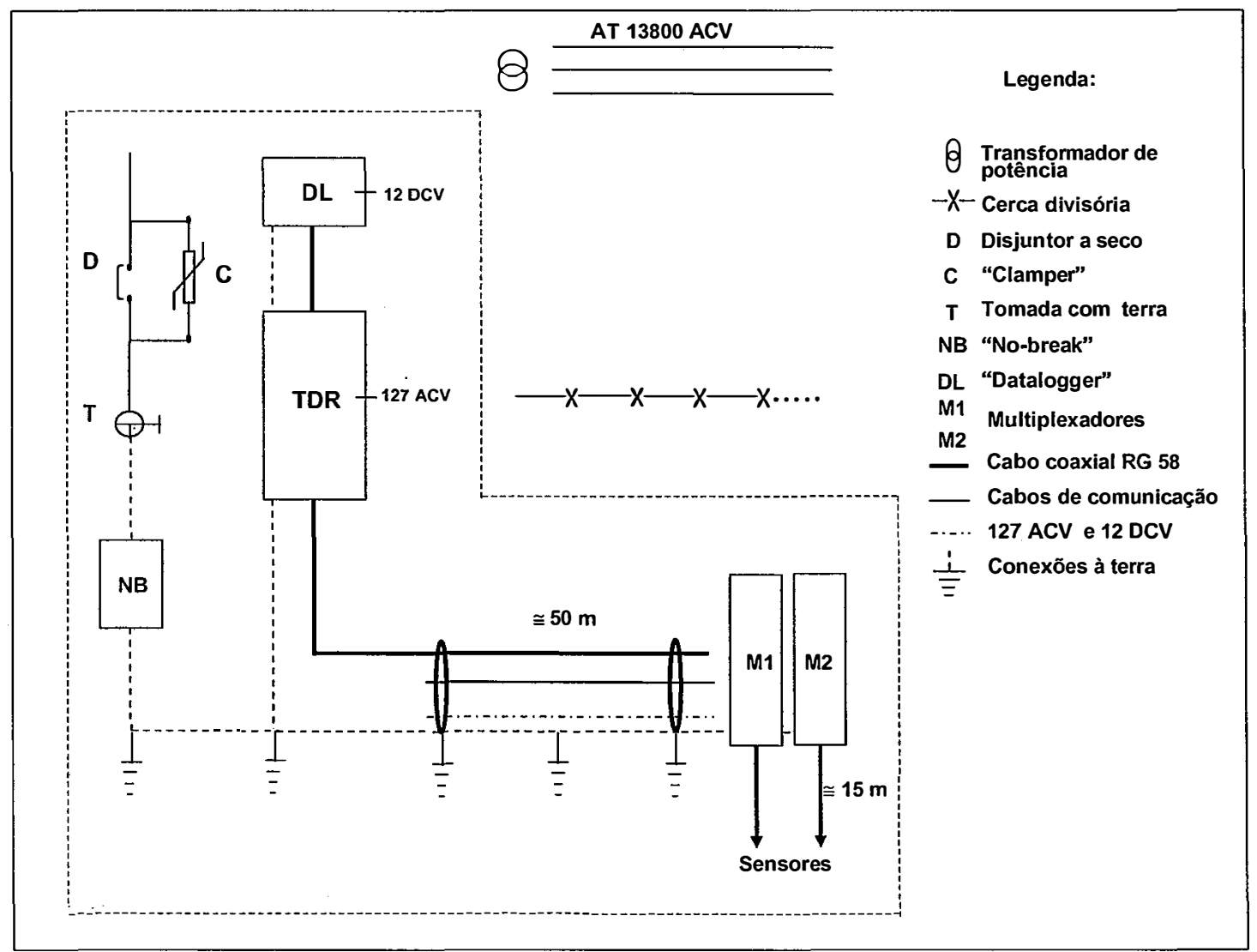

Figura 27 - Diagrama esquemático representando os equipamentos instalados no campo para monitoramento automático do teor de água no solo e respectiva proteção eletromagnética 
A fase inicial de proteção constou da instalação do TDR, DL, bateria, "nobreak", cabos associados, etc, em uma construção de alvenaria pré-existente em área próxima ao Posto Meteorológico utilizada como caixa de passagem. Nessa caixa existe um quadro de distribuição e dispositivos eletromagnéticos de proteção e acionamento de moto-bombas (Figura 15). O objetivo da utilização desse ambiente foi proporcionar ao sistema uma proteção mecânica e ao mesmo tempo submetê-lo a uma condição extrema em termos de possibilidade de interferência devido ao acionamento de relés. Para Capelli (2000), entre outros, a interferência eletromagnética pode causar vários problemas nos equipamentos eletroeletrônicos e sua causa pode ser quando um condutor de eletricidade percorrido por uma corrente elétrica, gera ao seu redor um campo eletromagnético. Dependendo da frequência e intensidade da corrente, esse campo pode ser maior ou menor. Se a intensidade ultrapassar determinados valores, alguns defeitos podem ocorrer, tais como: falha de comunicação entre equipamento e PC, erro na execução do programa, geralmente sem seguir um padrão específico, falhas esporádicas e que não seguem uma lógica, queima de circuitos eletrônicos, mesmo sendo novos e confiáveis, etc.

Após a proteção mecânica, procedeu-se a proteção primária que envolveu, inicialmente, a instalação de um disjuntor de $15 \mathrm{~A}$ com o objetivo de separar as fases, ou seja, tornar a alimentação do sistema (TDR e periféricos) independente de outros dispositivos já existentes.

O passo seguinte foi a instalação de duas tomadas monofásicas para alimentação do TDR e da bateria do DL. Como o sistema elétrico existente apresentou condições inadequadas de segurança com relação ao aterramento, instalou-se uma haste "cooperweld" a aproximadamente $2 \mathrm{~m}$ do sistema, conectando-se, então, o $3^{\circ}$ fio das tomadas. A partir dessa haste o sistema de aterramento foi ampliado, como será discutido adiante.

A blindagem eletromagnética dos cabos foi realizada da seguinte maneira: 0 cabo coaxial RG 58 e os cabos de comunicação serial foram inseridos em tubos galvanizados de irrigação de 3" de diâmetro, com engate rápido e $6 \mathrm{~m}$ de comprimento, perfazendo uma distância de $50 \mathrm{~m}$. A justificativa da utilização deste tubo foi, além de constituir um bom condutor de eletricidade, proporcionar uma "Gaiola de Faraday" (Kindermann, 1997) perfeita e também pela disponibilidade, já que não são mais 
utilizados em irrigação, visto que, atualmente, dá-se preferência aos tubos de PVC. Os cabos de energia 127 VAC e 12 VDC também foram protegidos por meio de canos de ferro de 3/4" de diâmetro e $6 \mathrm{~m}$ de comprimento (do tipo utilizado antigamente em instalações hidráulicas), paralelamente ao de comunicação. Todos os tubos utilizados para a proteção eletromagnética estavam disponiveis no Departamento de Ciências Exatas, possibilitando a reciclagem de material.

Para o aterramento, os dois tipos de tubulação foram enterradas a aproximadamente $0,10 \mathrm{~m}$ da superfície do solo e conectadas, via cordoalha de cobre e terminais bi-metálicos, a 7 hastes de "cooperweld" enterradas a cada $6 \mathrm{~m}$. A função da cordoalha de cobre foi manter o sistema de tubulações unidas, ou seja, amarrar os tubos de forma que qualquer movimento na superfície não causasse a separação dos mesmos. Os terminais bi-metálicos foram utilizados com o intuito de evitar problemas de corrosão, muito comum em sistemas de aterramento, devido a utilização de metais com diferentes eletronegatividades, no caso o cobre da cordoalha e o metal dos tubos galvanizados (Kindermann \& Campagnolo, 1998). Todo o sistema foi conectado aos terras dos multiplexadores, TDR, DL e tomadas de força, formando um único sistema equipotencial. Como as tubulações que conduzem os fios e cabos aos multiplexadores ficaram sob uma cerca divisória de arame farpado e não se dispunha de total segurança sobre a qualidade do aterramento da mesma, podendo ocorrer indução de cargas eletrostáticas nos arames farpados (Kindermann, 1997), optou-se pela conexão da cerca ao sistema de aterramento.

A avaliação do ruído de modo comum (Moreno \& Costa, s.d.) e da resistência de terra (Capelli, 2000) foi realizada utilizando-se o medidor $410 \mathrm{~S}$ da Kyoritsu, que indicou $0 \mathrm{~V}$ de diferença de potencial entre o "terra da fonte de energia" e o "terra ao qual o equipamento se refere". A resistência de aterramento indicou $4,8 \Omega$, o que está de acordo com a ABNT (1997), que indica $10 \Omega$ como valor máximo admissivel para a resistência de terra e Capelli (2000) que aconselha $5 \Omega$ como o máximo ideal para equipamentos eletrônicos.

A qualidade do terra permitiu a instalação de um supressor de transientes "Clamper", com o objetivo de melhorar o sistema primário de proteção, pois é comum a existência de flutuações de tensão na rede de energia (sobretensões ou subtensões) e dependendo da sensibilidade dos equipamentos utilizados, há a necessidade da 
utilização de protetores. A existência de um transformador próximo à área experimental evidenciou o problema, pois perto do mesmo a tensão pode ser um pouco maior do que o normal, enquanto que no final da linha, esta tensão pode cair bastante.

O supressor de transientes "Clamper" é composto por um varistor associado a um dispositivo térmico de segurança, que atua tanto por sobrecorrente quanto por sobretemperatura. Na Figura 28 observa-se o diagrama esquemático da instalação de um "Clamper", que funciona da seguinte maneira: o dispositivo é ligado em paralelo com a fase e se não houver tensão superior a tensão nominal do dispositivo, no caso $175 \mathrm{~V}$, o varistor é mantido aberto permitindo que a mesma seja enviada ao sistema via fase. Caso haja uma tensão superior a $175 \mathrm{~V}$, o varistor funde e desconecta o sistema, tornando-se um caminho preferencial para o envio da sobretensão para o terra, impedindo que os equipamentos conectados à fase sejam danificados. Este fato evidencia a importância da qualidade e da medição do aterramento utilizado.

A proteção secundária constituiu-se na instalação de um "no-break", marca $\mu \mathrm{SM} 600 \mathrm{~S}$, com o objetivo de filtrar a tensão de entrada, evitar os ruídos no sistema e também proporcionar o funcionamento do mesmo quando houvesse queda de energia na rede.

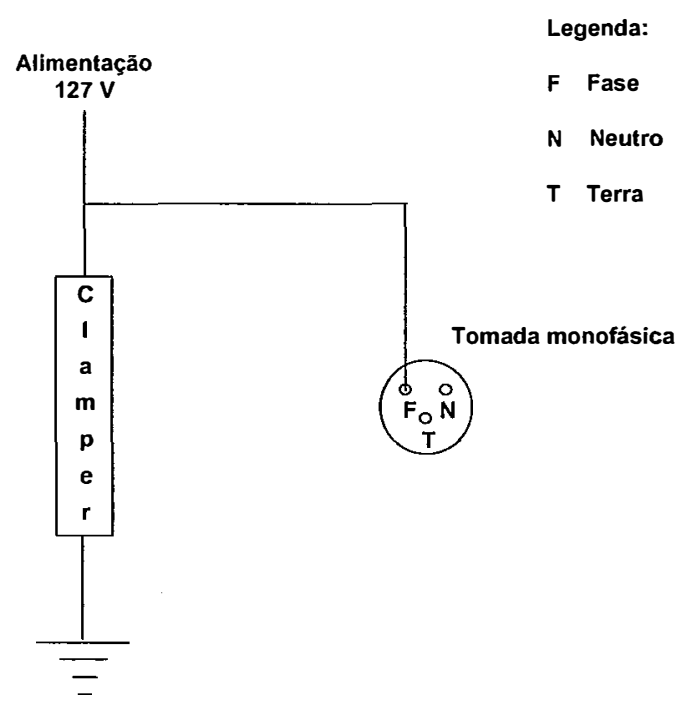

Figura 28 - Diagrama esquemático da instalação do supressor de transientes ("Clamper") 
Com relação à utilização do "no-break", marca $\mu \mathrm{SM} 600 \mathrm{~S}$, verificou-se que o mesmo não pode ser utilizado para alimentar equipamentos com fontes lineares e/ou compactas (eliminadores de pilha) (SMS, s.d.). A forma de onda produzida por este "no-break" é quase senoidal, e o estabilizador da bateria de 12 VDC necessita receber uma forma de onda senoidal perfeita. Essa utilização inadequada do "no-break" provavelmente foi a causa direta da queima da etapa de estabilização do alimentador da bateria do DL e indiretamente da placa de aquisição de dados do TDR e da inutilização do "Clamper" de proteção. Após investigação da possível causa, substituição do "Clamper", conserto do alimentador da bateria e instalação de um novo "no-break", marca Smart-UPS 1000, o sistema passou a operar sem novos problemas e queima dos instrumentos.

Nessas condições, o equipamento operou em todo o período chuvoso e mesmo em local elevado, com cerca de arame farpado junto aos cabos e alta tensão sobre todas as instalações, nenhum problema de queima de componentes ou interrupção prolongada na aquisição de dados foi verificada.

\subsection{Características físicas do solo}

\subsubsection{Densidade do solo e condutividade hidráulica do solo saturado}

A densidade do solo para cada profundidade, medida na época de implantação do experimento e respectivos coeficientes de variação são mostrados na Tabela 4. Verifica-se que a densidade praticamente não variou no perfil, exceto para as camadas de 0-0,40; 0,60-0,70 e 1,10-1,20 m, que apresentaram valores relativamente maiores, indicando a presença de uma possível camada compactada. Prevedello (1987), na mesma área experimental e nas mesmas camadas, observou que os valores de densidade foram consideravelmente maiores, variando cerca de $15 \%$ até $0,70 \mathrm{~m}$ e $5 \%$ a partir dessa camada.

Para os dados de coeficiente de variação nota-se que os valores foram relativamente mais baixos do que os obtidos por Warrick \& Nielsen (1980), que obtiveram coeficientes médios em torno de $7 \%$. Os autores consideram essa propriedade física como de baixa variação, quando comparada, por exemplo, a 
condutividade hidráulica do solo saturado, e indicam duas repetições como suficientes para obter-se valores representativos.

Tabela 4. Valores médios e coeficientes de variação da densidade do solo nas diferentes camadas de interesse

\begin{tabular}{ccc}
\hline $\begin{array}{c}\text { Prof. } \\
(\mathrm{m})\end{array}$ & $\begin{array}{c}\text { Densidade do solo } \\
\left(\mathrm{kg} \mathrm{m}^{-3}\right)\end{array}$ & $\begin{array}{c}\text { C.V. } \\
(\%)\end{array}$ \\
\hline $0-0,40$ & 1320 & 2,9 \\
$0,40-0,50$ & 1240 & 7,2 \\
$0,50-0,60$ & 1210 & 4,4 \\
$0,60-0,70$ & 1310 & 3,7 \\
$0,70-0,80$ & 1280 & 3,6 \\
$0,80-0,90$ & 1260 & 2,2 \\
$0,90-1,00$ & 1250 & 6,1 \\
$1,00-1,10$ & 1240 & 1,0 \\
$1,10-1,20$ & 1310 & 2,2 \\
$1,20-1,30$ & 1250 & 0,7 \\
\hline
\end{tabular}

Os valores são médias de três repetições.

Os resultados da condutividade hidráulica do solo saturado $\left(\mathrm{K}_{\mathrm{sat}}\right)$, obtidos com o permeâmetro de carga constante, e respectivos coeficientes de variação, para as diferentes camadas, encontram-se na Tabela 5. Segundo Kutílek \& Nielsen (1994), solos que apresentam condutividades hidráulicas saturadas entre $10^{-5}$ e $10^{-6} \mathrm{~m} \mathrm{~s}^{-1}$ possuem permeabilidade hidráulica média, enquanto que Klute \& Dirksen (1986) consideram que solos de classe textural argilo arenosa e com valores de $\mathrm{K}_{\text {sat }}$ entre $10^{-5}$ e $10^{-7} \mathrm{~m} \mathrm{~s}^{-1}$ possuem permeabilidade baixa. Para o solo Nitossolo Vermelho distrófico latossólico estudado, a classe textural obtida variou de argilosa na camada de 0-0,40 m a muito argilosa nas demais camadas (Tabela 1, item Material e Métodos) diferindo, portanto, daquela sugerida por Klute \& Dirksen (1986). Do exposto, verifica-se que cuidados devem ser tomados ao usar a classificação sugerida pelos autores citados, visto que para um mesmo solo, pode-se ter duas permeabilidades diferentes, uma média e a outra baixa. Questões relacionadas a compactação das amostras por ocasião da amostragem podem ser descartadas, visto que os valores de densidade 
mantiveram-se constantes ao longo do perfil e, portanto, poder-se-ia supor que o amostrador de Uhland foi utilizado com relativo sucesso. Tais classificações devem, portanto, serem usadas apenas com o intuito de averiguar ou especular sobre a facilidade de um solo em conduzir água em comparação a outro.

Analisando-se os valores de $\mathrm{K}_{\text {sat }}$, observa-se que nas camadas de 0,60-0,70 a 0,90-1,00 m, ocorreu uma diminuição dos mesmos, podendo estar relacionada aos menores valores de densidade do solo, cuja variação foi de 1310 a $1250 \mathrm{~kg} \mathrm{~m}^{-3}$, obtidos nas mesmas camadas estudadas. Sob o ponto de vista da análise granulométrica do solo, os dados mostram que para estas camadas (Tabela 1, item Material e Métodos), não ocorreram valores de argila discrepantes, que pudessem justificar as reduções de $\mathrm{K}_{\text {sat }}$ ao longo das camadas estudadas. Além disso, deve-se ressaltar que os valores de densidade do solo e condutividade hidráulica saturada foram obtidos a partir de uma mesma amostra de solo coletada.

Tabela 5. Valores médios e coeficientes de variação da condutividade hidráulica saturada $\left(\mathrm{K}_{\text {sat }}\right)$ obtida com permeâmetro de carga constante, para as diferentes camadas de interesse

\begin{tabular}{ccc}
\hline $\begin{array}{c}\text { Prof. } \\
(\mathrm{m})\end{array}$ & $\begin{array}{c}\mathrm{K}_{\text {sat }} \\
\left(\mathrm{m} \mathrm{s}^{-1}\right)\end{array}$ & $\begin{array}{c}\text { C.V. } \\
(\%)\end{array}$ \\
\hline $0-0,40$ & $4,3 \cdot 10^{-5}$ & 32,7 \\
$0,40-0,50$ & $3,5 \cdot 10^{-5}$ & 81,6 \\
$0,50-0,60$ & $1,0 \cdot 10^{-5}$ & 34,4 \\
$0,60-0,70$ & $7,6 \cdot 10^{-6}$ & 48,2 \\
$0,70-0,80$ & $8,1 \cdot 10^{-6}$ & 40,7 \\
$0,80-0,90$ & $6,8 \cdot 10^{-6}$ & 25,0 \\
$0,90-1,00$ & $6,6 \cdot 10^{-6}$ & 36,4 \\
$1,00-1,10$ & $1,0 \cdot 10^{-5}$ & 4,7 \\
$1,10-1,20$ & $1,1 \cdot 10^{-5}$ & 47,2 \\
$1,20-1,30$ & $2,6 \cdot 10^{-6}$ & 16,0 \\
\hline
\end{tabular}

Os valores são médias de três repetições. 
Apesar de $\mathrm{K}_{\text {sat }}$ ser uma propriedade que normalmente apresenta altos coeficientes de variação, além da presença de um "B textural", pode-se observar pequenas diferenças nos valores de $\mathrm{K}_{\text {sat }}$ ao longo do perfil do solo. Os valores dos coeficientes de variação oscilaram de 4 a $80 \%$ entre as camadas de solo e foram consideravelmente inferiores àqueles verificados por Warrick \& Nielsen (1994), que observaram que a condutividade hidráulica do solo saturado constitui uma propriedade das mais variáveis, alcançando coeficientes de variação maiores do que $100 \%$. Os autores assumem que a causa dessa variação está relacionada à metodologia envolvida na obtenção de $\mathrm{K}_{\text {sat, }}$ destacando-se as etapas desde o processo de amostragem até a sua determinação em laboratório. Guiberto (1999) trabalhando com um Latossolo Vermelho Amarelo também encontrou coeficientes de variação menores do que $100 \%$. O autor relacionou esses menores valores à pequena distância adotada na coleta, entre amostras de uma mesma camada, proporcionando, assim valores aproximadamente iguais.

Seja qual for o caso deve-se levar em consideração que o solo representa um sistema formado por poros contínuos e, portanto, qualquer interrupção nessa continuidade, poderá causar alterações nas medidas obtidas.

\subsubsection{Curva de retenção de água no solo}

Na Tabela 6 são apresentados os parâmetros da equação de ajuste, os quais seguem o modelo proposto por van Genuchten (1980), obtidos para cada camada de solo em estudo.

Os gráficos relacionando as umidades volumétricas e as tensões aplicadas, para cada camada de solo, obtidos a partir de três repetições, são apresentados na Figura 29.

Pela análise visual das curvas de retenção observa-se que os ajustes dos pontos em torno das curvas, para todas as profundidades, foram bons, como pode ser confirmado pelos elevados coeficientes de determinação indicados na Tabela 6. Provavelmente o grande número de pontos utilizados para confecção das curvas tenha sido a causa da obtenção de coeficientes de determinação próximos a 1. Nota-se, ainda, que tais curvas indicam um solo de textura argilosa, com distribuição de poros uniforme, quase se aproximando de uma reta, o que pode ser confirmado pela análise 
granulométrica e também pela lenta redistribuição de água que o mesmo apresenta. Nesse caso as perdas de água são menores e de forma gradativa, o que foi constatado durante a confecção das curvas em laboratório, onde as diferenças de pesagens obtidas após o equilíbrio, entre um ponto e outro foram muito pequenas.

Tabela 6. Parâmetros de ajuste da equação de van Genuchten (1980) correspondentes às diferentes profundidades de interesse

\begin{tabular}{cccccccccc}
\hline \multirow{2}{*}{ Parâmetro } & \multicolumn{8}{c}{ Profundidade $(\mathrm{m})$} \\
\cline { 2 - 9 } & 0,40 & 0,50 & 0,60 & 0,70 & 0,80 & 0,90 & 1,00 & 1,10 & 1,20 \\
\hline$\alpha(1 / \mathrm{m})$ & 8,41 & 5,80 & 3,86 & 17,21 & 3,75 & 29,60 & 73,26 & 38,44 & 20,79 \\
$\mathrm{~m}$ & 0,3331 & 0,2320 & 0,3185 & 0,1508 & 0,2007 & 0,1559 & 0,1619 & 0,1950 & 0,1554 \\
$\mathrm{n}^{*}$ & 1,4995 & 1,3021 & 1,4673 & 1,1776 & 1,2510 & 1,1846 & 1,1932 & 1,2422 & 1,1839 \\
$\theta_{\mathrm{r}}\left(\mathrm{m}^{3} \mathrm{~m}^{-3}\right)$ & 0,313 & 0,298 & 0,312 & 0,251 & 0,272 & 0,222 & 0,226 & 0,256 & 0,209 \\
$\theta_{\mathrm{s}}\left(\mathrm{m}^{3} \mathrm{~m}^{-3}\right)$ & 0,494 & 0,498 & 0,507 & 0,517 & 0,500 & 0,548 & 0,554 & 0,542 & 0,519 \\
$\mathrm{r}^{2}$ & 0,990 & 0,987 & 0,984 & 0,954 & 0,974 & 0,976 & 0,967 & 0,969 & 0,992 \\
\hline${ }^{*} \mathrm{n}$ dependente de $\mathrm{m}$ & & & & & & & &
\end{tabular}

É importante salientar que as amostras utilizadas tanto para as curvas de retenção de água no solo, densidade do solo e condutividade do solo saturado sofreram várias tentativas de saturação utilizando o processo convencional (sem préaquecimento). Como não houve sucesso, todas as amostras foram então transferidas para estufa a $60^{\circ} \mathrm{C}$, por 24 horas, e após submetidas novamente à saturação, ocorrendo rapidamente a elevação de água nas mesmas. Isto pode ter sido causado por problemas na amostragem como, umidade elevada na coleta, efeito da compactação ou características do próprio solo. Com relação a umidade elevada é importante salientar que apesar de não ter sido verificada durante a coleta, dez dias antes da realização da mesma, choveu o equivalente a 108,3 mm em um intervalo de 4 dias. Este fato provavelmente foi o responsável pela dificuldade encontrada no processo de saturação das amostras, visto que com relação a compactação não foram verificadas alterações nos valores de densidade do solo. 

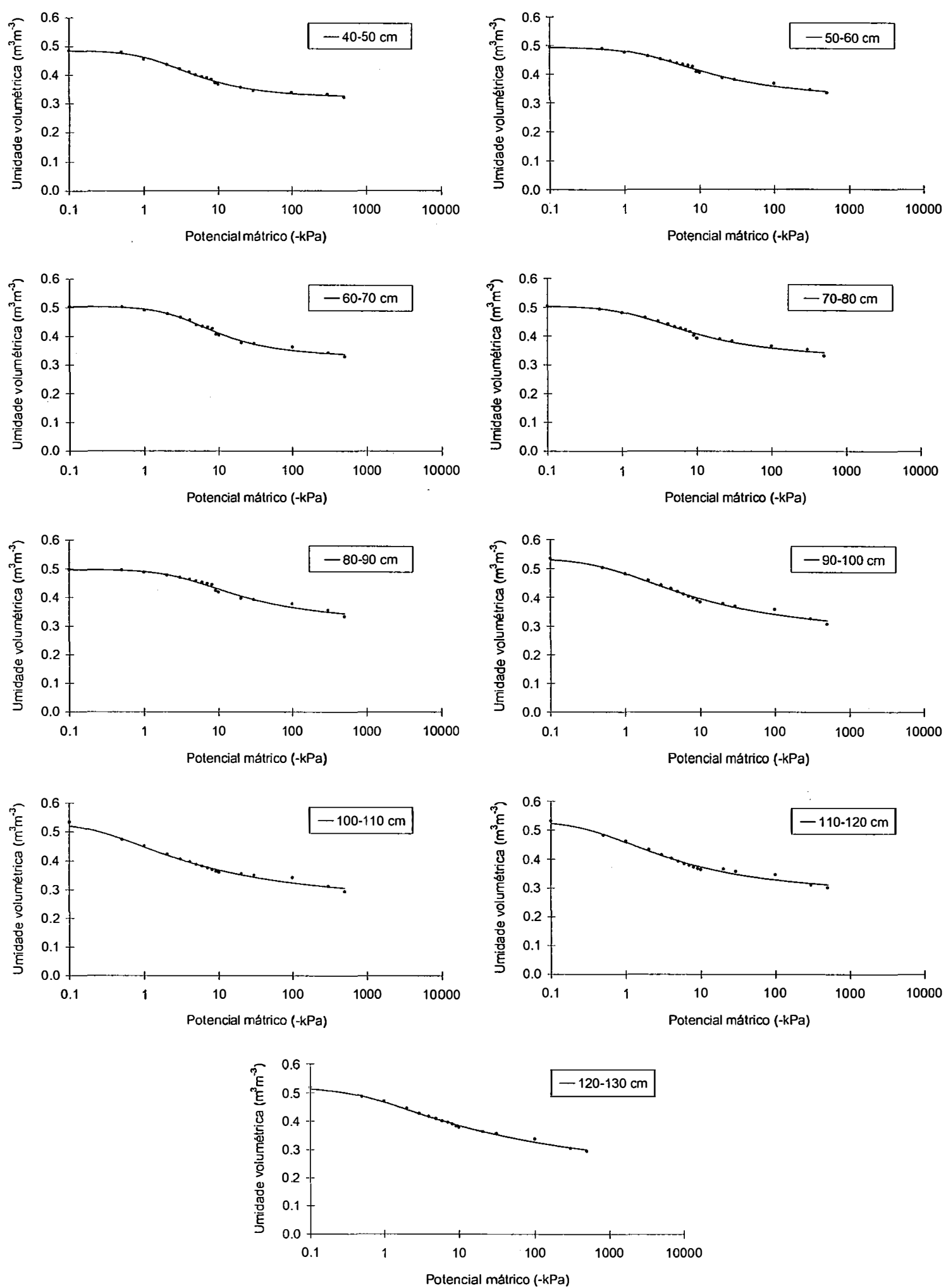

Figura 29 - Curvas de retenção de água no solo para as diferentes camadas do perfil 
Utilizando-se subamostras com alturas de $0,024 \mathrm{~m}$, o tempo total gasto na determinação das curvas de retenção foi relativamente menor, em torno de 120 dias, quando comparado ao tempo quando utiliza-se amostras com maior altura, já que segundo Klute (1986), o tempo necessário para atingir o equilíbrio aumenta de forma quadrática com acréscimos na altura.

\subsection{Calibração de equipamentos}

\subsubsection{Calibração da sonda de nêutrons}

Os gráficos de calibração da sonda de nêutrons para cada camada de solo, relacionando a umidade volumétrica em função da contagem relativa, para os dois métodos utilizados, direto e indireto, encontram-se na Figura 30.

As curvas foram obtidas pela análise de regressão considerando-se as leituras de sonda de nêutrons e determinação do teor de água da amostra coletada no método direto ( 6 pares de leituras) e no método indireto foram consideradas as leituras de sonda e umidade volumétrica obtidas por tensiometria, via curva de retenção (18 pares de leituras). A idéia de estudar um método de calibração indireta surgiu das peculiaridades que cada equipamento apresenta, isto é, da necessidade de tornar menor possivel a influência da variabilidade espacial da umidade na avaliação dos equipamentos. Para o tensiômetro, que é o equipamento padrão, haveria necessidade da curva de retenção para obter a umidade. Para a sonda de nêutrons e o TDR haveria que coletar amostras de solo para obter-se umidades para calibrações, que depois deveriam fornecer resultados comparáveis aos tensiômetros, mas em locais distintos (fora do círculo contendo os instrumentos), agravado ainda pelo fato de que a sonda de nêutrons expandiria o volume amostrado no ato de secamento. Assim, a opção indireta referiu a sonda e TDR à curva de retenção e aos tensiômetros como ponto em comum.

Os coeficientes de determinação $\left(r^{2}\right)$ variaram de 0,667 a 0,989 para o método direto e 0,819 a 0,990 para o método indireto. Para o método direto, Prevedello (1987), no mesmo solo e profundidades, encontrou valores de coeficiente de determinação que variaram de 0,505 a 0,886. Destaca-se nessa observação, a camada de $0,40 \mathrm{~m}$, onde se verificou o menor coeficiente $(0,667)$, sendo, no entanto, maior que o obtido pelo autor $(0,505)$. Prevedello (1987) atribuiu esse menor valor a 
problemas de variabilidade natural do solo nessa profundidade, já que o número de pontos utilizados foi suficientemente grande para não pôr em dúvida, a confiabilidade do conjunto de pontos obtidos. Também ressalta a possibilidade de ter havido a interferência de outros constituintes do solo, principalmente em camadas superficiais, que não a água, na moderação dos nêutrons rápidos.
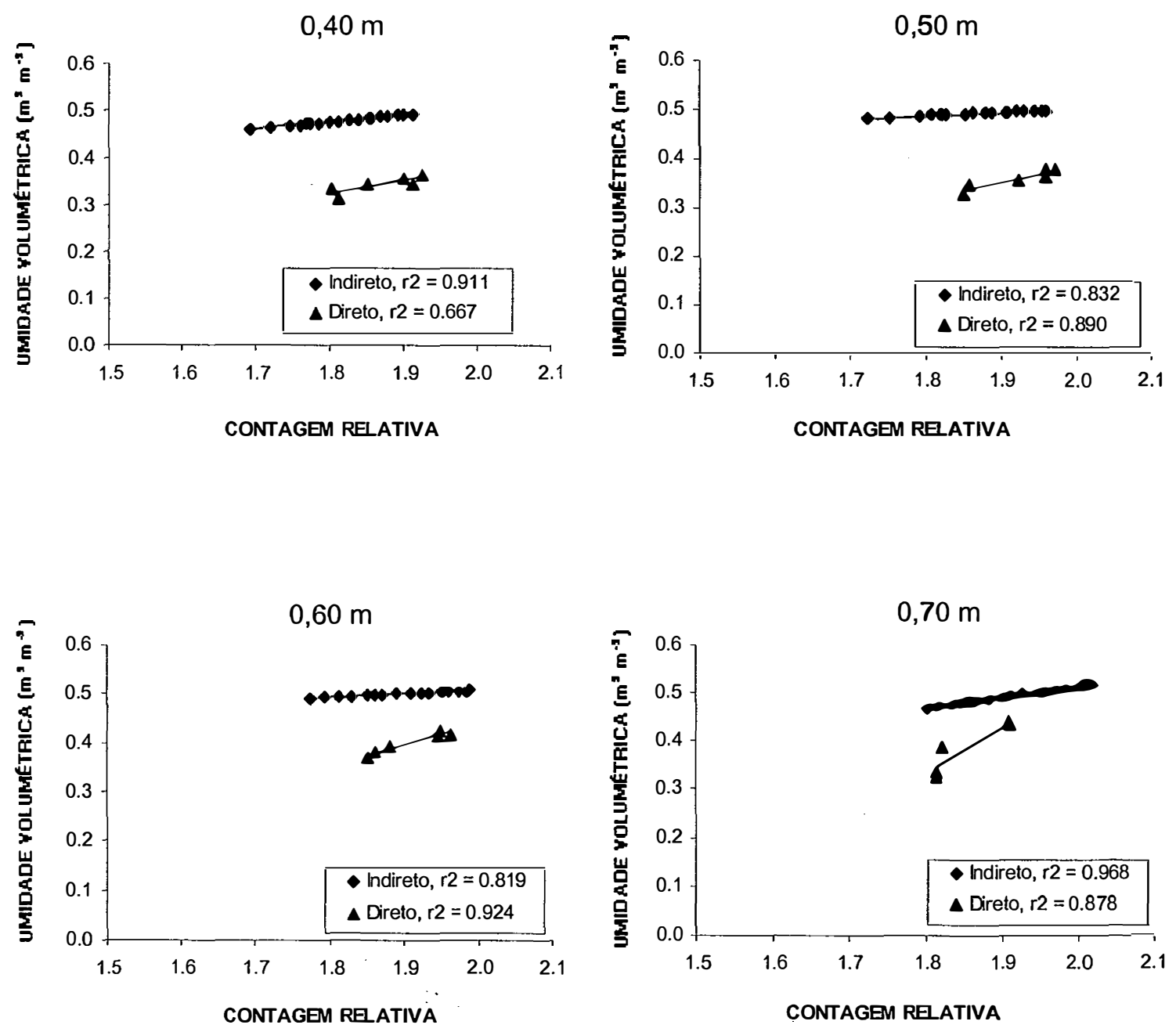

Figura 30 - Curvas de calibração para sonda de nêutrons obtidas pelos métodos direto e indireto, para as diferentes profundidades do solo 

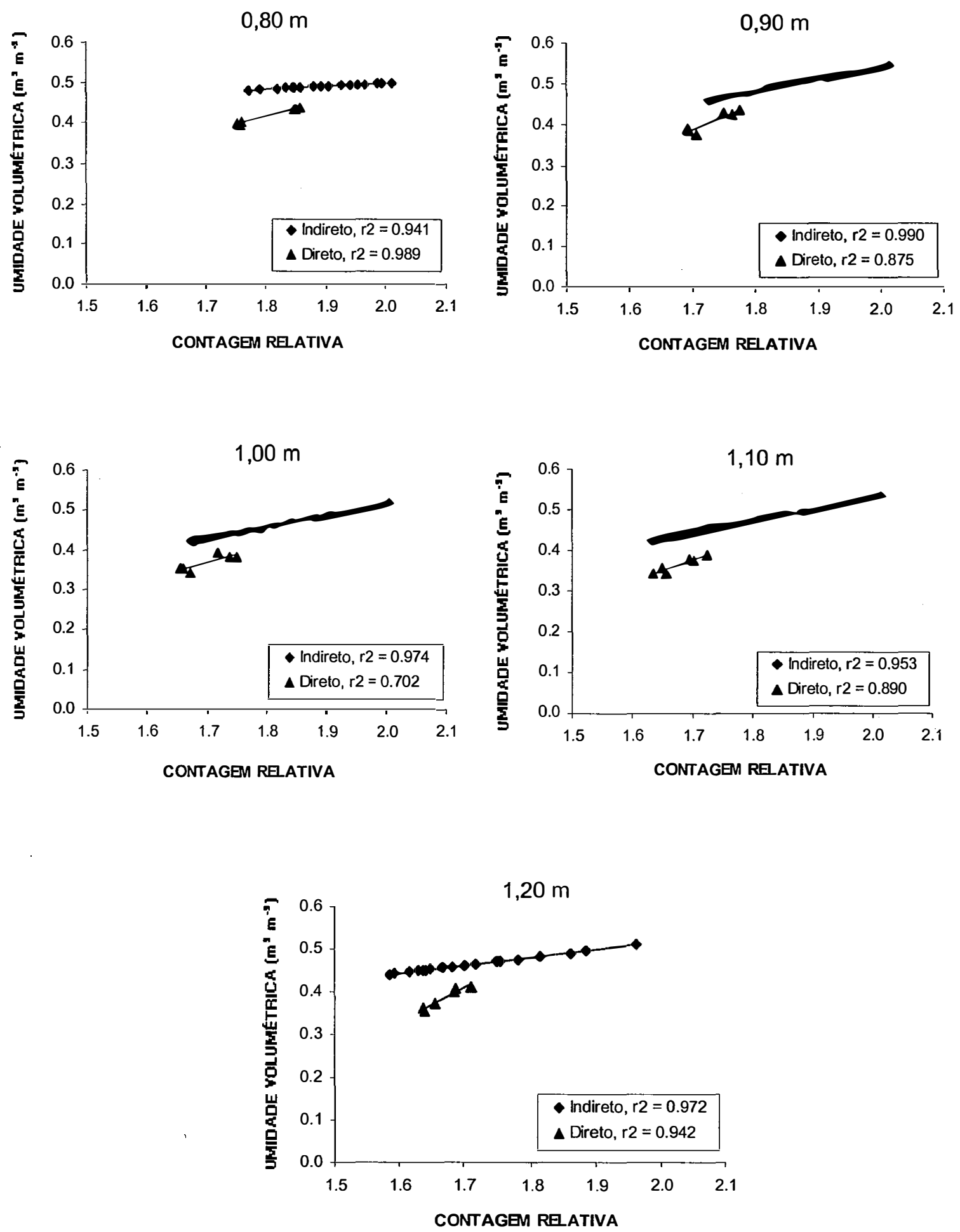

Figura 30 - Curvas de calibração para sonda de nêutrons obtidas pelos métodos direto e indireto, para as diferentes profundidades do solo 
Analisando a amplitude da faixa de umidade volumétrica obtida, pode-se verificar que foi bastante restrita, variando de $0,32 \mathrm{~m}^{3} \mathrm{~m}^{-3}$ a $0,44 \mathrm{~m}^{3} \mathrm{~m}^{-3}$, para o método direto, enquanto que Turatti et al. (1990), para o mesmo solo, encontrou valores que variaram de $0,26 \mathrm{~m}^{3} \mathrm{~m}^{-3}$ a $0,43 \mathrm{~m}^{3} \mathrm{~m}^{-3}$. Os autores também utilizaram um conjunto de 6 pares de dados, o que indica que haveria a possibilidade de estender-se o conjunto de dados obtidos, desde que se aguardasse um tempo maior para o secamento.

As equações de regressão obtidas para as diversas profundidades e para os dois métodos estudados, encontram-se na Tabela 7.

Tabela 7. Equações de calibração da sonda de nêutrons para os métodos direto e indireto, obtidas para as diferentes camadas

\begin{tabular}{|c|c|c|}
\hline \multirow{2}{*}{$\begin{array}{c}\text { Camadas } \\
(\mathrm{m})\end{array}$} & \multicolumn{2}{|c|}{ Equação de calibração(1) } \\
\hline & Método Direto & Método Indireto \\
\hline $0-0,40$ & $\theta=0,2679 C R-0,1559$ & $\theta=6,5343 C R-1,3129$ \\
\hline $0,40-0,50$ & $\theta=0,3621 C R-0,3388$ & $\theta=14,1252 C R-5,0709$ \\
\hline $0,50-0,60$ & $\theta=0,4322 C R-0,4258$ & $\theta=14,3652 C R-5,2919$ \\
\hline $0,60-0,70$ & $\theta=0,9635 C R-1,4034$ & $\theta=4,5914 C R-0,3498$ \\
\hline $0,70-0,80$ & $\theta=0,3839 C R-0,2763$ & $\theta=13,4039 \mathrm{CR}-4,6885$ \\
\hline $0,80-0,90$ & $\theta=0,6197 \mathrm{CR}-0,6674$ & $\theta=3,4667 C R+0,1323$ \\
\hline $0,90-1,00$ & $\theta=0,4299 C R-0,3637$ & $\theta=3,4234 \mathrm{CR}+0,2378$ \\
\hline $1,00-1,10$ & $\theta=0,5363 C R-0,5352$ & $\theta=3,6102 C R+0,0939$ \\
\hline $1,10-1,20$ & $\theta=0,8328 C R-1,0082$ & $\theta=5,4601 C R-0,8189$ \\
\hline
\end{tabular}

Observando-se os valores dos coeficientes angulares das equações de reta .para o método direto de calibração, mostrados na Tabela 7, verifica-se que os valores numéricos apresentam um leve acréscimo com o aumento da profundidade, com um mínimo de 0,2679 e um máximo de 0,9635. A variação encontrada é relativamente maior do que a encontrada por Prevedello (1987), no mesmo solo, mas com outro tipo de sonda de fabricação francesa, marca Nardeaux, modelo Solo-25. O autor encontrou um mínimo de 0,118 e um máximo de 0,162, variação considerada muito pequena, podendo então, para propósitos práticos, utilizar somente uma curva para qualquer 
profundidade do perfil. No caso em estudo como as diferenças encontradas foram maiores, há a necessidade da construção de curvas de calibração para cada profundidade de interesse. Villagra (1988) estudando a variabilidade de medidas de tensiômetro no mesmo solo e mesma sonda, encontrou, para a camada de 0,25 m, um coeficiente angular de 1,0424, diferindo, portanto, do encontrado por Prevedello (1987), cuja equação encontrada foi do tipo polinomial de segunda ordem. Considerando o método indireto de calibração nota-se uma variação muito maior, com um mínimo de 3,4234 e um máximo de 14,3652.

Da mesma forma para o coeficiente linear, considerando-se o método direto, observa-se uma grande variação em comparação com os valores obtidos por Prevedello (1987). O valor numérico mínimo encontrado foi de -1,4034 e o máximo 0,1559 , enquanto que os obtidos pelo referido autor foram $-0,1445$ de mínimo e 0,0223 de máximo.

Muitas vezes o critério adotado pelos pesquisadores para a análise das curvas de calibração é o coeficiente de determinação (Turatti et al., 1990; Santos et al., 1999). Considerando-se esse critério, poder-se-ia afirmar que, de modo geral, os dois métodos, para todas as profundidades, apresentaram coeficientes que indicariam possibilidade de utilização de todas as curvas de calibração. Mas a verificação visual da Figura 30, mostra que há diferenças variáveis entre os resultados dos métodos direto e indireto, para as nove camadas estudadas. As diferenças estão relacionadas principalmente a inclinação da reta obtida no método indireto em relação ao direto, faixas de umidade abrangidas por um e outro método e número de pontos obtidos. Com relação à inclinação verifica-se, de modo geral, que os métodos não apresentaram paralelismo entre as retas, com exceção das camadas de 0,40 e 1,00 m que mostraram possuir uma mesma inclinação. Para as faixas de umidade observa-se que somente para as profundidades de 0,80, 0,90 e 1,00 m, os valores obtidos não foram os mesmos. A amplitude de umidade conseguida com o método direto, tomado como padrão, provavelmente acentuou as diferenças encontradas entre os métodos e, com menor intensidade, o número de pontos utilizados. Se as faixas de umidade obtidas para esse método fossem maiores, com certeza ter-se-ia mais subsídios para inferir sobre a aplicabilidade do método indireto de calibração da sonda de nêutrons. 
Uma maneira de quantificar as diferenças entre os métodos utilizados é através de uma análise estatística robusta (independente de uma distribuição subjacente). Para tanto, utilizaram-se os seguintes índices: Índice de concordância (d) (Willmott et al., 1985), Coeficiente de determinação $(C D)$, Eficiência $(E F)$, Erro máximo $(M E)$, Raiz quadrada do erro médio quadrático normalizado (RMSE), Coeficiente de massa residual (CRM) e Erro absoluto médio(EAM) (Zacharias et al., 1996). Uma perfeita concordância entre as curvas obtidas pelos dois métodos resultaria em $d=C D=E F=1$ e $M E=R M S E=C R M=E A M=0$. A Tabela 8 apresenta os dados da análise para as profundidades de interesse.

Analisando-se os índices estatísticos utilizados, verifica-se que para o índice de concordância $(d)$, nenhuma camada apresentou $d$ igual a 1 , sendo que as camadas de 0,60 a $1,00 \mathrm{~m}$ e a camada de $1,20 \mathrm{~m}$ apresentaram $d$ maior do que 0,7 . Para os índices $C D$ e $E F$, as camadas não apresentaram sequer valores próximos a 0,5 , mas mesmo assim a camada de $0,90 \mathrm{~m}$ foi a que apresentou melhor resultado. Para os indices ME, EAM, RMSE e CRM as camadas que contêm as profundidades $0,80,0,90$, $1,00,1,10$ e 1,20 m tiveram melhor desempenho, alcançando valores mais próximos de 0 , quando comparadas as demais camadas. Portanto, das nove camadas analisadas, a camada de $0,90 \mathrm{~m}$ foi a que obteve uma maior concordância com os índices estudados e a camada de $0,50 \mathrm{~m}$ o pior resultado. Apesar do método indireto apresentar coeficientes de determinação considerados bons, a sua utilização deve ser feita com restrição.

Um outro trabalho que utilizou o coeficiente de determinação como único critério foi o de Santos et al. (1999). Os autores, com o objetivo de tornar a calibração da sonda de nêutrons, mais rápida, precisa e menos trabalhosa, utilizaram uma calibração simplificada, que considera valores extremos de umidade e, segundo os autores, pode substituir satisfatoriamente a calibração pelo método convencional. Os resultados obtidos pela metodologia simplificada indicam menor variação na estimativa do conteúdo de água no solo. É questionável a afirmação dos autores com relação à precisão do método utilizado, pois são considerados apenas dois pontos extremos de umidade e por eles traçado um segmento de reta. Os coeficientes de determinação obtidos foram 1, ou muito próximos deste valor, indicando que os ajustes encontrados foram bons. Como exemplo, podemos tomar a camada de $0,40 \mathrm{~m}$ para o método 
direto, onde obteve-se o pior valor de coeficiente de determinação $(0,667)$. Tomandose os valores extremos de umidade $\left(0,365 \mathrm{~m}^{3} \mathrm{~m}^{-3}\right.$ para o ponto mais úmido e $0,336 \mathrm{~m}^{3} \mathrm{~m}^{-3}$ para o mais seco), ajustando-se esses a uma reta e determinando-se o coeficiente de determinação a partir deles, obtém-se um valor de $r^{2}$ igual a 1 . Concluise, portanto, que utilizar o coeficiente de determinação como único critério para a seleção de metodologias nem sempre é adequado.

Tabela 8. Índices para verificação da concordância entre as curvas de calibração obtidas pelos métodos direto e indireto para cada profundidade do solo em estudo

\begin{tabular}{|c|c|c|c|c|c|c|c|}
\hline \multirow{2}{*}{$\begin{array}{l}\text { Prof. } \\
(\mathrm{m})\end{array}$} & \multicolumn{6}{|c|}{ Índice } & \multirow[b]{2}{*}{ EAM } \\
\hline & d & $C D$ & EF & ME & RMSE & CRM & \\
\hline 0,40 & 0,121 & 0,006 & $-173,325$ & 0,150 & 41,48 & $-0,415$ & $-0,143$ \\
\hline 0,50 & 0,051 & 0,012 & $-94,254$ & 0,176 & 47,47 & $-0,474$ & $-0,159$ \\
\hline 0,60 & 0,758 & 0,126 & $-2,484$ & 0,123 & 26,22 & $-0,260$ & $-0,103$ \\
\hline 0,70 & 0,772 & 0,168 & $-1,574$ & 0,122 & 23,22 & $-0,226$ & $-0,089$ \\
\hline 0,80 & 0,897 & 0,277 & 0,142 & 0,085 & 16,47 & $-0,163$ & $-0,068$ \\
\hline 0,90 & 0,910 & 0,313 & 0,306 & 0,069 & 13,58 & $-0,134$ & $-0,055$ \\
\hline 1,00 & 0,720 & 0,111 & $-3,387$ & 0,065 & 16,09 & $-0,161$ & $-0,059$ \\
\hline 1,10 & 0,618 & 0,074 & $-7,048$ & 0,084 & 20,19 & $-0,201$ & $-0,074$ \\
\hline 1,20 & 0,794 & 0,173 & $-1,314$ & 0,093 & 18,50 & $-0,181$ & $-0,070$ \\
\hline
\end{tabular}

\subsubsection{Calibração do testador de cabos}

A maioria dos trabalhos encontrados na literatura que utilizam a técnica de TDR estão relacionados a calibração do equipamento e, normalmente, com o objetivo de encontrar uma equação universal, como a proposta por Topp et al. (1980). Em métodos empíricos, é incluido um grande número de variáveis como densidade do solo, textura, matéria orgânica, no sentido de abranger uma ampla faixa de solos com características as mais variadas, tornando a calibração às vezes complicada (Jacobsen \& Schjonning, 1993). Os modelos normalmente utilizados para a calibração são classificados como empíricos, ou seja, são apenas relações funcionais entre as 
variáveis, onde uma é dependente e as outras independentes. Tommaselli (1997) estudou vários modelos de calibração de TDR, dentre eles os modelos empíricos, semi-empíricos e os modelos físicos e encontrou que os modelos de regressão linear múltipla foram superiores a todos os outros, apresentando os maiores valores de coeficientes de correlação.

As curvas de calibração para este estudo foram obtidas através de pares de valores de umidade volumétrica, obtidos por tensiometria, e valores de Ka (Topp et al., 1980), onde o número de pares de pontos estudados variou de 11 a 18, dependendo da coincidência de horários de leituras existentes entre os tensiômetros e o testador de cabos. Para não introduzir erros devido a variabilidade espacial da umidade, utilizou-se tanto para a sonda de nêutrons quanto para o testador de cabos, as leituras dos equipamentos e o potencial mátrico, que pode ser correlacionada a umidade volumétrica, via curva de retenção.

Os gráficos de calibração do TDR para cada camada de solo, incluindo as repetições, encontram-se na Figura 31 (a distribuição das repetições no perfil do solo foi apresentada anteriormente, Figura 19, item Material e Métodos).

A equação de ajuste das curvas foi escolhida dentro de uma família de 107 equações diferentes, segundo critérios de facilidade de utilização da equação e valores dos coeficientes de determinação. Como os valores obtidos do coeficiente de determinação foram muito próximos daqueles obtidos pela curva que melhor se ajustou aos dados, optou-se pela utilização da equação linear de ajuste dos dados (ex.: para a camada de $1,00 \mathrm{~m}$, repetição 2 , a equação que melhor se ajustou aos dados foi do tipo potência com a forma $y=a+b x^{c}$ e $r^{2}$ igual a 0,832 e para a equação na forma linear o coeficiente obtido foi 0,792 ).

A análise das curvas de calibração do TDR possibilita a visualização das diferenças existentes nas repetições dos sensores de TDR, em uma mesma camada no solo. Uma provável explicação poderia ser a localização física dos sensores no perfil, podendo ter havido fluxo preferencial ao redor das hastes e dessa forma ocasionar diferenças nas leituras de Ka. Por ocasião da instalação da chapa galvanizada e dos sensores lateralmente a área experimental (Figuras 5 e 18, item Material e Métodos), foi aberta uma trincheira para instalação dos mesmos e coleta de 
amostras, seguida por recolocação do solo, o que pode ter proporcionado um caminho preferencial para a água, no sentido longitudinal aos sensores.
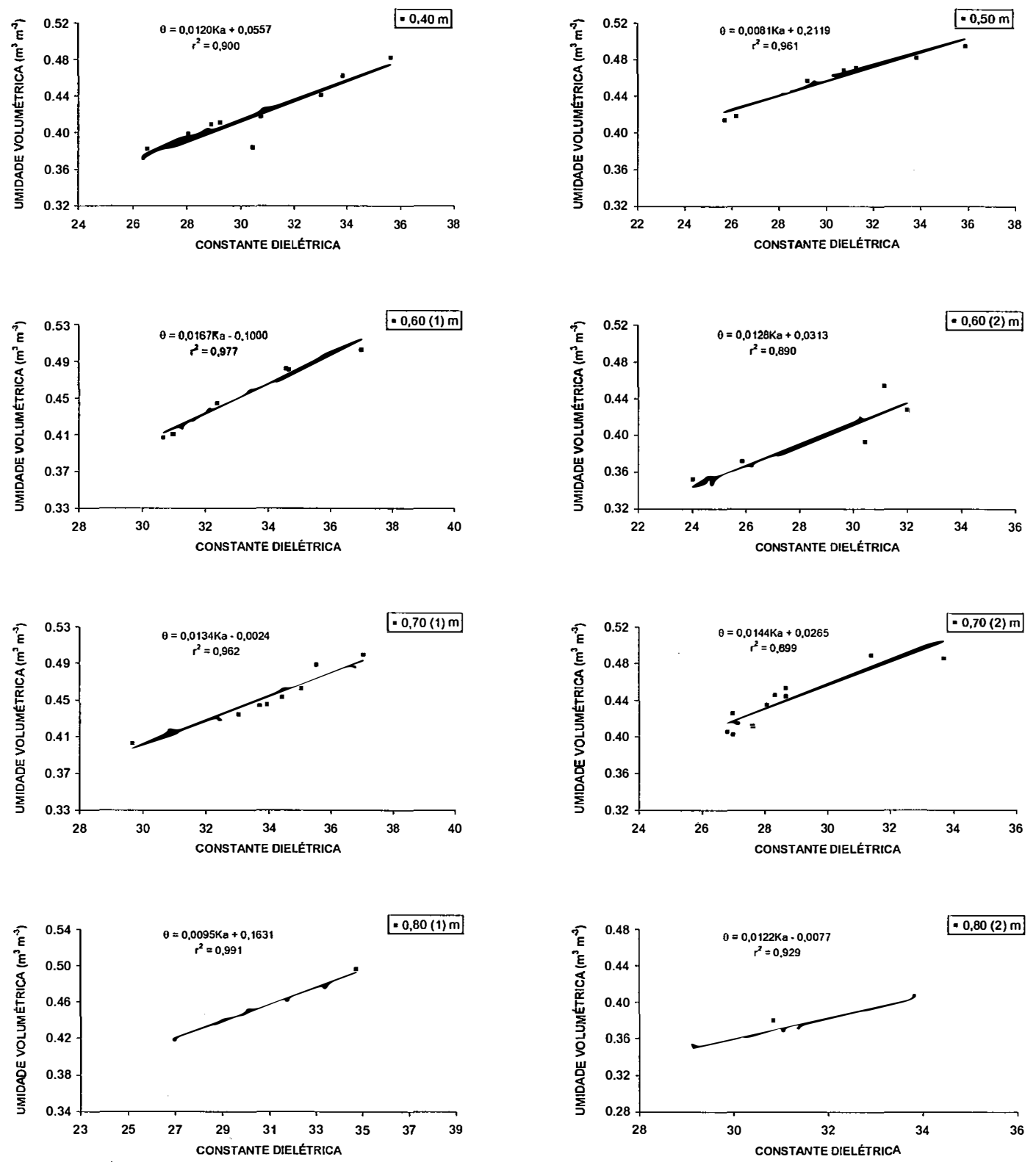

Figura 31 - Curvas de calibração para o TDR, obtidas para as diferentes profundidades do solo 

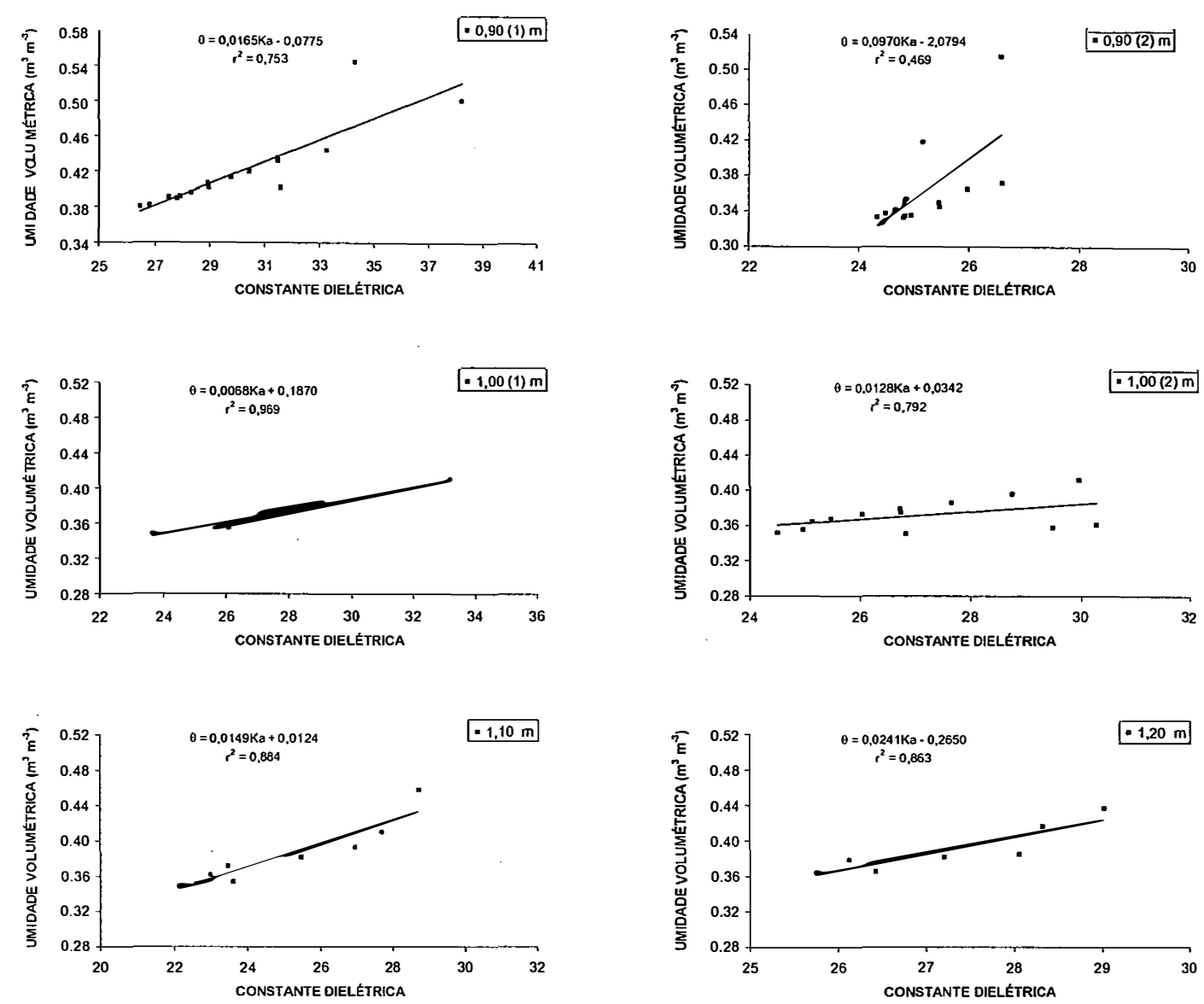

Figura 31 - Curvas de calibração para o TDR, obtidas para as diferentes profundidades do solo

Foram tomados os seguintes cuidados durante essa etapa: instalação dos sensores espaçados regularmente $(0,20 \mathrm{~m}$ na horizontal e $0,10 \mathrm{~m}$ na vertical), para evitar perturbação no solo; foi aguardado um tempo relativamente longo para acomodação dos equipamentos na área experimental (cerca de cinco meses) e também instalação dos sensores no sentido horizontal a fim de evitar justamente o fluxo preferencial que poderia ocorrer, principalmente neste solo com características expansivas, se fosse realizada a instalação na direção vertical. Mas mesmo tomando os cuidados acima não se dispõe de garantias de que não tenha havido infiltração preferencial por entre os sensores. Zegelin et al. (1989) detectaram esse problema de 
fluxo preferencial de água ao longo das hastes, o que reforça a problemática de análise de Ka em solos muito úmidos ou próximos a saturação.

É importante salientar que a introdução dos sensores pode causar uma perturbação no solo e por consequência nas medidas de umidade volumétrica obtidas. Segundo Rothe et al. (1997) os efeitos da alteração da estrutura variam em função da suscetibilidade do solo a compressão, tipo do sensor e teor de água no momento da instalação. Os autores observaram que apesar do sensor de três hastes apresentar uma reflexão do sinal com maior clareza, os efeitos da instalação aumentam com o diâmetro da haste e consideram que para a instalação de sondas com diâmetro maior do que $6 \mathrm{~mm}$, deve ser realizada a remoção do solo e após a introdução do sensor, principalmente em solos compressiveis e em altos conteúdos de água. No presente estudo não foi realizada uma avaliação das alterações causadas pela instalação do sensor na estrutura do solo, mas observou-se que o sensor utilizado é relativamente grande e, portanto, pode ter causado algum efeito na estrutura.

Analisando-se as curvas em geral, observa-se que na maioria dos casos, os coeficientes de determinação foram bons, com exceção da camada de 0,90 m, repetição 1, que alcançou o menor valor. Levin (1987) faz algumas considerações sobre o coeficiente de correlação, o qual expressa numericamente tanto a força quanto o sentido da correlação e propõe uma distribuição para classificar os coeficientes. Nessa classificação a maioria dos valores dos coeficientes de correlação obtidos pelas equações lineares apresentou valores de correlação entre positiva forte e positiva perfeita, com exceção das camadas de $0,90 \mathrm{~m}$, repetições 1 e 2 e de 1,00 m, repetição 2 , que apresentaram valores entre correlação positiva moderada e correlação positiva forte. Isso mostra que a equação linear ajustou-se satisfatoriamente aos dados experimentais.

Considerando-se as faixas de umidade alcançadas, observa-se que a camada de $0,90 \mathrm{~m}$ foi a que apresentou valores mais amplos, 0,38 a $0,50 \mathrm{~m}^{3} \mathrm{~m}^{-3}$ para a repetição 1 e de 0,33 a $0,52 \mathrm{~m}^{3} \mathrm{~m}^{-3}$ para a repetição 2 . Enquanto que a camada de $1,00 \mathrm{~m}$ foi a que apresentou a faixa de variação de umidade mais restrita, variando de 0,35 a $0,41 \mathrm{~m}^{3} \mathrm{~m}^{-3}$ para as repetições 1 e 2 . Essa variação de umidade observada entre a camada de 0,90 e a de $1,00 \mathrm{~m}$ pode estar relacionada a presença de horizontes geneticamente densos ("B textural") ou compactados em decorrência de seu 
manejo inadequado. Como a chapa galvanizada utilizada para o confinamento da parcela experimental atingiu uma profundidade de apenas $0,80 \mathrm{~m}$, a água proveniente da infiltração pode ter sido confinada na profundidade correspondente a camada de $0,90 \mathrm{~m}$, em função da existência da camada de impedimento. Este fato pode ter causado fluxo lateral e por consequência, dificuldade na saturação do perfil em camadas mais profundas. É possível verificar a localização do "B textural" na descrição morfológica do solo utilizado (Anexo B), onde o mesmo alcança a profundidade de $1,05 \mathrm{~m}$. Uma das possibilidades é que a variação do "B textural", confirmado por Costa \& Libardi (1999), que avaliaram a caracterização hídrica no mesmo solo em estudo pelo método do perfil instantâneo, onde o "B textural" encontrado, através da descrição morfológica, variou de 0,21 a 0,90 m. Conclui-se, portanto, que a utilização de chapas galvanizadas para o confinamento da área experimental deva alcançar camadas mais profundas ainda, principalmente em solos que apresentam problema de camada de impedimento, a fim de ultrapassá-la.

Convém ressaltar o comportamento diferenciado da repetição 2 da camada $0,90 \mathrm{~m}$, apresentando uma grande declividade, comparativamente as outras, onde a variação de Ka obtida foi em torno de 2 e a de umidade volumétrica a maior. Este fato pode estar relacionado a existência de dois pontos específicos que estão bastante fora do conjunto de dados. Caso estes pontos sejam excluídos, o coeficiente de determinação passaria de 0,469 para 0,755 , mas alteraria relativamente pouco a declividade e por conseguinte as faixas de $\mathrm{Ka}$ e de umidade volumétrica. Isto demonstra a grande variabilidade que pode ser encontrada em valores de Ka obtidos de sensores localizados bastante próximos (0,20 m um do outro).

Uma outra possibilidade para essa diferença é a localização eletrônica das repetições no sistema de multiplexação, ou seja, os sensores que representam as repetições no perfil do solo estão conectados em um mesmo multiplexador. Poder-seia "suspeitar" que os aumentos de impedância criados pela comunicação entre o nivel 1 de multiplexação e o nivel 2, seria uma possivel causa das diferenças encontradas, visto que sistemas eletrônicos são bastante sensiveis até mesmo a problemas de contato eletrônico entre os cabos e os terminais de conexão. Este fato associado ao comprimento do cabo coaxial de $50 \Omega$ utilizado, que foi de cerca de $30 \mathrm{~m}$, poderia ter contribuído para as dificuldades normalmente encontradas na reflexão do sinal, visto 
que Herkelrath et al. (1991) sugerem que o comprimento de cabos não deva ultrapassar $27 \mathrm{~m}$. Essa é uma questão interessante e que merece ser estudada, a fim de elucidar essas hipóteses ou então associar essas diferenças à própria variabilidade natural do solo em estudo.

\subsection{Condutividade hidráulica do solo não saturado}

Neste item serão discutidos alguns fatores que exercem papel fundamental na determinação da função $K(\theta)$, pelo método do perfil instantâneo e que podem proporcionar diferenças entre os equipamentos utilizados no aspecto de detecção ou não desses fatores, que incluem a questão da saturação da parcela experimental e a variabilidade nos valores de umidade volumétrica para cada equipamento utilizado. $O$ intuito é identificar possíveis variações que podem ser encontradas na condutividade hidráulica do solo não saturado a partir das diferenças encontradas nestes fatores.

\subsubsection{Saturação da parcela experimental}

Em estudos de movimento da água no solo é importante a obtenção de valores de umidade volumétrica que variem de uma faixa bastante úmida até valores mais baixos, a fim de que a função $K(\theta)$ obtida, atinja uma amplitude de faixas o mais ampla possível (Libardi, 2000). Um dos métodos bastante utilizados para a obtenção da função $K(\theta)$ é o do perfil instantâneo, tanto para condições de campo quanto de laboratório (Hillel et al., 1972). O método pressupõe que sejam satisfeitas algumas condições de contorno que exigem que a parcela experimental seja saturada e após, coberta com um plástico a fim de evitar perdas e entradas de água. A seguir são realizadas leituras de potencial mátrico e umidade do solo ao longo do processo de drenagem interna. Neste contexto, a saturação da parcela experimental é importante, mas nem sempre o procedimento adotado para a sua obtenção é realizado com sucesso. Mesmo sob condições de laboratório, onde a saturação normalmente é lenta; a imbebição pode ser realizada de baixo para cima; utilizando amostras indeformadas que possuem volume bem menor que o volume da parcela experimental no campo; a água utilizada para embebição é previamente deaerada, o processo, às vezes, pode apresentar dificuldades, como no presente caso (item 4.2.2) é de se supor que no 
campo esse problema se manifeste de forma muito mais acentuada, uma vez que quase nenhum dos cuidados anteriores pode ser observado. Arya et al. (1998) comentam que os valores de saturação obtidos em amostras de pequeno tamanho, são geralmente, maiores do que os valores observados sob condições de campo e Dirksen (1991) considera que estes valores observados no campo não ultrapassam $90 \%$ da porosidade total do solo.

Com o intuito de tentar diferenciar os desempenhos da sonda de nêutrons e do testador de cabos na detecção de diferenças na umidade durante o procedimento normalmente adotado no método do perfil instantậneo, foram realizadas várias inundações, como explicado anteriormente, no item Material e Métodos.

O momento adequado para o fechamento da parcela, referente a eleição do tempo zero, foi acompanhado pelas leituras dos manômetros de mercúrio dos tensiômetros, correspondentes ao potencial mátrico nulo. As leituras de altura de mercúrio encontram-se na Tabela 9.

Tabela 9. Valores de altura de coluna de mercúrio $\left(\mathrm{cm} \mathrm{H}_{\mathrm{g}}\right)$ correspondentes ao potencial mátrico nulo

\begin{tabular}{ccccc}
\hline \multirow{2}{*}{ Prof. } & \multicolumn{4}{c}{ Altura $\left(\mathrm{cm} \mathrm{H}_{\mathrm{g}}\right)$} \\
\cline { 2 - 5 } & $1^{\text {a }}$ Bateria & $2^{\text {a }}$ Bateria & $3^{\text {a }}$ Bateria & Média \\
\hline 0,40 & $-0,12$ & 0,23 & 0,31 & 0,14 \\
0,50 & 0,67 & 1,03 & 1,11 & 0,94 \\
0,60 & 1,46 & 1,82 & 1,90 & 1,73 \\
0,70 & 2,26 & 2,62 & 2,70 & 2,53 \\
0,80 & 3,05 & 3,41 & 3,49 & 3,32 \\
0,90 & 3,84 & 4,20 & 4,28 & 4,11 \\
1,00 & 4,64 & 5,00 & 5,08 & 4,91 \\
1,10 & 5,43 & 5,79 & 5,87 & 5,70 \\
1,20 & 6,23 & 6,58 & 6,66 & 6,49 \\
1,30 & 7,02 & 7,38 & 7,46 & 7,29 \\
\hline
\end{tabular}


As alturas nos manômetros de mercúrio foram obtidas através da eq. (11), atribuindo-se o valor zero ao potencial mátrico, correspondente a saturação. As variações de alturas observadas, para cada bateria de tensiômetros, estão relacionadas a localização diferenciada das cubas de mercúrio em relação a superfície do solo e diferenças na colocação das réguas para leitura.

Para estudar a evolução do processo de "saturação" é apresentado na Figura 32, um exemplo da variação do potencial mátrico com o tempo, onde as leituras de altura de coluna de mercúrio foram realizadas em horários antes e após cada inundação. Os valores obtidos referem-se a profundidade de 0,70 m, bateria 3 , antes do tempo zero, escolhida por ser a situação mais extrema em função da oscilação entre os valores de potencial mátrico antes e após cada inundação. Nota-se que a medida que se sucediam as inundações o potencial mátrico aos poucos ia se tornando próximo de zero, e não após uma inundação específica, indicando que o processo de saturação deve ser bastante lento. Foram necessários em torno de 125 horas, ou seja, 5 dias para que o potencial se tornasse positivo nessa profundidade.

Observa-se que a medida que se sucediam as inundações, ocorreram variações no potencial mátrico, às vezes relativamente grandes como, por exemplo, próximo ao tempo de 125 horas, onde o potencial em torno de $-1 \mathrm{kPa}$ rapidamente elevou-se para $3,5 \mathrm{kPa}$ e após uma tendência do valor do potencial de pressão final estabilizar com o tempo. Convém ressaltar ainda as mudanças bastante bruscas de um valor de potencial negativo para um positivo, o que, segundo Bruce \& Luxmmore (1986), provavelmente indica a existência de ar aprisionado nos poros do solo influenciado pelos procedimentos de aplicação de água, caso bastante comum em processo de saturação rápida. A existência de uma massa de ar ocasionada pelo processo de inundação rápida provavelmente faz com que as leituras fornecidas pelo tensiômetro sejam oriundas da influência dessa massa de ar e não de leituras de potencial mátrico alcançados na "saturação". Esse fato vem enfatizar os erros que normalmente são cometidos em inundações que duram apenas algumas horas, onde é suposto o alcance da saturação, o que nem sempre ocorre, proporcionando um movimento rápido da água no início do processo, a medida que ocorre a dissolução da massa de ar, e lento no final. A hipótese de que os tensiômetros são "enganados" pelas mudanças no potencial mátrico provenientes do efeito de massas de ar 
aprisionadas no solo durante o processo de "saturação", será também testada com o TDR, a fim de verificar se essas alterações são encontradas.

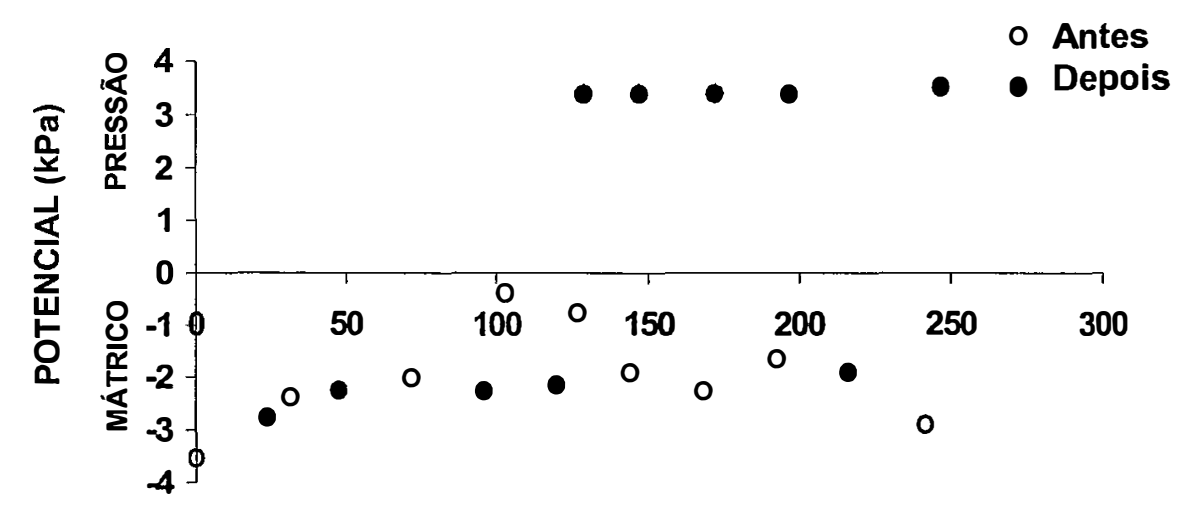

TEMPO (Horas)

Figura 32 - Variação dos potenciais mátrico e de pressão em função do tempo, obtida por tensiometria antes do fechamento da parcela, para a profundidade de $0,70 \mathrm{~m}$ (terceira bateria de tensiômetros)

A mesma hipótese foi confirmada por Guiberto (1999) que, estudando a drenagem interna em um outro solo e utilizando somente leituras de tensiômetros, verificou que a umidade inicial esteve entre 70 e $90 \%$ da porosidade total, possivelmente devido a existência de ar aprisionado e também a dificuldade na escolha do tempo zero, ou seja, fechamento da parcela e início das leituras. Segundo o autor, isso ocorreu principalmente devido às variações que ocorreram nas leituras de potencial, onde alguns tensiômetros de uma mesma bateria fornecem leituras de potencial mátrico e outros de pressão.

Analisando-se a situação sob o ponto de vista do TDR é possivel observar na Figura 33 a evolução do potencial mátrico com o tempo, obtida também para a camada de $0,70 \mathrm{~m}$, repetição 1 , durante a execução das inundações da parcela e, portanto, antes do fechamento da mesma. O tempo de leitura para os tensiômetros e o TDR foi diferente, uma vez que o sistema ainda não estava devidamente ajustado, ocorrendo uma simultaneidade de leituras entre 145 a 195 horas após a primeira inundação e antes do tempo zero. 


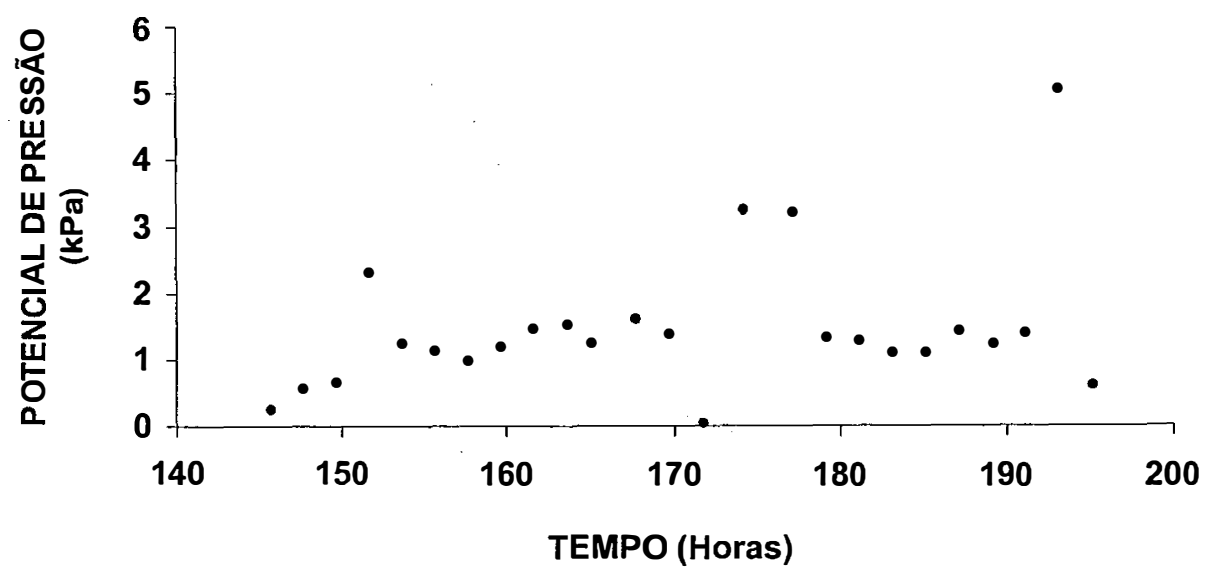

Figura 33 - Variação do potencial de pressão em função do tempo, obtida pelo TDR antes do fechamento da parcela, para a profundidade de $0,70 \mathrm{~m}$ (repetição 1)

Narfaixa de tempo estudado do TDR em comparação com a evolução do potencial mátrico obtida com o tensiômetro (Figura 32), para a mesma camada, observa-se que não houveram valores de potencial mátrico, somente de pressão. Pode-se supor pelo gráfico que o potencial assumiu valores positivos em torno de 145 horas, após o início da inundação, atingindo valores, em média, de 1,2 kPa com uma tendência a se manter constante, apesar de alguns valores apresentarem-se discrepantes.

Contudo, para os valores de potenciais lidos com o tensiômetro, essa transposição ocorreu em torno de 125 horas após o começo da inundação. Dirksen (1991) considera que, inicialmente, próxima a "saturação", a umidade volumétrica e o potencial mátrico devem ser medidos com bastante frequência devido a variações bastante rápidas com o tempo e, portanto a obtenção de resultados precisos torna-se difícil sem um sistema automático de aquisição de dados. Por outro lado, Tommaselli (1997) estudando a influência de algumas características do solo sobre a calibração de um TDR, encontrou uma grande variabilidade nos valores de $\mathrm{Ka}$ e portanto, na umidade volumétrica próximo à "saturação". O autor atribuiu esta alta variabilidade a provável formação de bolsas de ar ou de água ao redor das hastes portadoras do sinal do TDR, sendo uma dificuldade praticamente inerente à técnica. Esta hipótese torna-se bastante razoável, visto que os valores de Ka e 
consequentemente das umidades volumétricas obtidas com o TDR, representados na Figura 33, são bastante variáveis a medida que o processo de inundação é realizado, mas, no entanto, não atinge valores de potenciais negativos, como no caso do tensiômetro. Isto indica que o TDR em comparação ao tensiômetro, não consegue detectar as variações do potencial mátrico que ocorrem devido à existência da massa de ar aprisionado, ao longo do tempo de redistribuição. É coerente afirmar que o tensiômetro, para a camada de $0,70 \mathrm{~m}$, possui maior sensibilidade e resposta mais rápida do que o TDR, na detecção de diferenças de valores de potencial acompanhadas durante o processo de inundação.

\subsubsection{Sensibilidade dos equipamentos tensiômetro, testador de cabos e sonda de nêutrons na detecção da umidade do solo}

Dado o número de profundidades estudadas, as análises dos resultados e respectivas discussões, ficarão restritas às camadas correspondentes as profundidades de 0,70 e 1,00 m. As duas profundidades são bem representativas do processo, evitando portanto, a repetividade da discussão e como há repetições para o TDR, sonda e tensiômetros, pode-se comparar também a variabilidade entre elas.

A Figura 34 apresenta a variação da umidade volumétrica a partir do tempo zero, isto é, imediatamente após o fechamento da parcela com a lona plástica, até o final do experimento, para as três baterias de tensiômetros da camada de $0,70 \mathrm{~m}$. Os maiores valores de umidade volumétrica obtidos próximos ao tempo zero, foram 0,52 , 0,51 e $0,5.0 \mathrm{~m}^{3} \mathrm{~m}^{-3}$ para as baterias 1,2 e 3 , respectivamente. As três baterias de tensiômetros apresentaram valores de umidade volumétricas iguais a $0,40 \mathrm{~m}^{3} \mathrm{~m}^{-3}$ no final do experimento, e corresponderam a um tempo total de 1260 horas. Comparandose os maiores valores de umidade obtidos, para as três baterias, que teoricamente corresponderiam a saturação, com os obtidos pelo ajuste dos dados através do modelo de van Genuchten (1980) (Tabela 6), para a mesma camada, observa-se que os valores estiveram bastante próximos daqueles obtidos pelo ajuste que foi de $0,52 \mathrm{~m}^{3} \mathrm{~m}^{-3}$. Entretanto, para os valores referentes a umidade volumétrica residual, estes ficaram bem acima dos obtidos pelo ajuste, onde o valor encontrado foi de $0,25 \mathrm{~m}^{3} \mathrm{~m}^{-3}$. Isto evidencia a dificuldade encontrada em estudos de drenagem neste 
solo, onde o movimento é bastante lento, fato também observado por Jong van Lier \& Libardi (1999).
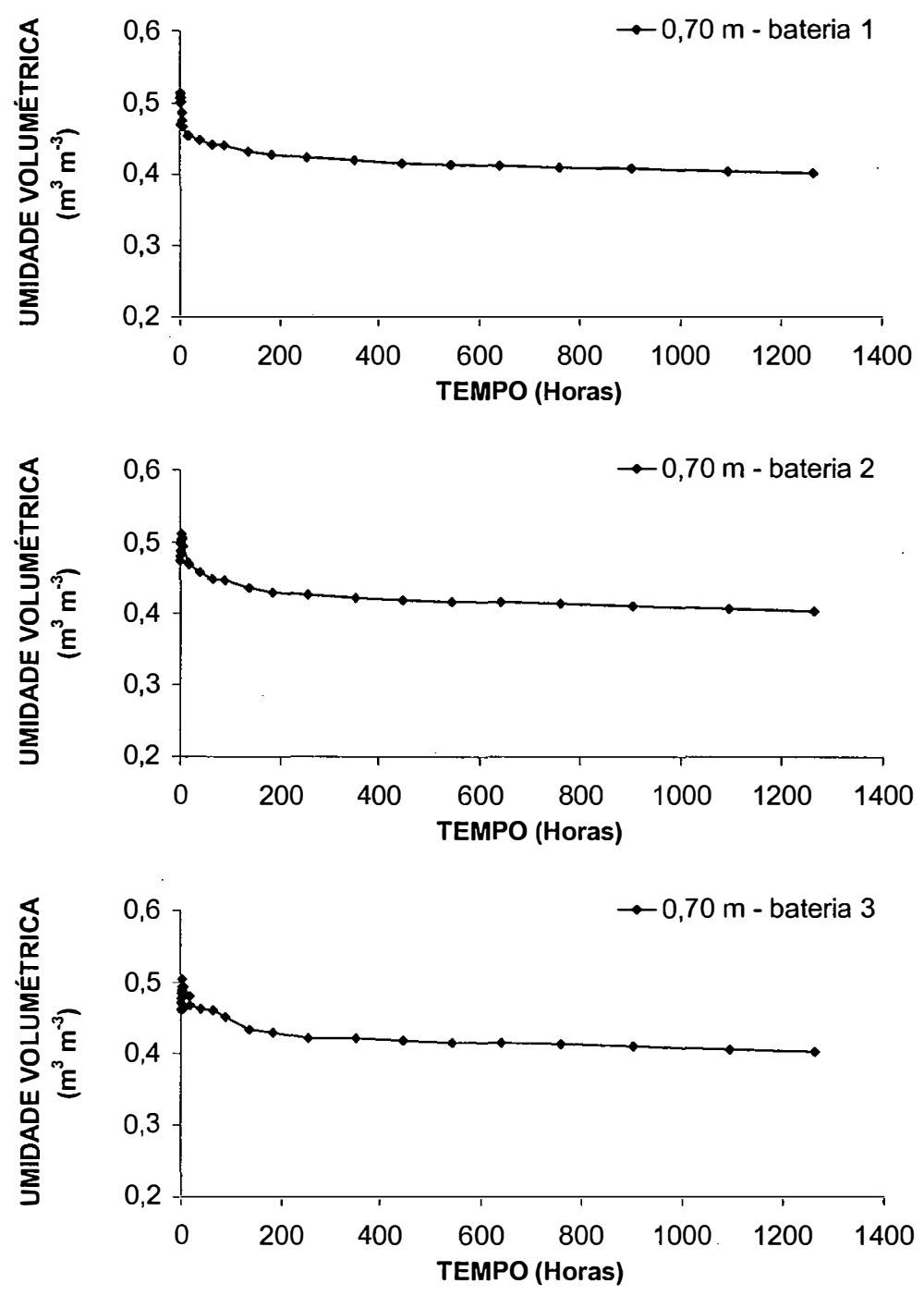

Figura 34 - Variação da umidade volumétrica com o tempo para as três baterias de tensiômetros, profundidade de 0,70 m

Observa-se que das três baterias estudadas, a terceira apresentou uma pequena oscilação da umidade nos tempos iniciais do processo de redistribuição. Essa variação ocorreu devido provavelmente, ao nivelamento não uniforme do solo na parcela experimental por ocasião da instalação do experimento, fato verificado visualmente durante as sucessivas inundações realizadas. 
Analisando-se a camada correspondente a 1,00 m, a Figura 35 apresenta a variação da umidade volumétrica a partir do tempo zero até o final do experimento. Ao contrário do que ocorreu para a camada de $0,70 \mathrm{~m}$, os valores de umidade obtidos, correspondentes ao tempo zero, $0,43,0,43$ e $0,52 \mathrm{~m}^{3} \mathrm{~m}^{-3}$, para as baterias 1,2 e 3 , respectivamente, estiveram abaixo dos estimados pelo ajuste proposto por van Genuchten (1980), que foi $0,55 \mathrm{~m}^{3} \mathrm{~m}^{-3}$. Da mesma forma ocorreu para as umidades ao final do experimento, cujos valores encontrados foram $0,35 \mathrm{~m}^{3} \mathrm{~m}^{-3}$ para as três baterias de tensiômetros, valores maiores que os estimados pelo ajuste que foi de $0,23 \mathrm{~m}^{3} \mathrm{~m}^{-3}$.

O fato de não ter ocorrido um bom nivelamento na parcela experimental, por ocasião da instalação do experimento, manifestou-se também na camada de 1,00 m, onde os valores de umidade volumétrica obtidos no tempo zero foram $21 \%$ maiores na terceira bateria quando comparada as demais.

Comparando-se as camadas entre si, pode-se supor, pelos valores obtidos através do ajuste de dados de van Genuchten (1980), que não ocorreu a saturação, apesar das leituras dos manômetros de mercúrio terem indicado que houve. Este fato vem confirmar a hipótese levantada no item anterior (item 4.4.1) sobre a existência de ar aprisionado no solo. A comparação da sensibilidade instrumental coloca agora a questão de se o testador e a sonda de nêutrons apresentaram o mesmo tipo de comportamento.

Considerando-se as leituras de umidade volumétrica obtidas pela sonda de nêutrons, observa-se na Figura 36, a variação da umidade com o tempo para os três tubos de acesso para a profundidade de $0,70 \mathrm{~m}$. Os valores de umidade volumétrica obtidos no tempo zero para os tubos 1,2 e 3 foram, respectivamente, 0,56, 0,57 e $0,57 \mathrm{~m}^{3} \mathrm{~m}^{-3}$, sendo superiores ao valor estimado pelo ajuste que foi de $0,52 \mathrm{~m}^{3} \mathrm{~m}^{-3}$. Provavelmente esses maiores valores de umidade estão relacionados a maior densidade do solo nessa profundidade, que foi de $1310 \mathrm{~kg} \mathrm{~m}^{-3}$ (Tabela 4). Para Turatti et al. (1990) a sonda de nêutrons amostra diferentes volumes do solo, variando em função do tipo de solo, da distribuição da densidade do solo e da umidade, tornando o uso da mesma dependente da variabilidade dessas características. Para a umidade volumétrica ao final do experimento, os valores encontrados foram $0,37,0,32$ e $0,35 \mathrm{~m}^{3} \mathrm{~m}^{-3}$ acima, portanto, do estimado pelo ajuste que foi de $0,25 \mathrm{~m}^{3} \mathrm{~m}^{-3}$. 
Observando-se os valores de porosidade total calculados a partir da relação PT $=1-\rho / \rho_{\mathrm{s}}$ (Tabela 10), verifica-se que os valores de umidade correspondentes a saturação foram maiores do que os calculados pela porosidade, para a camada correspondente a profundidade de 0,70 m. Para a profundidade de $1,00 \mathrm{~m}$ os valores obtidos na saturação estiveram bastante próximos dos calculados pela porosidade. $A$ superação da porosidade total calculada pelo $\theta_{\mathrm{s}}$ estimado, ou os valores não atingidos de $\theta_{r}$ pelos instrumentos utilizados não é de se estranhar, uma vez que estes parâmetros não necessariamente possuem significado físico desejado, podendo inclusive o $\theta_{\mathrm{r}}$ atingir valores negativos. Já a superação do valor da curva de retenção a partir da tensiometria leva a suspeitar de compactação na amostragem, que poderia ter causado um aumento da densidade do solo e, portanto, diminuição da porosidade total.

Tabela 10. Valores médios e coeficientes de variação da porosidade total calculada, para as diferentes camadas do perfil em estudo

\begin{tabular}{ccc}
\hline $\begin{array}{c}\text { Prof. } \\
(\mathrm{m})\end{array}$ & $\begin{array}{c}\text { Porosidade total } \\
\left(\mathrm{m}^{3} \mathrm{~m}^{-3}\right)\end{array}$ & $\begin{array}{c}\text { C.V. } \\
(\%)\end{array}$ \\
\hline $0-0,40$ & 0,493 & 3,0 \\
$0,40-0,50$ & 0,524 & 6,7 \\
$0,50-0,60$ & 0,464 & 5,2 \\
$0,60-0,70$ & 0,423 & 5,0 \\
$0,70-0,80$ & 0,404 & 5,3 \\
$0,80-0,90$ & 0,379 & 3,6 \\
$0,90-1,00$ & 0,466 & 7,1 \\
$1,00-1,10$ & 0,465 & 1,2 \\
$1,10-1,20$ & 0,437 & 2,8 \\
$1,20-1,30$ & 0,455 & 0,8 \\
\hline
\end{tabular}

Os valores são médias de três repetições.

Analisando-se a Figura 37, profundidade de $1,00 \mathrm{~m}$, observa-se que para a umidade relativa a saturação, os valores obtidos com a sonda de nêutrons, para os três tubos de acesso, ficaram em torno de $0,49 \mathrm{~m}^{3} \mathrm{~m}^{-3}$, valores subestimados em relação ao valor obtido pelo ajuste adotado, que foi de $0,55 \mathrm{~m}^{3} \mathrm{~m}^{-3}$. Para as umidades relativas ao final do experimento os valores encontrados $0,37,0,35$ e $0,35 \mathrm{~m}^{3} \mathrm{~m}^{-3}$, para os tubos 
1,2 e 3 , respectivamente, foram maiores do que o fornecido pelo ajuste que foi de $0,23 \mathrm{~m}^{3} \mathrm{~m}^{-3}$.

Há que se destacar ainda uma certa instabilidade nas leituras da sonda de nêutrons na camada correspondente a $0,70 \mathrm{~m}$, que talvez possa ser melhor identificada na repetição 3 , tanto da sonda de nêutrons quanto do tensiômetro.
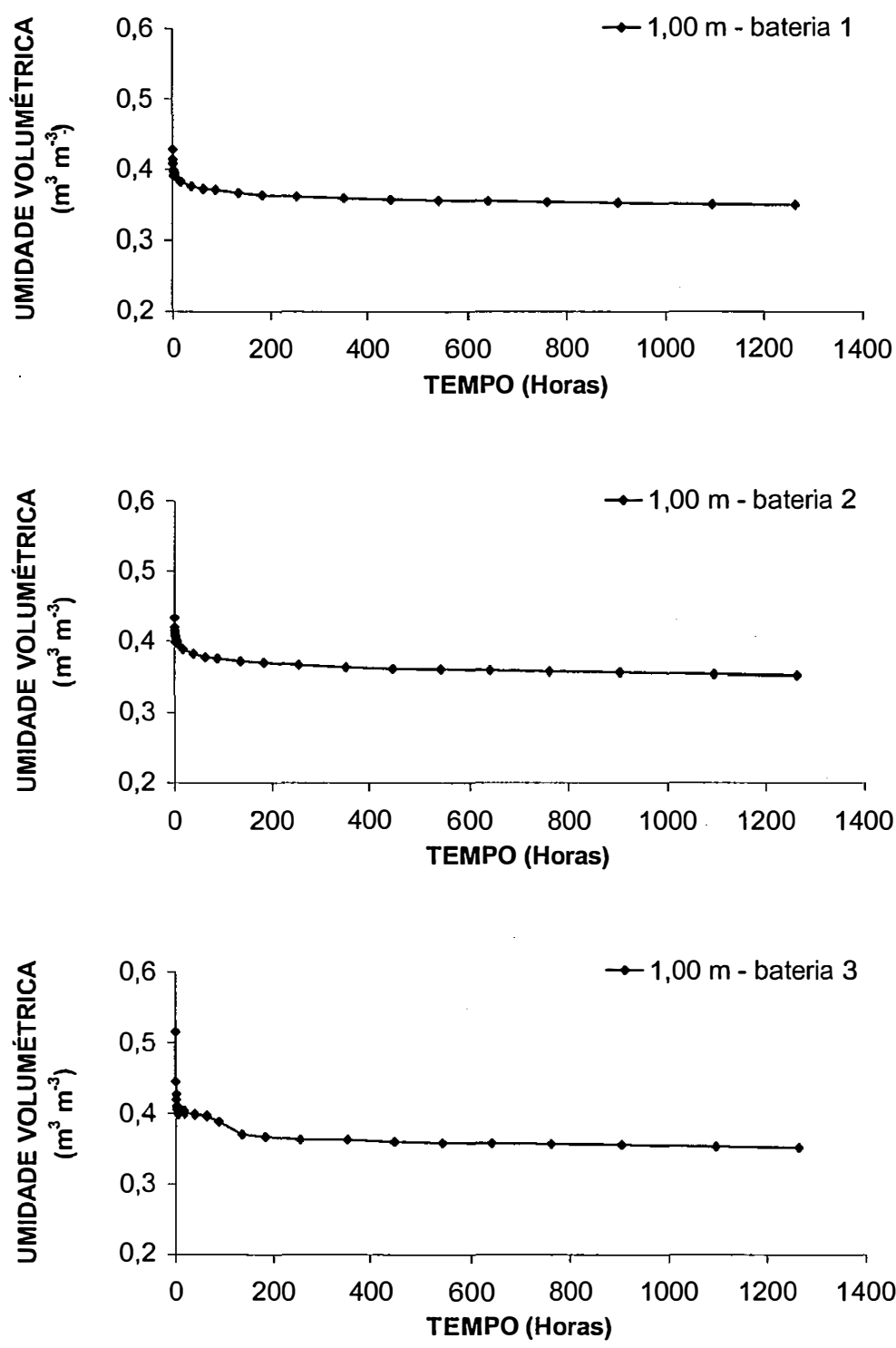

Figura 35 - Variação da umidade volumétrica com o tempo para as três baterias de tensiômetros, profundidade de $1,00 \mathrm{~m}$ 

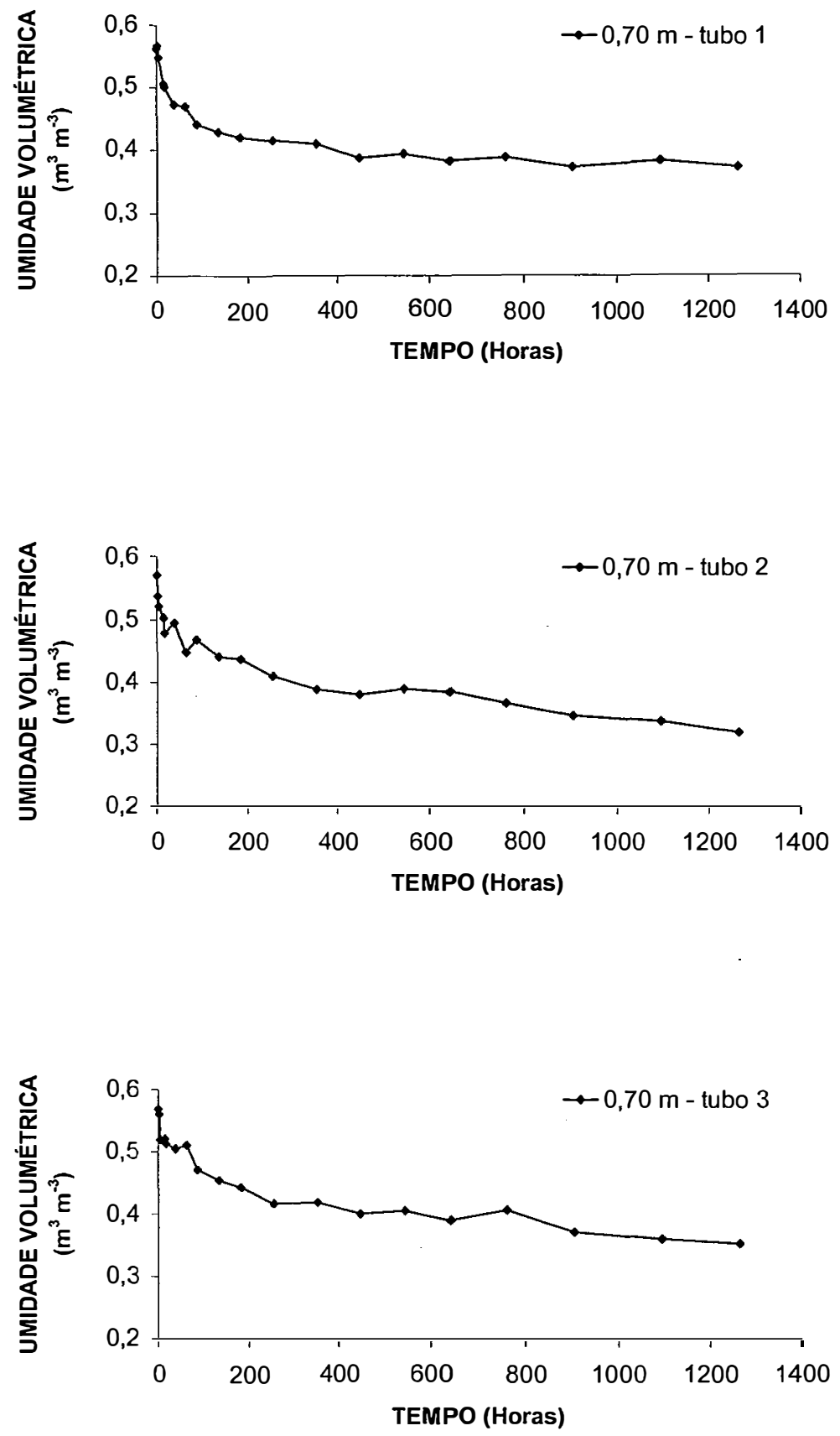

Figura 36 - Variação da umidade volumétrica com o tempo para os três tubos de acesso da sonda de nêutrons, profundidade de $0,70 \mathrm{~m}$ 

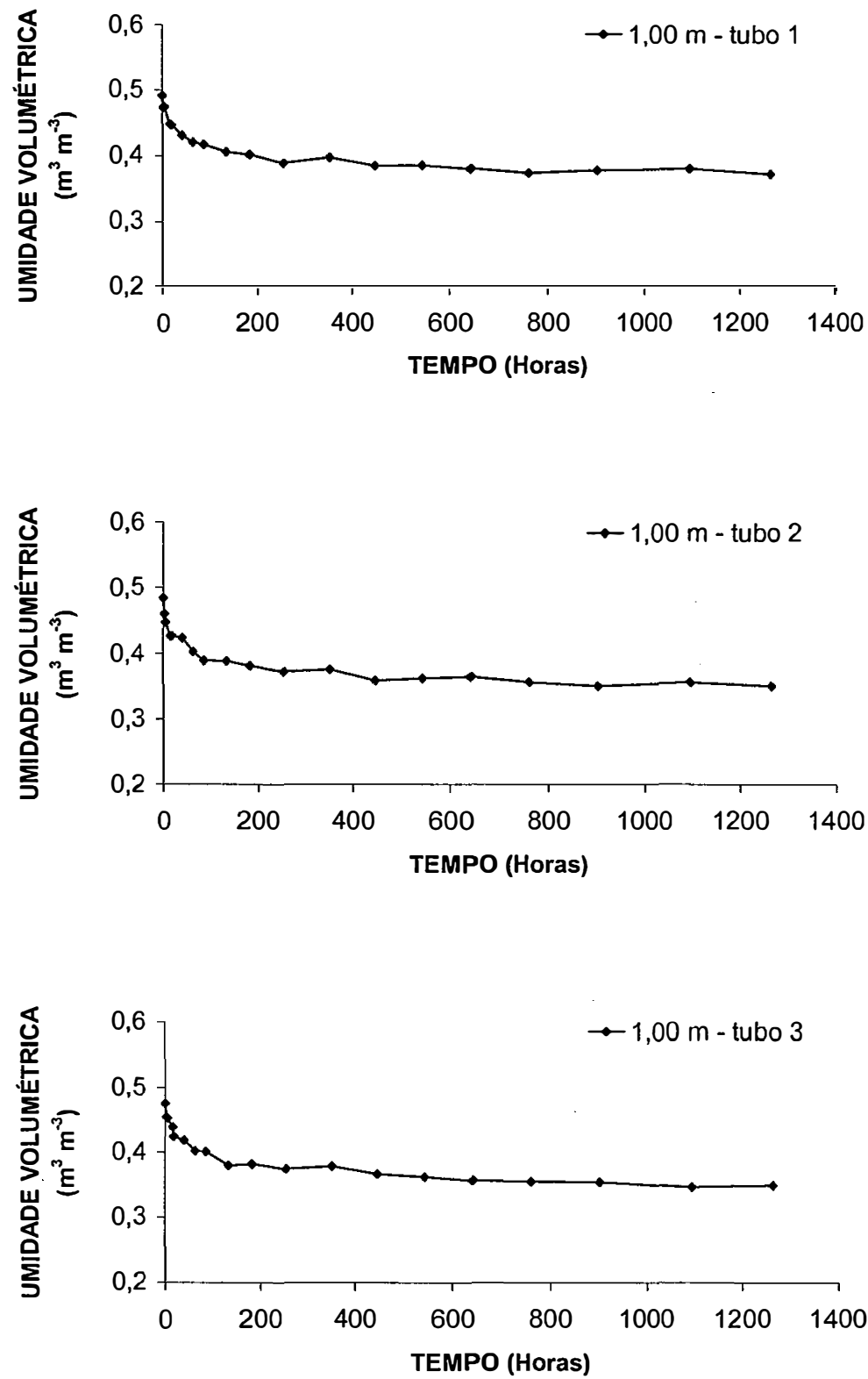

Figura 37 - Variação da umidade volumétrica com o tempo para os três tubos de acesso da sonda de nêutrons, profundidade de 1,00 m

Considerando-se as leituras de umidade volumétrica obtidas pelo TDR, observa-se na Figura 38, a variação da umidade com o tempo para os dois sensores da profundidade de $0,70 \mathrm{~m}$. Os valores de umidade volumétrica obtidos no tempo zero para os sensores 1 e 2 foram, respectivamente, 0,49 e 0,51 $\mathrm{m}^{3} \mathrm{~m}^{-3}$, sendo bastante próximos ao valor estimado pelo ajuste que foi de $0,52 \mathrm{~m}^{3} \mathrm{~m}^{-3}$. Para a umidade 
volumétrica ao final do experimento, os valores encontrados foram $0,40 \mathrm{~m}^{3} \mathrm{~m}^{-3}$ para os dois sensores, cujos valores ficaram acima do estimado pelo ajuste que foi de $0,25 \mathrm{~m}^{3} \mathrm{~m}^{-3}$. A falta de dados de umidade volumétrica observados entre os tempos de 800 e 1000 horas, para as duas profundidades e repetições (Figuras 38 e 39), correspondem a falha nas leituras da constante dielétrica, devido a um travamento ocorrido no "datalogger", do qual não se pode identificar a causa.
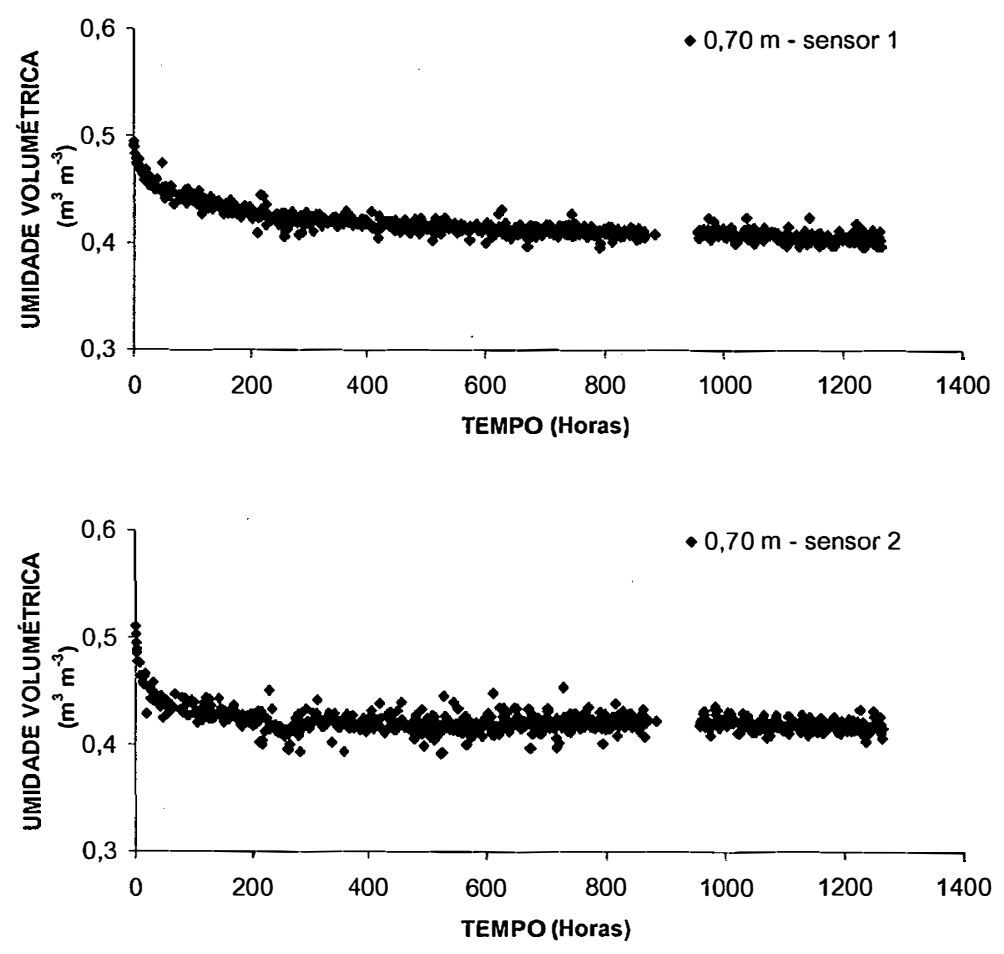

Figura 38 - Variação da umidade volumétrica com o tempo para os dois sensores de TDR, profundidade de $0,70 \mathrm{~m}$

A Figura 39 apresenta a variação da umidade volumétrica para os dois sensores de TDR para a camada de $1,00 \mathrm{~m}$. Os valores de umidade volumétrica obtidos no tempo zero para os sensores 1 e 2 foram, respectivamente, 0,41 e $0,42 \mathrm{~m}^{3} \mathrm{~m}^{-3}$, sendo inferiores ao valor estimado pelo ajuste que foi de $0,55 \mathrm{~m}^{3} \mathrm{~m}^{-3}$. Para a umidade volumétrica ao final do experimento, os valores encontrados foram $0,35 \mathrm{~m}^{3} \mathrm{~m}^{-3}$ e $0,38 \mathrm{~m}^{3} \mathrm{~m}^{-3}$ para os sensores 1 e 2 , respectivamente, cujos valores ficaram acima do estimado pelo ajuste que foi de $0,23 \mathrm{~m}^{3} \mathrm{~m}^{-3}$. A mesma observação 
feita para a sonda de nêutrons quanto as umidades máximas e mínimas atingidas, $\theta_{\mathrm{s}}$, $\theta_{\mathrm{r}}$ e porosidade total valem para o TDR.

Ressaltem-se as diferenças encontradas nas repetições dos sensores do TDR para uma mesma camada, por exemplo a correspondente a 1,00 m (Figura 39) onde se observa um maior espalhamento nos dados. Apesar desse espalhamento relativamente grande do sensor 2 em relação ao 1, os valores extremos de umidade volumétrica estiveram bastante próximos dos obtidos para o sensor 1 .
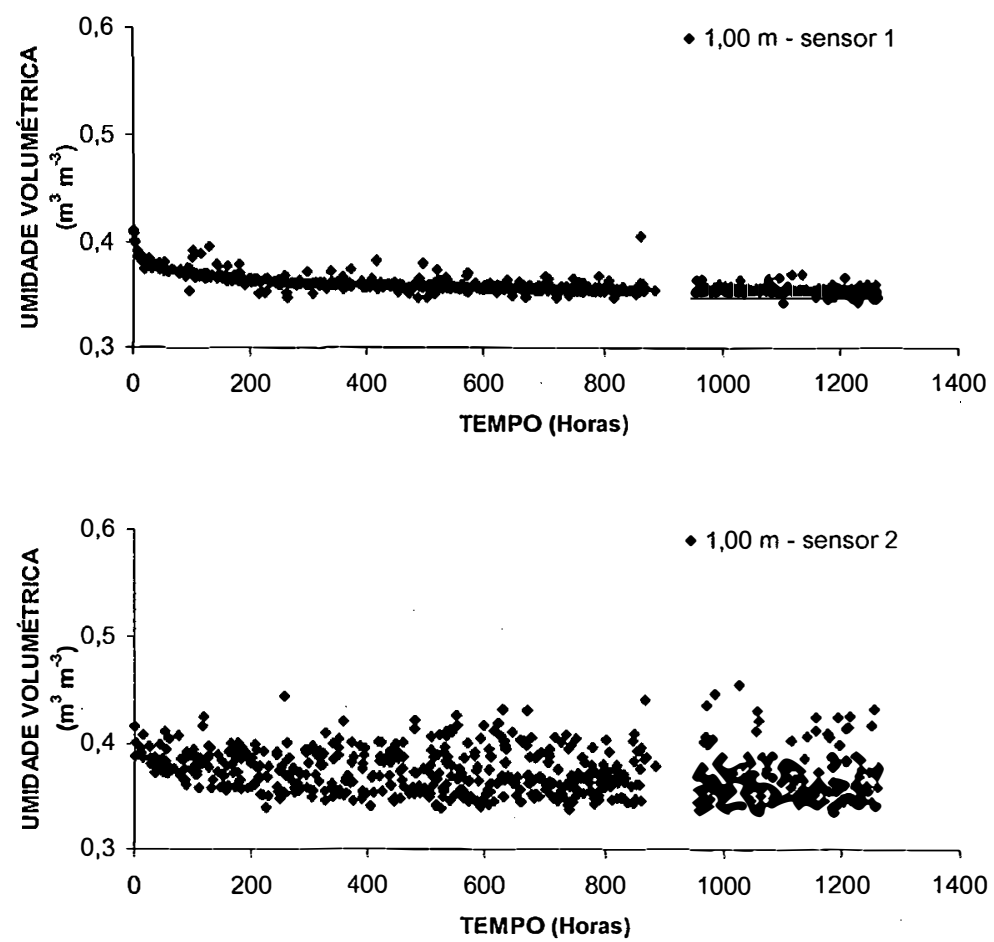

Figura 39 - Variação da umidade volumétrica com o tempo para os dois sensores de TDR, profundidade de $1,00 \mathrm{~m}$

Analisando-se agora o comportamento dos três equipamentos utilizados para a obtenção da umidade volumétrica média e adotando-se as leituras obtidas pelo tensiômetro como padrão, tem-se na Tabela 11, que para a camada correspondente a profundidade de $0,70 \mathrm{~m}$, o TDR apresentou valores bastante próximos, tanto para as altas umidades quanto para as baixas. Entretanto, a sonda de nêutrons superestimou 
os valores de umidade volumétrica na saturação e subestimou os valores obtidos no final do experimento.

Tabela 11. Valores médios de umidade volumétrica máximos $\left(\theta_{\text {máx }}\right)$ e mínimos $\left(\theta_{\min }\right)$ obtidos pelos diferentes equipamentos

\begin{tabular}{lccc}
\hline \multirow{2}{*}{ Equipamento } & Profundidade & $\theta_{\text {máx }}$ & $\theta_{\text {min }}$ \\
\cline { 2 - 4 } & $(\mathrm{m})$ & \multicolumn{2}{c}{$\left(\mathrm{m}^{3} \mathrm{~m}^{-3}\right)$} \\
\hline Tensiômetro & 0,70 & 0,51 & 0,40 \\
Sonda de Nêutrons & & 0,57 & 0,35 \\
TDR & & 0,50 & 0,40 \\
& \multirow{2}{*}{1,00} & & \\
Tensiômetro & & 0,46 & 0,35 \\
Sonda de Nêutrons & & 0,49 & 0,36 \\
TDR & & 0,41 & 0,37 \\
\hline
\end{tabular}

Para a camada correspondente a profundidade de 1,00 m, observa-se que na umidade de saturação, a sonda de nêutrons apresentou valores mais próximos aos obtidos pelos tensiômetros do que o TDR. Os valores de umidade volumétrica obtidos na saturação foram superestimados pela sonda, enquanto que na umidade verificada ao final do experimento, praticamente não houve variação entre os equipamentos utilizados.

Para verificar a influência das diferenças de leitura dos instrumentos sobre a propriedade condutividade hidráulica do solo não saturado, utilizou-se a eq. (10) e também a relação $K_{r}=K(\theta) / K_{\text {sat }}$ para as umidades correspondentes aos tempos de leituras de 200, 400,600, 800, 1000 e 1200 horas, a partir do tempo zero.

Observa-se nas Tabelas 12 e 13 os valores de $K(\theta)$ obtidos para cada equipamento nas profundidades de 0,70 e 1,00 m. Os valores encontrados foram mais discrepantes na profundidade da camada correspondente a $0,70 \mathrm{~m}$, enquanto que para a profundidade de $1,00 \mathrm{~m}$, os valores de $\mathrm{K}(\theta)$, em geral, apresentaram a mesma ordem de grandeza. 
Considerando-se a camada correspondente a profundidade de 0,70 m, tempo de $200 \mathrm{~h}$, verifica-se na Tabela 12, que os valores de $K(\theta)$ encontrados foram $4,60 \cdot 10^{-8}, 7,50 \cdot 10^{-8}$ e 2,60 $\cdot 10^{-8} \mathrm{~m} \mathrm{~s}^{-1}$, para o tensiômetro, sonda de nêutrons e TDR, respectivamente. Prevedello (1987), no mesmo solo, profundidade e tempo encontrou $6,13 \cdot 10^{-9} \mathrm{~m} \mathrm{~s}^{-1}$. Nota-se, portanto, que os valores da função $K(\theta)$ encontrados foram superestimados pelos equipamentos utilizados, quando comparados ao valor obtido pelo referido autor.

Os valores de $\mathrm{K}(\theta)$ obtidos para os três equipamentos, na profundidade correspondente a $1,00 \mathrm{~m}$, podem ser comparados aos obtidos por Saunders et al. (1978), considerando o mesmo solo, profundidade de 1,20 m, utilizando sonda de nêutrons e a função $K(\theta)$ obtida pelo método do perfil instantâneo. Para o tempo de $200 \mathrm{~h}$, os valores de $\mathrm{K}(\theta)$ encontrados foram $6,31.10^{-10}, 5,28 \cdot 10^{-9}$ e $1,84.10^{-9} \mathrm{~m} \mathrm{~s}^{-1}$, para o tensiômetro, sonda de nêutrons e TDR, respectivamente, enquanto que para Saunders et al. (1978), para o mesmo tempo foi $3,36 \cdot 10^{-9} \mathrm{~m} \mathrm{~s}^{-1}$, com uma umidade volumétrica média de $0,339 \mathrm{~m}^{3} \mathrm{~m}^{-3}$. Nota-se que a sonda de nêutrons apresentou valor de $K(\theta)$ da mesma ordem de grandeza citado pelos autores, seguida do TDR e por último o tensiômetro.

Com o objetivo de quantificar as diferenças entre as condutividades hidráulicas do solo não saturado, foram utilizados os mesmo índices estatísticos citados no item 4.3.1: Índice de concordância (d) (Willmott et al., 1985), Coeficiente de determinação $(C D)$, Eficiência $(E F)$, Erro máximo $(M E)$, Raiz quadrada do erro médio quadrático normalizado (RMSE), Coeficiente de massa residual (CRM) e Erro absoluto médio ( $E A M)$ (Zacharias et al., 1996). Uma perfeita concordância entre a eficiência dos equipamentos testados resultaria em $d=C D=E F=1$ e $M E=R M S E=C R M=E A M=$ 0 . Para a comparação foram utilizados os valores de $K(\theta)$ entre o tensiômetro, tomado como padrão, e a sonda de nêutrons e entre o tensiômetro e o TDR, considerando as profundidades de 0,70 e 1,00 m. A Tabela 14 apresenta os dados da análise para as profundidades de interesse.

Comparando-se os índices estatísticos utilizados, observa-se na Tabela 14 que, de modo geral, para a profundidade de $0,70 \mathrm{~m}$, o TDR apresentou um comportamento mais próximo ao obtido pelo tensiômetro, quando comparado a sonda 
de nêutrons. Em contrapartida, para a profundidade de 1,00 m, observa-se que os indices que apresentaram valores mais próximos aos necessários para uma perfeita concordância, foram os obtidos pela interação tensiômetro e sonda de nêutrons.

Tabela 12. Condutividade hidráulica do solo não saturado $(K(\theta))$ obtida para os três equipamentos, correspondente a profundidade de $0,70 \mathrm{~m}$

\begin{tabular}{cccc}
\hline & \multicolumn{3}{c}{$\mathrm{K}(\theta)-\left(\mathrm{m} \mathrm{s}^{-1}\right)$} \\
\cline { 2 - 4 } Tempo $(\mathrm{h})$ & Tensiômetro & Sonda de Nêutrons & TDR \\
\hline 200 & $4,60 \cdot 10^{-8}$ & $7,50 \cdot 10^{-8}$ & $2,60 \cdot 10^{-8}$ \\
400 & $1,90 \cdot 10^{-8}$ & $1,97 \cdot 10^{-9}$ & $2,39 \cdot 10^{-8}$ \\
600 & $1,47 \cdot 10^{-8}$ & $1,02 \cdot 10^{-9}$ & $1,26 \cdot 10^{-8}$ \\
800 & $1,29 \cdot 10^{-8}$ & $2,77 \cdot 10^{-9}$ & $1,27 \cdot 10^{-8}$ \\
1000 & $6,81 \cdot 10^{-9}$ & $2,39 \cdot 10^{-10}$ & $1,73 \cdot 10^{-8}$ \\
1200 & $5,25 \cdot 10^{-9}$ & $7,99 \cdot 10^{-11}$ & $8,85 \cdot 10^{-9}$ \\
\hline
\end{tabular}

Tabela 13. Condutividade hidráulica do solo não saturado $(K(\theta))$ obtida para os três equipamentos, correspondente a profundidade de $1,00 \mathrm{~m}$

\begin{tabular}{cccc}
\hline & \multicolumn{3}{c}{$\mathrm{K}(\theta)-\left(\mathrm{m} \mathrm{s}^{-1}\right)$} \\
\cline { 2 - 4 } Tempo $(\mathrm{h})$ & Tensiômetro & Sonda de Nêutrons & TDR \\
\hline 200 & $6,31 \cdot 10^{-10}$ & $5,28 \cdot 10^{-9}$ & $1,84 \cdot 10^{-9}$ \\
400 & $2,88 \cdot 10^{-10}$ & $1,26 \cdot 10^{-9}$ & $1,28 \cdot 10^{-10}$ \\
600 & $2,29 \cdot 10^{-10}$ & $8,96 \cdot 10^{-10}$ & $1,80 \cdot 10^{-10}$ \\
800 & $1,99 \cdot 10^{-10}$ & $4,75 \cdot 10^{-10}$ & $6,01 \cdot 10^{-9}$ \\
1000 & $1,33 \cdot 10^{-10}$ & $6,82 \cdot 10^{-10}$ & $6,29 \cdot 10^{-10}$ \\
1200 & $1,16 \cdot 10^{-10}$ & $3,42 \cdot 10^{-10}$ & $7,34 \cdot 10^{-10}$ \\
\hline
\end{tabular}


Tabela 14. Índices para verificação da concordância entre as condutividades hidráulicas obtidas para as profundidades de 0,70 e 1,00 m considerando as interações entre os equipamentos

\begin{tabular}{ccccc}
\hline \multirow{2}{*}{ Índices } & \multicolumn{2}{c}{ Tensiômetro $\times$ Sonda de Nêutrons } & \multicolumn{2}{c}{ Tensiômetro $\times$ TDR } \\
\cline { 2 - 5 } & $0,70 \mathrm{~m}$ & $1,00 \mathrm{~m}$ & $0,70 \mathrm{~m}$ & $1,00 \mathrm{~m}$ \\
\hline $\mathrm{d}$ & 0,116 & 0,204 & 0,415 & 0,058 \\
$\mathrm{CD}$ & 0,00324 & 0,00716 & 2,76495 & 0,00529 \\
$\mathrm{EF}$ & $-290,33$ & $-125,52$ & $-0,39$ & $-191,81$ \\
$\mathrm{ME}$ & $7,06.10^{-7}$ & $4,66.10^{-9}$ & $4,31.10^{-8}$ & $5,83.10^{-9}$ \\
$\mathrm{RMSE}$ & 782,93 & 393,29 & 54,07 & 485,51 \\
$\mathrm{CRM}$ & $-4,287$ & $-3,527$ & 0,316 & $-3,829$ \\
EAM & $-4,44.10^{-8}$ & $-0,50 \cdot 10^{-9}$ & $3,27 \cdot 10^{-9}$ & $-5,41.10^{-10}$ \\
\hline$d=1$ & $C D=1 \quad E F=1$ & $M E=0$ & RMSE $=0 \quad$ CRM $=0$ & $E A M=0$
\end{tabular}




\section{CONCLUSÕES}

A partir dos resultados obtidos pode-se concluir que:

- A utilização de material metálico reciclado e dispositivos convencionais de proteção permitiu obter um aterramento do aparato testador de cabos, "datalogger" e multiplexadores dentro de padrões internacionais de segurança $\left(R_{\text {terra }} \leq 5 \Omega\right)$ e ao mesmo tempo realizar a blindagem eletromagnética sem custo adicional;

- A utilização de um método indireto usando tensiômetros e curvas de retenção para a obtenção de curvas de calibração de sonda de nêutrons não se mostrou, em geral, adequado para substituir o método direto;

- O testador de cabos não apresentou a mesma sensibilidade dos tensiômetros na detecção de bolsões de ar (oscilações entre potencial de pressão e mátrico), durante o processo de embebição do solo, como preparação para aplicação do método do perfil instantâneo para determinação da condutividade hidráulica do solo;

- Embora o TDR apresente como grande vantagem a possibilidade de automatização das medições, o experimento não permitiu concluir pela sua superioridade na obtenção de valores de umidade para monitoramento da condutividade hidráulica do solo não saturado ao longo do tempo, a não ser pelo fato da automação em si. 
ANEXOS 
ANEXO A - Subsídios para compreensão do princípio de funcionamento do TDR

\section{- Corrente, Tensão e Resistência}

O movimento de elétrons num material condutor constitui uma corrente elétrica (I), definida como a razão instantânea com a qual uma carga $(Q)$ passa por uma determinada área do condutor, ou seja,

$$
I=\frac{d Q}{d t}
$$

A corrente elétrica é medida em coulombs por segundo, unidade que é denominada Ampere $(A)$.

A energia necessária para que haja o movimento orientado do elétron de um ponto a outro do condutor é denominada diferença de potencial elétrico (ddp, $\mathrm{V}$ ) entre os dois pontos. A diferença de potencial é medida em termos de trabalho (W) por unidade de carga, ou seja,

$$
V=\frac{W}{Q}
$$

A diferença de potencial elétrico é, portanto, medida em Joules por Coulomb, unidade denominada Volt $(\mathrm{V})$.

A resistência que o material que constitui o condutor oferece ao movimento de cada elétron devido às múltiplas colisões em seu interior é chamada de resistividade $(\rho)$.

Além do material que constitui o condutor, a área de sua seção disponível ao fluxo $(A)$ e o comprimento $(L)$ também influem na resistência $(R)$ do condutor, tal que:

$$
R=\frac{\rho L}{A}
$$


A unidade de resistividade ( $\rho$ ) é $\Omega . m$ onde $\Omega$ (letra grega ômega) representa o termo "ohm".

Assim, a unidade de resistência é:

$$
R=\frac{\Omega m \times m}{m^{2}}=\Omega(\mathrm{ohm})
$$

O inverso da resistência elétrica é a condutância elétrica é a condutância elétrica, cuja unidade é o "ohm" escrito ao contrário: "mho" ou "siemens".

\section{- Lei de Ohm:}

A corrente que circula num condutor é proporcional a energia (diferença de potencial entre dois pontos) fornecida. Quanto maior a energia, maior a intensidade de corrente num mesmo condutor e vice-versa. A constante de proporcionalidade é a resistência elétrica $(R)$ do condutor:

$$
V=R I
$$

A eq. (5) é conhecida como Lei de Ohm.

\section{- Lei de Joule:}

A energia cinética dos elétrons, resultante da aceleração pelo campo elétrico pode ser dissipada, parcial ou totalmente em colisões inelásticas dentro do condutor, dando origem a energia térmica.

A potência $(P)$ dissipada no condutor é dada por:

$$
P=\frac{d W}{d t}=\frac{d(Q V)}{d t}=V \frac{d Q}{d t}=V I
$$

Pela Lei de Ohm (eq. 5): 


$$
P=I^{2} R
$$

Conhecida como Lei de Joule. De acordo com essa lei, é dissipada potência elétrica num condutor sempre que circula uma corrente elétrica.

\section{- Resistor e Bateria:}

Resistor: é o elemento de um circuito com um valor de resistência especificado. De acordo com a Lei de Ohm, aparece uma diferença de potencial nos terminais do resistor, como resultado da corrente que circula por ele.

Bateria: de acordo com a Lei de Joule, qualquer condutor dissipa energia elétrica quando percorrido por uma corrente. Nos circuitos de corrente contínua (C.C.) a fonte dessa energia é muitas vezes uma bateria química. Numa bateria, a energia química é convertida em elétrica e as reações químicas mantêm uma diferença de potencial entre seus terminais, chamada de força eletromotriz, para distinguir entre a diferença de potencial que aparece numa resistência, pela Lei de Ohm.

\section{- Circuitos Simples:}

Se os componentes elétricos de um circuito (como os resistores) são conectados deforma que a corrente seja igual para todos diz-se que formam um circuito em série.

Se os componentes elétricos de um circuito (como os resistores) são conectados de forma que a diferença de potencial seja igual para todos, diz-se que formam um circuito em paralelo.

\section{- Capacitor plano, Dielétrico e Polarização de um dielétrico:}

A função de um capacitor é armazenar cargas elétricas e consequentemente energia. O capacitor plano é constituido por duas placas (armaduras) planas, iguais, de área $A$, separadas de uma distância $d$, uma da outra (Figura 1), quando carregada uma placa apresenta falta de elétrons (+) e a outra excesso (-). Entre as armaduras existe 
um isolante que, inicialmente será considerado o vácuo. O capacitor carrega quando submetido a uma tensão, estabelecendo-se um campo elétrico uniforme $\vec{E}$ em seu interior.

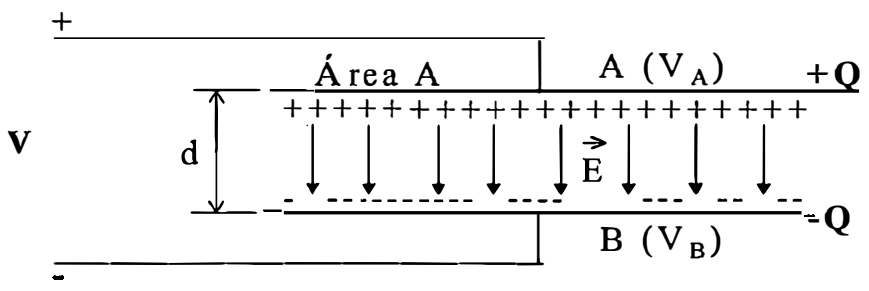

Figura 1 - Diagrama esquemático de um capacitor plano

A capacitância $(C)$ do capacitor plano é dada por:

$$
C=\varepsilon_{0} \cdot \frac{A}{d}
$$

Onde $\varepsilon_{0}$ é denominada permitividade absoluta do vácuo e vale $8,8 \cdot 10^{-12} \mathrm{~F}$ $\mathrm{m}^{-1}$. A capacitância de um capacitor qualquer é igual a:

$$
C=\frac{Q}{V}
$$

onde $\mathrm{Q}$ é a carga do capacitor e $\mathrm{V}$ a sua ddp, tem-se: $\varepsilon_{0} \cdot \frac{A}{d}=\frac{Q}{V}$

Se o campo elétrico entre as armaduras de um capacitor for uniforme, diz-se que $V=E d$ e portanto:

$$
\begin{aligned}
& \varepsilon_{0} \cdot \frac{A}{d}=\frac{Q}{E d} \\
& E=\frac{Q}{\varepsilon_{0} A}
\end{aligned}
$$


Mas como $\frac{Q}{A}=\sigma$ é a densidade superficial de cargas, tem-se a seguinte expressão para a intensidade do campo elétrico entre as placas de um capacitor plano:

$$
E=\frac{\sigma}{\varepsilon_{0}}
$$

A partir da definição de capacitor plano é possível a definição de dielétrico:

a)
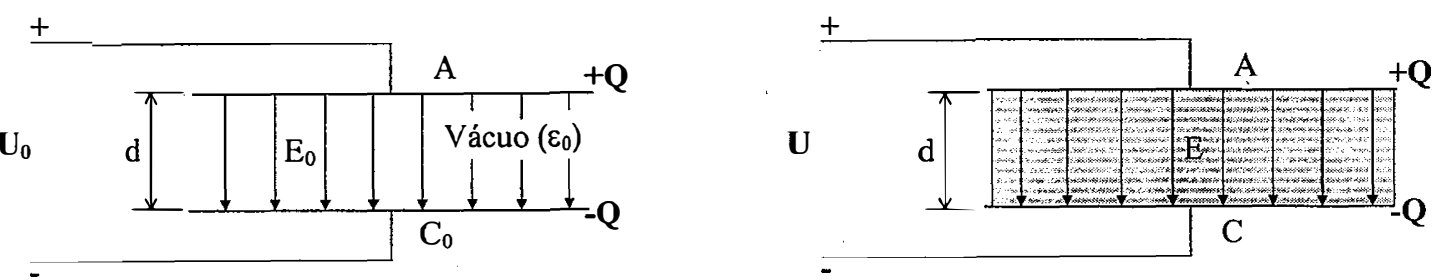

Figura 2 - Esquema de um capacitor a vácuo (a) e um capacitor com um dielétrico qualquer (b)

Considerando-se um capacitor plano a vácuo (permitividade absoluta $\varepsilon_{0}$ ) de capacitância $C_{0}=\varepsilon_{0} \frac{A}{d}$ e se $\mathrm{V}_{0}$ é a ddp de um gerador que eletriza o capacitor com carga $\mathrm{Q}$, a intensidade do campo elétrico entre as armaduras é $E_{0}=\frac{V_{0}}{d}$.

Pode-se definir dielétrico como um material que não conduz corrente elétrica, pela não existência de cargas elétricas livres em seu interior. Se o espaço entre as armaduras for preenchido com um dielétrico (Figura $2 b$ ), a relação entre a capacitância C do capacitor com dielétrico e a capacitância $C_{0}$ do capacitor a vácuo é uma constante característica do dielétrico e denominada constante dielétrica do isolante, indicada por $\mathrm{K}_{\mathrm{a}}$ :

$$
K_{a}=\frac{C}{C_{0}}
$$


O Quadro 1 abaixo apresenta alguns valores de constante dielétrica considerando, entre as armaduras de um capacitor, diferentes materiais.

\begin{tabular}{|lc|}
\hline \multicolumn{1}{|c|}{ Dielétrico } & $\mathrm{K}_{\mathrm{a}}$ \\
\hline Vácuo & 1 \\
$\mathrm{Ar}$ & 1,0006 \\
Água pura & 81 \\
Papel & 3,5 \\
Mica & 5,4 \\
\hline
\end{tabular}

Fonte: Ramalho Júnior et al. (1993)

Quadro 1 - Valores da constante dielétrica $(k)$ para alguns dielétricos

Outra característica importante é a polarização de um dielétrico, podendo ser classificada em dois tipos: polares e não polares. A polarização de moléculas polares é aquela que apresenta um momento dipolar permanente (a molécula da água, por exemplo) e normalmente, uma distribuição não-simétrica de cargas elétricas em seu interior (Figura 3). Neste caso, o campo elétrico tende a alinhar os momentos dipolares individuais das moléculas para criar um momento dipolar macroscópico.

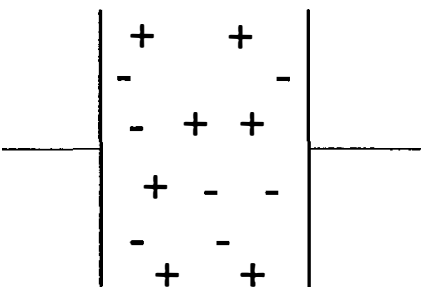

(a)

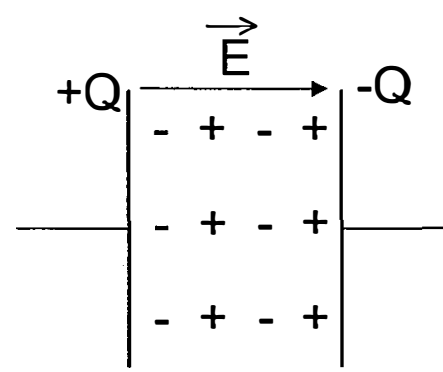

(b)

Figura 3 - Dielétrico constituido por moléculas polares entre as armaduras de um capacitor plano, inicialmente neutro (a) e orientadas após a polarização das armaduras (b) 
Em qualquer tipo de polarização o campo elétrico resultante entre as armaduras do capacitor é menor quando comparado ao campo tendo-se o vácuo como material entre as armaduras. Isto ocorre porque no interior do dielétrico, existe uma compensação entre as cargas positivas e negativas, mas nas superfícies formam-se duas distribuições de cargas $-Q_{p} e+Q_{p}$, chamadas cargas de polarização (Figura 4). Essas cargas diminuem o campo elétrico resultante no interior do dielétrico. Portanto, a constante dielétrica $(k)$ de um material é uma medida de sua propriedade de reduzir a intensidade de um campo elétrico estabelecido em seu interior.

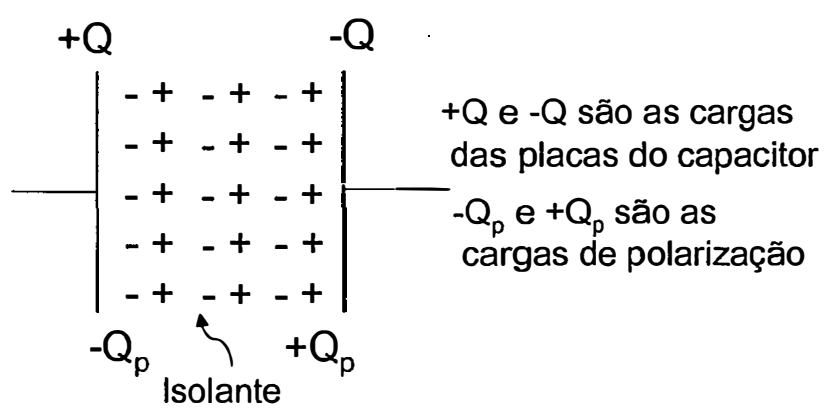

Figura 4 - Distribuição das cargas de polarização no interior de um capacitor 
ANEXO B - Caracterização morfológica do solo (realizada em trincheira aberta na área anteriormente a instalação do experimento)

$\mathrm{Ap}_{1}$ 0-7 cm;

vermelho acinzentado (10R4/2, úmido); argila; estrutura modificada pelo uso agrícola, composto por blocos compactados de tamanho variável; muito firme, plástico e pegajoso; carvões pequenos esparsos; transição gradual difusa; plana.

$\mathrm{Ap}_{2}$ 7-18 cm;

bruno-avermelhado (2.5 4/4, úmido); muito argiloso; estrutura modificada pelo uso agrícola composta por blocos compactados de tamanho variável; muito firme, muito plástico e muito pegajoso; carvões pequenos esparsos; transição gradual difusa; plana.

$\mathrm{Ap}_{3}$ 18-27 cm; vermelho-acinzentado (10R 4/3, úmido); muito argiloso; estrutura modificada pelo uso agrícola composta por blocos compactados de tamanho variável; muito firme, muito plástico e muito pegajoso; carvões pequenos esparsos; transição gradual difusa; plana.

$\mathrm{Bt}_{1}$ 27-45 cm; vermelho-acinzentado (10R 4/3, úmido); muito argiloso; forte; pequeno a médio, blocos subangulares; cerosidade moderada a forte, abundante; muito firme, muito plástico e muito pegajoso; carvões pequenos esparsos; transição gradual difusa; plana.

$\mathrm{Bt}_{2}$ 45-68 cm; vermelho-acinzentado (10R 4/4, úmido); muito argiloso; forte; 
pequeno a médio, blocos subangulares; cerosidade moderada a forte e abundante; muito firme, muito plástico e muito pegajoso; carvões pequenos esparsos; transição gradual difusa; ondulado.

$\mathrm{Bt}_{3}$ 68-105 cm; vermelho-escuro-acinzentado (10R 3/4, úmido); muito argiloso; moderado; pequeno, blocos subangulares/granular; cerosidade fraca e pouca; firme, muito plástico e muito pegajoso; transição gradual difusa; ondulado.

$\mathrm{Bw}_{1}$ 105-160 cm; $\quad$ vermelho-acinzentado (10R 4/3, úmido); muito argiloso; forte; pequeno a médio, blocos subangulares; cerosidade moderada a forte, abundante; muito firme, muito plástico e muito pegajoso; carvões pequenos esparsos; transição gradual difusa; plana.

$\mathrm{Bw}_{2}$ 160-200 cm+; vermelho-escuro (10R 3/6, úmido); muito argiloso; macroestrutura maciça, muito porosa; micro-estrutura muito forte pequena, granular; muito friável, muito plástico e muito pegajoso; transição clara e plana.

\section{Observações:}

1) Os horizontes $A p_{1}, A p_{2}, A p_{3}$, apresentam apenas variações quanto a cor.

2) Raizes: muitas, médias e finas no $\mathbf{A p}$; comuns e finas no $\mathbf{B t}_{1}$; raras e muito finas nos demais horizontes.

3) Porosidade: são encontrados poros muito pequenos, comuns nos horizontes Ap e Bt e poros pequenos médios, abundantes nos demais horizontes. 
ANEXO C - Programa para obtenção das constantes dielétricas

PROGRAMA.CSI, Table 1

; $\{$ CR10X $\}$

*Table 1 Program

01: $1800 \quad$ Execution Interval (seconds)

1: Batt Voltage (P10)
1: 1
Loc [Bateria ]

2: Do (P86)

1: 10

Set Output Flag High (Flag 0)

3: Real Time (P77)

1: 1220

Year, Day, Hour/Minute $($ midnight $=2400)$

4: Do (P86)
1: 44
Set Port 4 High

5: Excitation with Delay (P22)
1: 1
Ex Channel
2: 0
Delay W/Ex (units $=0,01 \mathrm{sec}$ )
3: 1000
Delay After Ex (units $=0,01 \mathrm{sec}$ )
4: 0
mV Excitation

6: TDR Measurement (P100)
1: 11
2: 4080
3: .3
4: 84.6
5: 2007
6: 2
7: 1
8: 0

SDM Address

$\mathrm{La} / \mathrm{L}$ with Probe Correction in $\mathrm{mm}$

Probe Lenght (meters)

Cable Lenght (meters)

MMP Mux \& Probe Selection

Loc [RaizKa1 ]

Mult

Offset

7: TDR Measurement (P100)
1: 11
2: 4080
3: .3
4: 84.6
5: 1108
6: 9
7: 1
8: 0

SDM Address

$\mathrm{La} / \mathrm{L}$ with Probe Correction in $\mathrm{mm}$

Probe Lenght (meters)

Cable Lenght (meters)

MMP Mux \& Probe Selection

Loc [RaizKa8 ]

Mult

Offset

8: Do (P86)

1: 54

Set Port 4 Low

9: Sample (P70)
1: 16
2: 1

Reps

Loc [Bateria ]

*Table 2 Program

01: 0

Execution Interval (seconds) 
*Table 3 Subroutines

PROGRAMA.CSI, Input Locations

Addr Name

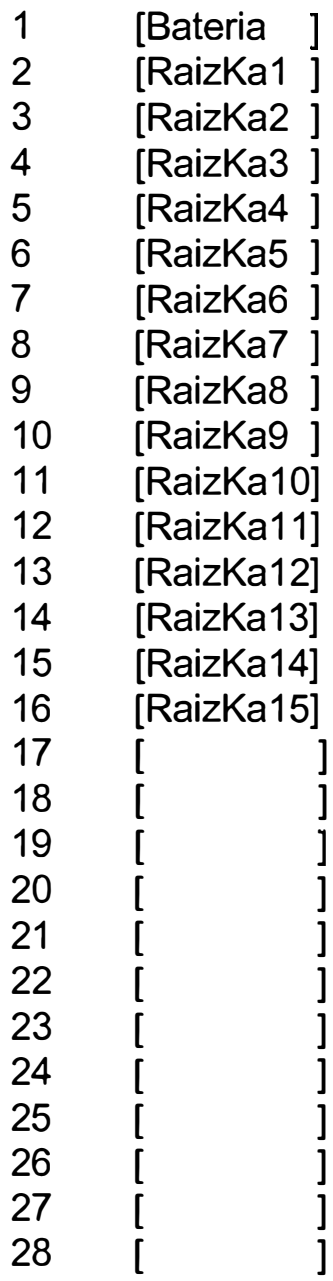

Flags \#Reads

\#Writes

RW--

RW--

R--

R--

R--

R--

R--

R--

RW--

R--

R--

R--

R--

R--

R--

R--

---

$--$

$-$

$--$

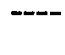

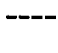

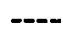

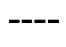

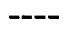

$-$

$-$
1

1

1

1

1

1
1

1

1

1

1

1

1

1

1

1

1

1

$$
0
$$

0

0

0

0

0

0

0

0

0

0

0
Blocks

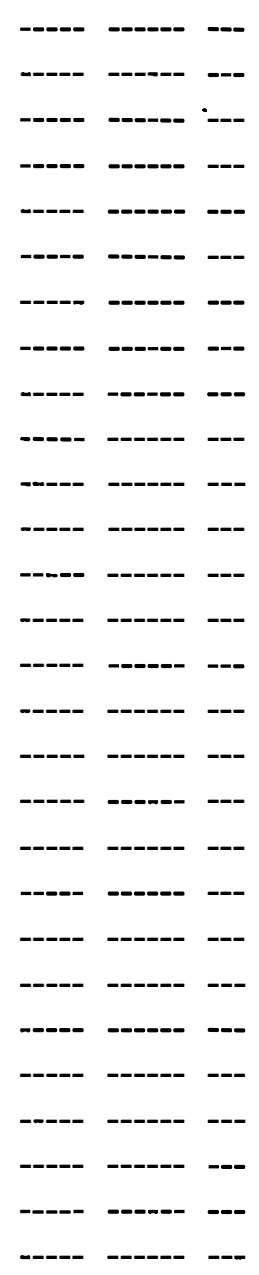


ANEXO D - Instruções utilizadas para instalar o programa na DL e coletar os dados para o módulo de armazenamento SM192

a) Instalação do programa na DL

Após a confecção do programa no "software" PC208W, o mesmo deverá ser compilado para detecção de erros e posteriormente carregado no módulo de armazenamento SM192, utilizando as orientações contidas no manual do "software".

Para a transferência do programa para a $\mathrm{DL}$ deverão ser executadas as seguintes instruções:

- interconectar o "Keyboard display", o módulo e a DL

- digitar *D no display

- digitar 71

- $\operatorname{digitar}$ A

- digitar 21

- digitar A novamente

- digitar *0

Para ver o programa na memória na Tabela 1 da DL, basta digitar *1.

b) Coleta dos dados contidos na DL

Para a transferência dos dados da DL para o módulo de armazenamento SM192 deverão ser realizadas as seguintes operações:

- interconectar o display, o módulo e a DL

- digitar 71

- digitar A

- $\operatorname{digitar} A$

- digitar A

- digitar um número qualquer e digitar $A$

- digitar *0

Para a transferência dos dados coletados do módulo de armazenamento para o PC deverão ser seguidas as instruções contidas no manual do "software" PC208W. 


\section{REFERÊNCIAS BIBLIOGRÁFICAS}

ARYA, L.M.; LEIJ, F.J.; SHOUSE, P.J.; VAN GENUCHTEN, M.T. Relationship between the hydraulic conductivity function and the particle-size distribution. Soil Science Society of America Journal, v.63, p.1063-1070, 1999.

ARYA, L.M.; DIEROLF, T.S.; SOFYAN, A.; WIDJAJA-ADHI, I.P.G.; VAN GENUCHTEN, M.T. Field measurement of the saturated hydraulic conductivity of a macroporous soil with unstable subsoil structure. Soil Science, v.163, n.11, p.841-852, 1998.

ASSIS JÚNIOR, R.N. de. Análise de desempenho do tensiômetro de câmara de ar na avaliação do potencial mátrico da água. Piracicaba, 1995. 85p. Tese (Doutorado) Escola Superior de Agricultura "Luiz de Queiroz", Universidade de São Paulo.

ASSOCIAÇÃO BRASILEIRA DE NORMAS TÉCNICAS. Instalações elétricas de baixa tensão: NBR 5410/1997. Rio de Janeiro, 212p, 1997.

BACCHI, O.O.O.; REICHARDT, K.; CALVACHE, M. Sondas de neutrones y gamma y sus aplicaciones en agronomia. Viena: International Atomic Energy Agency, 1998. 94p. (Curso de Treinamento)

BAKER, J.M.; ALLMARAS, R.R. System for automating and multiplexing soil moisture measurement by time-domain reflectometry. Soil Science Society of America Journal, v.54, p.1-6, 1990. 
BLAKE, G.R.; HARTGE, K.H. Bulk density. In: KLUTE, A. (Ed.) Methods of soil analysis. Part I: Physical and mineralogical methods. Madison: American Society of Agronomy, 1986. cap. 13, p.363-375.

BRUCE, R.R,; LUXMOORE, R.J. Water retention: Fields methods. In: KLUTE, A. (Ed.) Methods of soil analysis. Part I: Physical and mineralogical methods. Madison: American Society of Agronomy, 1986. cap. 27, p.663-686.

BUCKINGHAM, E. Studies on the movement of soil moisture. Bureaux of Soils, v.38, p.1-61, 1907.

CAMPBELL PACIFIC NUCLEAR CORPORATION. Operating manual. Utah: CPN, 1980. 70p.

CAMPBELL SCIENTIFIC DO BRASIL Ltda. Curso de treinamento para sistemas TDR. Piracicaba, 1999. 22p. (Curso Técnico)

CAPELLI, A. Aterramento elétrico. Saber Eletrônica, n.329, p.56-59, jun. 2000.

CHUDINOVA, S.M.; PONIZOVSKII, A.A. The effect of soil texture on the time domain reflectometry calibration for soil water content measurement. Eurasian Soil Science, v.31, n.1, p.17-24, 1998.

COSTA, A.C.S. da; LIBARDI, P.L. Caracterização físico-hídrica de um perfil de terra roxa estruturada latossólica pelo método do perfil instantâneo. Revista Brasileira de Ciência do Solo, v.23, p.669-677, 1999.

DALTON, F.N.; VAN GENUCHTEN, M.T. The time-domain reflectometry method for measuring soil water content and salinity. Geoderma, v.38, p.237-250, 1986.

DARCY, H. Les fontaines publiques de la Ville de Dijon. Paris: Victor Dalmont, 1856. 647p. 
DASBERG, S.; DALTON, F.N. Time domain reflectometry field measurements of soil water content and electrical conductivity. Soil Science Society of America Journal, v.49, p.293-297, 1985.

DASBERG, S.; HOPMANS, J.W. Time domain reflectometry calibration for uniformly and nonuniformly wetted sandy and clayey loam soils. Soil Science Society of America Journal, v.56, p.1341-1345, 1992.

DIRKSEN, C. Unsaturated hydraulic conductivity. In: SMITH, K.A.; MULLINS, C.E. (Ed.) Soil analysis: physical methods. New York: Marcel Dekker, 1991. p.209-269.

DIRKSEN, C.; DASBERG, S. Improved calibration of time domain reflectometry soil water content measurements. Soil Science Society of America Journal, v.57, p.660-667, 1993.

DONG WANG, D.; YATES, S.R.; ERNST, F.F. Determining soil hydraulic properties using tension infiltrometers, time domain reflectometry, and tensiometers. Soil Science Society of America Journal, v.62, p.318-325, 1998.

DOURADO NETO, D.; JONG VAN LIER, Q.; BORTEL, T.A.; LIBARDI, P.L. Programa para confecção da curva de retenção de água no solo utilizando o modelo de van Genutchen. Engenharia Rural, v.1, p.92-102, 1990.

EMPRESA BRASILEIRA DE PESQUISA AGROPECUÁRIA. Sistema brasileiro de classificação de solos. Brasilia: EMBRAPA, CNPS, 1999. 412p.

FELLNER-FELDEGG, $\mathrm{H}$. The measurement of dielectrics in the time domain. Journal Physical Chemical, v.73, p.616-623, 1969.

FENG, W.; LIN, C.P.; DESCHAMPS, R.J.; DRNEVICH, V.P. Theoretical model of a multisection time domain reflectometry measurements system. Water Resources Research, v.35, n.8, p.2321-2331, 1999. 
FREELAND, R.S.; HENRY, Z.A. Protection of instrumentation systems from lightning. American Society of Agricultural Engineers. p.17/1-17/5. 1991.

GARDNER, C.M.K.; BELL, J.P.; COOPER, D.; DEAN, T.J.; HODNETT, M.G.; GARDNER, N. Soil water content. In: SMITH, K.A.; MULLINS, C.E. (Ed.) Soil analysis: physical methods. New York: Marcel Dekker, 1991. p.1-65.

GARDNER, W.; KIRKHAM, D. Determination of soil moisture by neutron scattering. Soil Science, v.73, p.391-401, 1952.

GUIBERTO, P.J. Metodologias para a obtenção de parâmetros utilizados em modelos de infiltração da água no solo. Piracicaba, 1999. 79p. Dissertação (Mestrado) Escola Superior de Agricultura Luiz de Queiroz, Universidade de São Paulo.

HERKELRATH, W.N.; HAMBURG, S.P.; MURPHY, F. Automatic, real-time monitoring of soil moisture in a remote field area with time domain reflectometry. Water Resources Research, v.27, n.5, p.857-864, 1991.

HILLEL, D.A.; KRENTOS, V.K.; STILIANOV, Y. Procedure and test of an internal drainage method for measuring soil hydraulic characteristics in situ. Soil Science, v.114, p.395-400, 1972.

HOKETT, S.L.; CHAPMAN, J.B.; RUSSEL, C.E. Potential use of time domain reflectometry for measuring water content in rock. Journal of Hydrology, v.138, p.89-96, 1992.

HOOK, W.R.; LIVINGSTON, N.J. Propagation velocity errors in time domain reflectometry measurements of soil water. Soil Science Society of America Journal, v.59, p.92-96, 1995. 
INTERNATIONAL ATOMIC ENERGY AGENCY. Comparison of soil water measurement using the neutron scattering, time domain reflectometry and capacitance methods. Viena, 2000. 162p. (Reunião Técnica da Division of Nuclear Techniques in Food and Agriculture)

JACOBSEN, O.H.; SCHJONNING, P. A laboratory calibration of time domain reflectometry for soil water measurement including effects of bulk density and texture. Journal of Hydrology, v.151, p.147-157, 1993.

JONG van LIER, Q.; LIBARDI, P.L. Variabilidade dos parâmetros da equação que relaciona a condutividade hidráulica com a umidade do solo no método do perfil instantâneo. Revista Brasileira de Ciência do Solo, v.23, p.1005-1014, 1999.

KINDERMANN, G. Descargas atmosféricas. 2.ed. Porto Alegre: Sagra Luzzatto, 1997. 134p.

KINDERMANN, G.; CAMPAGNOLO, J.M. Aterramento elétrico. Porto Alegre: Sagra Luzzatto, 1998. 214p.

KLUTE, A. Water retention: Laboratory methods. In: KLUTE, A. (Ed.) Methods of soil analysis. Part I: Physical and mineralogical methods. Madison: American Society of Agronomy, 1986. cap. 26, p.635-660.

KLUTE, A.; DIRKSEN, C. Hydraulic Conductivity and Diffusivity: Laboratory Methods. In: KLUTE, A. (Ed.) Methods of soil analysis. Part I: Physical and mineralogical methods. Madison: American Society of Agronomy, 1986. cap. 28, p.687-732.

KLUTE, A.; GARDNER, W.R. Tensiometer response time. Soil Science, v.93, n.1, p.204-207, 1962.

KUTíLEK, M.; NIELSEN, D.R. Soil hydrology. Berlin: Catena Verlag, 1994. 370p. 
LEVIN, J. Estatística aplicada a ciências humanas. 2.ed. São Paulo: Harbra, 1987. $392 p$.

LIBARDI, P.L. Dinâmica da água no solo. Piracicaba: edição do autor, 2000. 509p.

LIBARDI, P.L.; REICHARDT, K.; NIELSEN, D.R.; BIGGAR, J.W. Simplified field methods for estimating the unsaturated hydraulic conductivity. Soil Science Society of America Journal, v.44, p.3-6, 1980.

MORAES, S.O. Heterogeneidade hidráulica de uma terra roxa estruturada. Piracicaba, 1991. 141p. Tese (Doutorado) - Escola Superior de Agricultura Luiz de Queiroz, Universidade de São Paulo.

MORENO, H.; COSTA, P.F. Aterramento elétrico. São Paulo: Instituto Brasileiro do Cobre, s.d. 39p.

MUALEN, Y. A new model for predicting the hydraulic conductivity of unsaturated porous media. Water Resources Research, v.12, n.3, p.513-522, 1976.

NADLER, A.; DASBERG, S.; LAPID, I. Time domain reflectometry measurements of water content and electrical conductivity of layered soil columns. Soil Science Society of America Journal, v.55, p.938-943, 1991.

NOBORIO, K.; HORTON, R.; TAN, C.S. Time domain reflectometry probe for simultaneous measurement of soil matric potential and water content. Soil Science Society of America Journal, v.63, p.1500-1505, 1999.

OLITTA, A.F. Construção de tensiômetros para controle da irrigação. O Solo, v.68, n.2, p.16-20, 1976.

OR, D.; WRAITH, J.M. A new soil matric potential sensor based on time domain reflectometry. Water Resources Research, v.35, n.11, p.3399-3407, 1999. 
PAULETTO, E.A.; LIBARDI, P.L.; MANFRON, P.A.; MORAES, S.O. Determinação da condutividade hidráulica de solos a partir da curva de retenção de água. Revista Brasileira de Ciência do Solo, v.12, p.189-195, 1988.

PREVEDELLO, C.L. Teoria do fluxo da água em solos não saturados: novos conceitos e aplicações. Piracicaba, 1987. 264p. Tese (Doutorado) - Escola Superior de Agricultura "Luiz de Queiroz", Universidade de São Paulo.

PREVEDELLO, B.M.S.; PREVEDELLO, C.L.; LIBARDI, P.L. Simplificação analítica do perfil instantâneo para obtenção da condutividade hidráulica não saturada em condições de campo. Revista Brasileira de Ciência do Solo, v.5, p.93-97, 1981.

RAMALHO JÚNIOR, F.; FERRARO, N.G.; SOARES, P.A.T. Os fundamentos da física. 6.ed. São Paulo: Moderna, 1993. v.3, 479p.

REICHARDT, K. A água em sistemas agrícolas. São Paulo: Manole, 1990. 188p.

RICHARDS, L. A. Capillary conduction of liquids through porous medium. Physics, v.1, p. 318-333, 1931.

ROTH, K.; SCHULIN, R.; FLÜHLER, H.; ATTINGER, W. Calibration of time domain reflectometry for water content measurement using a composite dielectric approach. Water Resources Research, v.26, n.10, p.2267-2273, 1990.

ROTHE, A.; WeIS, W.; KREUTZER, K.; MATTHIES, D.; HESS, U.; ANSORGE, B. Changes in soil structure caused by the installation of time domain reflectometry probes and their influence on the measurement of soil moisture. Water Resources Research, v.33, n.7, p.1585-1593, 1997.

SANTOS, R.F.dos; CARLESSO, R.; VILAS BOAS, M.A. Calibração simplificada de sonda de nêutrons para a determinação do conteúdo de água no solo. Revista de Agricultura, v.74,n.2, p.201-216, 1999. 
SAUNDERS, L.C.U.; LIBARDI, P.L.; REICHARDT, K. Condutividade hidráulica da Terra Roxa Estruturada em condições de campo. Revista Brasileira de Ciência do Solo, v.2, p.164-167, 1978.

SENTELHAS, P.C.; MARIN, F.R.; PEREIRA, A.R.; ANGELOCCI, L.R.; VILLA NOVA, N.A.; BARBIERI, V. Análise dos dados climáticos e de balanço hídrico climatológico de Piracicaba (1917-1997). Piracicaba: ESALQ, DFM, 1998. 81p.

SERRARENS, D.; MACLNTYRE, J.L.; HOPMANS, J.W.; BASSOI, L.H. Soil moisture calibration of tdr multilevel probes. Scientia Agricola, v.57, n.2, p.349-354, 2000.

SMS TECNOLOGIA ELETRÔNICA Ltda. Manual de instalação e operação. São Paulo: SMS, s.d. 24p. (Manual Técnico)

TIMLIN, D.J.; PACHEPSKY, Y.A. Comparison of three methods to obtain the apparent dielectric constant from time domain reflectometry wave traces. Soil Science Society of America Journal, v.60, p.970-977, 1996.

TOMASELLA, J.; HODNETT, M.G. Estimating unsaturated hydraulic conductivity of Brazilian soils using soil-water retention data. Soil Science, v.162, n.10, p.703-712, 1997.

TOMMASELLI, J.T.G. Influência de algumas características do solo sobre a calibração de um aparelho de TDR (Time-domain reflectometry). Piracicaba, 1997. 109p. Tese (Doutorado) - Centro de Energia Nuclear na Agricultura, Universidade de São Paulo.

TOPP, G.C.; DAVIS, J.L. Detecting infiltration of water through soil cracks by timedomain reflectometry. Geoderma, v.26, p.13-23, 1981.

TOPP, G.C.; DAVIS, J.L.; ANNAN, A.P. Electromagnetic determination of soil water content: measurements in coaxial transmission lines. Water Resources Research, v.16, p.574-582, 1980. 
TOPP, G.C.; DAVIS, J.L.; ANNAN, A.P. Electromagnetic determination of soil water content using TDR: I. Applications to wetting fronts and steep gradients. Soil Science Society of America Journal, v.46, p.672-678, 1982.

TURATTI, A.L.; VILLAGRA, M.M.; PONCE, J.E.; BACCHI, O.O.S.; REICHARDT, K. Variabilidade espacial do solo e sua implicação na calibração de sondas de nêutrons. Revista Brasileira de Ciência do Solo, v.14, p.259-262, 1990.

YANUKA, M.; TOPP, G.C.; ZEGELIN, S.; ZEBCHUK, W.D. Multiple reflection and attenuation of time domain reflectometry pulses: theoretical considerations for applications to soil and water. Water Resources Research, v.24, p.939-944, 1988.

YOUNGS, E.G. Hydraulic conductivity of saturated soils. In: SMITH, K.A.; MULLINS, C.E. (Ed) Soil analysis: physical methods. New York: Marcel Dekker, 1991. p.161207.

YU, C.; WARRICK, A.W.; CONKLIN, M.H.; YOUNG, M.H.; ZREDA, M. Two- threeparameter calibrations of time domain reflectometry for soil moisture measurement. Water Resources Research, v.33, n.10, p.2417-2421, 1997.

VAN GENUCHTEN, M.T. A closed-form equation for predicting the hydraulic conductivity of unsaturated soils. Soil Science Society of America Journal, v.44, p.892-898, 1980.

VILLAGRA, M.M. Variabilidade de medidas de tensiômetro em terra roxa estruturada. Piracicaba, 1988. 64p. Dissertação (Mestrado) - Centro de Energia Nuclear na Agricultura, Universidade de São Paulo.

VILLAGRA, M.M.; MATSUMOTO, O.M.; BACCHI, O.O.S.; MORAES, S.O.; LIBARDI, P.L.; REICHARDT, K. Tensiometria e variabilidade espacial em terra roxa estruturada. Revista Brasileira de Ciência do Solo, v.12, p.205-210, 1988. 
WARRICK, A.W.; NIELSEN, D.R. Spatial variability of soil physical properties in the field. In: HILLEL, D. (Ed.) Applications of soil physics. New York: Academic Press, 1980. p.319-344.

WATSON, K.K. An instantaneous profile method for determining the hydraulic conductivity of unsaturated porous materials. Water Resources Research, v.2, p.709-715, 1966.

WHALLEY, W.R. Considerations on the use of time-domain reflectometry (TDR) for measuring soil water content. Journal of Soil Science, v.44, p.1-9, 1993.

WILLMOTT, C.J.; ACKLESON, S.G.; DAVIS, R.E. Statistics for the evaluation and comparison of models. Journal of Geophysical Research. v.90, n.5, p.8995-9005, 1985.

ZACHARIAS, S.; HEATWOLE, C. D.; CAKLEY, C. W. Robust quantitative techniques for validating pesticide transport models. Transactions of the ASAE, v.39, n.1, p.47-54. 1996.

ZEGELIN, S.J.; WHITE, I.; JENKINS, D.R. Improved field probes for soil water content and electrical conductivity measurement using time domain reflectometry. Water Resources Research, v.25, n.11, p.2367-2376, 1989. 